FABRÍCIO RAMOS DA FONSECA

MODELO DE SISTEMA DE AUTOMAÇÃO APLICADO À SETORIZAÇÃO DE REDES DE ABASTECIMENTO HÍDRICO

São Paulo

2011 


\section{MODELO DE SISTEMA DE AUTOMAÇÃO APLICADO À SETORIZAÇÃO DE REDES DE ABASTECIMENTO HÍDRICO}

Tese apresentada à Escola Politécnica da Universidade de São Paulo para obtenção do título de Doutor em Engenharia.

Área de Concentração:

Automação de Sistemas Elétricos de

Potência e Processos Industriais.

Orientador:

Prof. Dr. Eduardo Mário Dias.

São Paulo

2011 


\section{FICHA CATALOGRÁFICA}

Fonseca, Fabrício Ramos da

Modelo de sistema de automação aplicado à setorização de redes de abastecimento hídrico / F.R. da Fonseca. -- São Paulo, 2011.

$155 \mathrm{p}$.

Tese (Doutorado) - Escola Politécnica da Universidade de São Paulo. Departamento de Engenharia de Energia e Automação Elétricas.

1. Abastecimento de água 2. Automação industrial 3. Controle digital 4. Sistema de aquisição de dados I. Universidade de São Paulo. Escola Politécnica. Departamento de Engenharia de Energia e Automação Elétricas II. t. 
À minha família, pelo amor, carinho, compreensão e apoio, desde o início desta caminhada. 


\section{AGRADECIMENTOS}

A Deus, pela graça da vida.

Ao meu orientador, Prof. Dr. Eduardo Mário Dias, pelo apoio, incentivo e orientação.

À Gerência de Educação do SENAI-SP, representada pelo Prof. João Ricardo Santa Rosa.

À equipe da Gerência de Manutenção da Superintendência do Litoral da Companhia de Saneamento Básico do Estado de São Paulo.

A todos aqueles que, de forma direta ou indireta, contribuíram para realização deste trabalho. 


\section{SUMÁRIO}

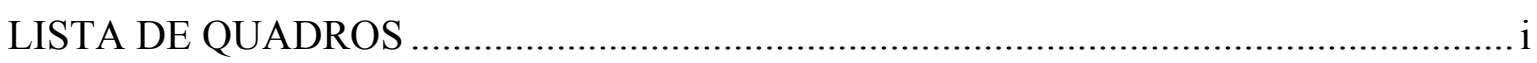

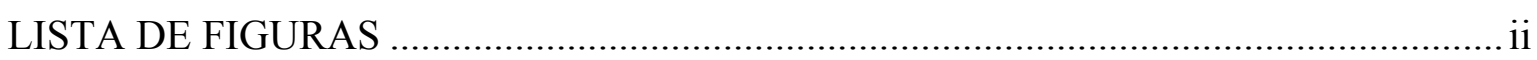

LISTA DE SIGLAS E ABREVIATURAS ….......................................................... vi

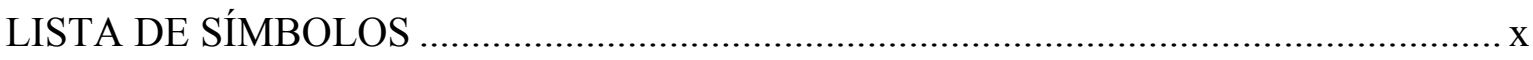

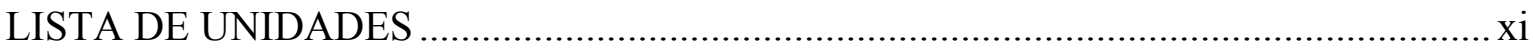

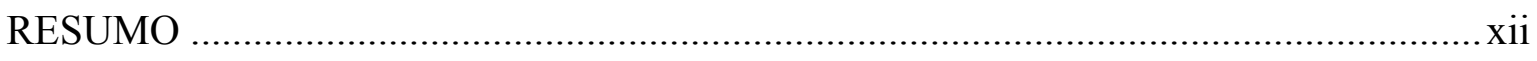

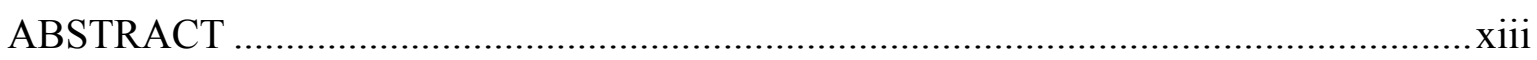

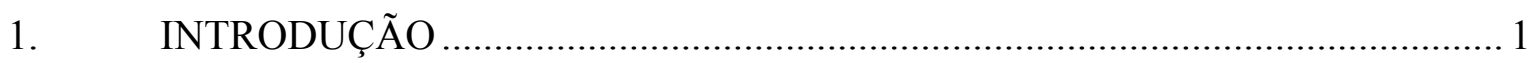

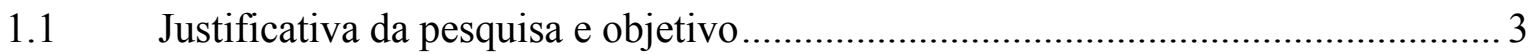

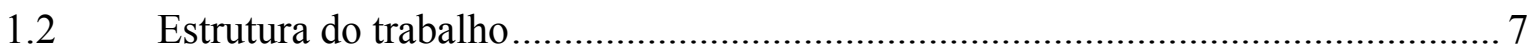

2. SETORIZAÇÃO DE REDES DE ABASTECIMENTO HÍDRICO..................... 9

2.1 Uso e exploração dos recursos hídricos .................................................... 9

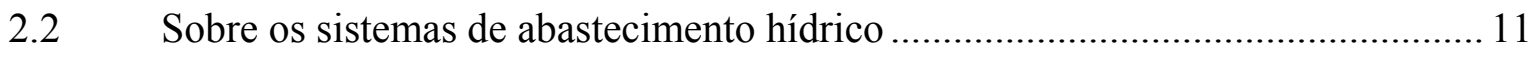

2.3 A automação e o controle das perdas hídricas ...................................................... 13

2.4 Estado da arte da técnica de setorização .............................................................. 15

2.5 Planejamento da automação dos sistemas de abastecimento ............................... 20

2.6 Sistemas de controle Fieldbus aplicados à setorização...................................... 23

2.7 Redes baseadas no protocolo Foundation Fieldbus.......................................... 25

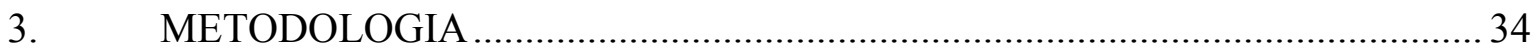

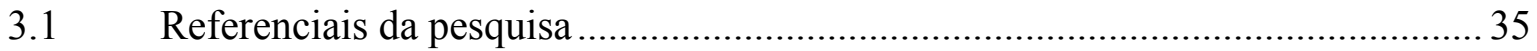

4. MODELO DE SISTEMA DE AUTOMAÇÃO APLICADO À SETORIZAÇÃO DE REDES DE ABASTECIMENTO HÍDRICO............................................................. 38

4.1 Projeto de setorização da cidade de São Vicente................................................ 38

4.2 Componentes do sistema de controle automático das zonas pitométricas............ 40 
4.3 Funcionamento das válvulas redutoras de pressão das zonas pitométricas

4.4 Dispositivos de medição e controle das zonas pitométricas 44

4.5 Funcionamento do sistema de controle das zonas pitométricas. 46

4.6 Proposta de um sistema de controle baseado no protocolo Foundation Fieldbus 50

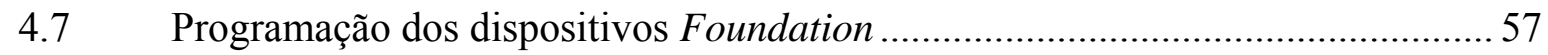

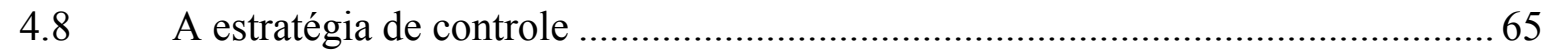

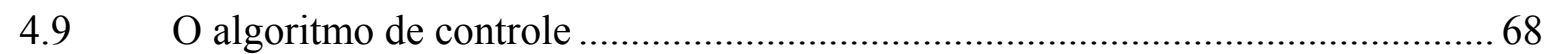

4.10 Arquitetura do sistema aquisição e controle .................................................. 83

4.11 Sistema de supervisão das estações de controle das zonas pitométricas ...............87

4.12 Sistema Integrado de Compartilhamento e Gestão de Informações de Abastecimento Hídrico. 90

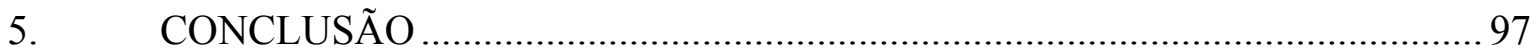

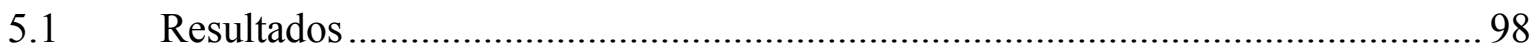

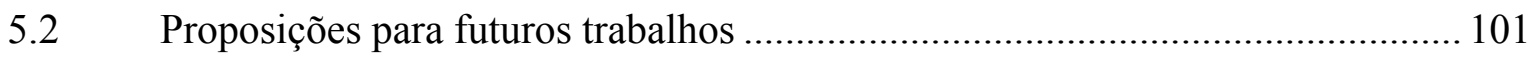

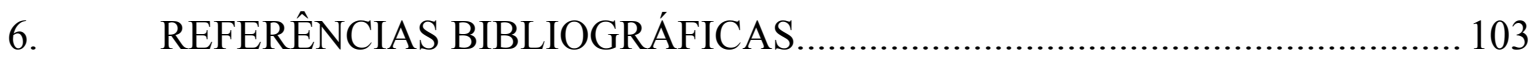

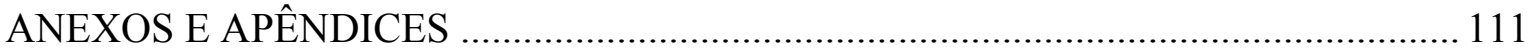

ANEXO 1 - Gráfico demonstrando a relação entre o coeficiente de descarga de um orifício de $1 \mathrm{~mm}$ de diâmetro e o número de Reynolds

ANEXO 2 - Detalhamento do bloco AI utilizado na estratégia de controle Foundation..... B ANEXO 3 - Detalhamento do bloco SPG utilizado na estratégia de controle Foundation.. D ANEXO 4 - Detalhamento do bloco ISEL utilizado na estratégia de controle Foundation. G ANEXO 5 - Planilha de compartilhamento de informações do módulo de controle operacional ilustrando a disposição das informações operacionais obtidas a partir do sistema de supervisão. 
ANEXO 6 - Planilha do módulo de análise e solução de problemas de perdas ilustrando a disposição das informações sobre os limites de operação dos principais pontos do sistema. $\mathrm{J}$ ANEXO 7 - Planilha do módulo de dados de análises químicas, ilustrando a disposição das informações obtidas a partir dos dados dos analisadores de processo, em comparação com os dados obtidos por meio de análises laboratoriais. K

APÊNDICE 1 - Quadro comparativo entre os protocolos Profibus PA e Foundation Fieldbus. L

APÊNDICE 2 - Diagrama ilustrando a relação entre as camadas de um protocolo padronizadas pelo modelo ISO/OSI e as utilizadas pelo protocolo Foundation Fieldbus. Elaborado com base no diagrama exposto por BERGE (1998). M APÊNDICE 3 - Esquema ilustrando a implementação dos padrões físicos contemplados no modelo Foundation em diferentes topologias de rede. $\mathrm{N}$

APÊNDICE 4 - Regras de interconexão entre instrumentos Foundation Fieldbus. $\mathrm{O}$ APÊNDICE 5 - Requisitos físicos e elétricos mínimos para cabos utilizados na interligação de instrumentos em uma rede Foundation Fieldbus.

APÊNDICE 6 - Esquema ilustrando as regras relacionadas ao comprimento dos cabos, impostas para cada topologia aplicável a projetos baseados em instrumentos Foundation Fieldbus. $\mathrm{R}$ APÊNDICE 7 - Especificações do protocolo Foundation relacionadas à camada link de dados 


\section{LISTA DE QUADROS}

Quadro 1. Características consideradas na priorização da modernização dos sistemas de automação das zonas pitométricas.

Quadro 2. Comparação entre vantagens e desvantagens relacionadas às diferentes topologias possibilitadas pelo protocolo Foundation Fieldbus.

Quadro 3. Comparação entre o grau de complexidade relacionado aos documentos de projeto gerados no planejamento de um sistema DCS e FCS. Fieldbuses for Process Control: Engineering, Operation, Maintenance. Carolina do Norte, EUA: The Instrumentation, Systems, and Automation Society, 1998. 51

Quadro 4 - Faixas que determinam os tipos de atuação nas válvulas solenoides da VRP...... 73 


\section{LISTA DE FIGURAS}

Figura 1 - Ilustração simplificada de um sistema de abastecimento hídrico - Disponível em < http://www.sabesp.com.br/CalandraWeb/ > . Acesso em: 02 Jul. 2008, 23h12min 12 Figura 2 - Esquema de setorização com área de abastecimento redundante - Fonte: Documento técnico de apoio do programa nacional de combate ao desperdício de água D1 - Secretaria Especial de Desenvolvimento Urbano, Brasília,1999. 19

Figura 3 - Diagrama ilustrando a visão expandida proporcionada pelos sistemas de controle Fieldbus.

Figura 4 - Esquema ilustrando as possíveis topologias aplicáveis a projetos baseados em instrumentos Foundation Fieldbus. 31

Figura 5 - Diagrama ilustrando os componentes do modelo de sistema de automação aplicado à setorização de redes de abastecimento hídrico. 34

Figura 6 - Esquema da divisão da cidade de São Vicente em nove zonas pitométricas. Projeto de setorização da cidade de São Vicente - Fonte: Companhia de Saneamento Básico do Estado de São Paulo - Superintendência do Litoral, 2008. 39

Figura 7 - Diagrama ilustrando os módulos do sistema de acionamento de uma VRP Fonte: Memorial descritivo do projeto típico de automação de válvulas redutoras de pressão, SABESP - Superintendência do Litoral, 2006.

Figura 8 - Visão do circuito hidráulico de uma VRP aberta.

Figura 9 - Visão do circuito hidráulico de uma VRP fechada.

Figura 10 - Diagrama P\&I de uma estação remota de controle de uma VRP. Fonte: Memorial descritivo do projeto típico de automação de válvulas redutoras de pressão, SABESP - Superintendência do Litoral, 2006. 46

Figura 11 - Malha de um sistema de controle baseado em instrumentação eletrônica....52 
Figura 12 - Esquema da proposta de um sistema de automação baseado no protocolo Foundation Fieldbus para controle da pressão das zonas pitométricas.

Figura 13 - Tela do software de configuração de sistemas Foundation Syscon, demonstrando o projeto da rede Foundation para o controle da zona pitométrica centro da cidade de São Vicente. 59

Figura 14 - Tela do software de configuração de sistemas Foundation Syscon demonstrando os blocos parametrizados no segmento da rede Foundation localizada na ERT-1- Controle da VRP.

Figura 15 - Tela do software de configuração de sistemas Foundation Syscon demonstrando os blocos parametrizados no segmento da rede Foundation localizada na ERT-2- Ponto crítico da zona pitométrica. 62

Figura 16 - Tela do software de configuração de sistemas Foundation Syscon demonstrando os blocos parametrizados no segmento da rede Foundation localizada na ERT-3- Ponto crítico redundante.

Figura 17 - Tela de informação dos instrumentos de campo que compõem o sistema de controle de uma zona pitométrica. Fonte: Sistema Integrado de Compartilhamento e Gestão de Informações de Abastecimento Hídrico da SABESP - Superintendência do Litoral, 2009 63

Figura 18 - Bloco FFB referenciado às variáveis de controle da rede Foundation. 64

Figura 19 - Tela do software de configuração de sistemas Foundation Syscon contendo a estratégia de controle de um setor pitométrico. 66

Figura 20 - Fragmento do algoritmo de controle da VRP responsável pelo estabelecimento da banda morta do set-point........

Figura 21 - Fragmento do algoritmo de controle responsável pelo estabelecimento da faixa de ajuste grosso da VRP. 70 
Figura 22 - Fragmento do algoritmo de controle da VRP responsável pela verificação do valor da variável de processo em relação aos limites de banda morta de ajuste grosso... 71 Figura 23 - Fragmento do algoritmo de controle responsável pelo estabelecimento da faixa de ajuste fino da VRP. 71

Figura 24 - Fragmento do algoritmo de controle da VRP responsável pela verificação do valor da variável de processo em relação aos limites da faixa de ajuste fino 72 Figura 25 - Fragmento do algoritmo de controle responsável pela movimentação da constante de pulsação para atuação do ajuste médio da VRP. 73

Figura 26 - Fragmento do algoritmo de controle responsável pela movimentação da constante de pulsação para atuação do ajuste fino da VRP. .74

Figura 27 - Fragmento do algoritmo de controle responsável pela habilitação da atuação remota na VRP e do seu fechamento automático. .74

Figura 28 - Fragmento do algoritmo de controle responsável pela habilitação da atuação remota na VRP e da sua abertura automática. 75

Figura 29 - Fragmento do algoritmo de controle que estabelece um degrau de 2,5 mca para abertura da VRP a cada período de estabilização da malha controlada. .76 Figura 30 - Fragmento do algoritmo de controle que determina a abertura da VRP em degraus condicionada às condições estabelecidas pelo modo de atuação momentâneo. .78 Figura 31 - Fragmento do algoritmo de controle que estabelece um degrau de 2,5 mca para fechamento da VRP a cada período de estabilização da malha controlada. 79 Figura 32 - Fragmento do algoritmo de controle que determina o fechamento da VRP em degraus condicionado às condições estabelecidas pelo modo de atuação momentâneo. .80 Figura 33 - Fragmento do algoritmo de controle que transfere o resultado da lógica de acionamento automático das válvulas solenóides às saídas físicas do controlador. 81 
Figura 34 - Fragmento do algoritmo de controle que possibilita o acionamento manual remoto das válvulas solenóides que comandam a VRP. 82

Figura 35 - Fragmento do algoritmo de controle desativa o comando remoto da VRP. .82 Figura 36 - Fotografia demonstrando os comandos hidráulicos de acionamento manuallocal da VRP, em paralelo às válvulas solenóides de acionamento - ERT Centro de São Vicente - SABESP - Superintendência do Litoral, 2011 .83

Figura 37 - Diagrama ilustrando diferentes tipos de estações pertencentes ao sistema de supervisão de arquitetura segmentada adotado na Superintendência do Litoral da SABESP. 84

Figura 38 - Tela do sistema de supervisão de uma estação remota de controle de uma VRP - Fonte: Sistema de supervisão da Companhia de Saneamento Básico do Estado de São Paulo - Superintendência do Litoral, 2009. 88

Figura 39 - Tela do sistema de supervisão de uma estação remota correspondente à interface de configuração dos parâmetros de controle de um das zonas pitométricas Fonte: Sistema de supervisão da Companhia de Saneamento Básico do Estado de São Paulo - Superintendência do Litoral, 2009. 90

Figura 40 - Gráfico do sistema de supervisão ilustrando as curvas de resposta das variáveis referentes à zona pitométrica "Centro" da cidade de São Vicente - Fonte: Companhia de Saneamento Básico do Estado de São Paulo - Superintendência do Litoral, 2009. .99

Figura 41 - Gráfico do sistema de supervisão ilustrando as curvas de resposta das variáveis referentes à zona pitométrica "Praias" da cidade de São Vicente - Fonte: Companhia de Saneamento Básico do Estado de São Paulo - Superintendência do Litoral, 2009. 100 


\section{LISTA DE SIGLAS E ABREVIATURAS}

1xRTT - 1 x Round Trip Time - Tecnologia de comunicação de dados que se utiliza de múltiplos canais de rádio comunicação.

3G - Terceira geração de padrões e tecnologias de telefonia móvel.

ABCON - Associação Brasileira das Concessionárias Privadas de Serviços Públicos de Água e Esgoto.

AI - Analog In - Entrada Analógica.

ANATEL - Agência Nacional de Telecomunicações.

ATM - Asynchronous Transfer Mode - Modo de transferência assíncrono de informação.

CAR - Carregar.

$\mathrm{CCO}$ - Centro de Controle Operacional.

CDMA - Code Division Multiple Access - Acesso Múltiplo por Divisão de Código - método de acesso a canais em sistemas de comunicação. É utilizado tanto para a telefonia celular quanto para o rastreamento.

CIESP - Centro das Indústrias do Estado de São Paulo.

CLP - Controlador Lógico Programável.

DIAG - Diagnóstico.

DSP - Display.

D - Desliga.

ERP - Enterprise Resource Planning - Sistema Integrado de Gestão Empresarial.

ERT - Estação Remota de Telemetria.

EUA - Estados Unidos da América.

FFB - Flexible Function Block - Bloco de Função Flexível. 
Frame Relay - Tecnologia de comunicação usada para transmitir informação digital através de uma rede de dados, dividindo essas informações em frames (quadros) enviados a um ou muitos destinos de um ou muitos end-points.

Fig. - Figura.

FL - Filtro.

fr - Frequência.

FTP - File Transfer Protocol - Protocolo de Transferência de Arquivos.

GPRS - General Packet Radio Service - Serviço geral de pacotes de informação digital por rádio comunicação (tecnologia celular).

GSM - Global System for Mobile Communications - Sistema Global para Comunicações Móveis.

GTW - Gateway.

H1 - Padrão físico de comunicação do protocolo Foundation Fieldbus.

HSE - High Speed Ethernet - Padrão de comunicação Ehernet de alta velocidade.

IEC - International Engineering Consortium - Consórcio Internacional de Engenharia.

ISEL - In Selector - Seletor de Entrada.

IP - Internet Protocol - Protocolo de Internet.

L - Liga.

LAS - Link Active Scheduler - Relacionador de Link Ativo.

MIB - Management Information Base - Base de Gerenciamento de Informação.

MOV - Movimentar.

$\mathrm{N}^{0}$ - Número.

NBR - Norma Brasileira.

NEG - Negação.

OMS - Organização Mundial da Saúde. 
OPC - OLE for Process Control - Padrão industrial público para conectividade entre sistemas, cujo propósito é fornecer uma infraestrutura padrão para o controle e troca de dados. P\&I - Processo e Instrumentação (diagrama).

Pg. - Página.

PNCDA - Programa Nacional de Combate ao Desperdício de Água.

SABESP - Companhia de Saneamento Básico do Estado de São Paulo.

SCADA - Supervisory Control and Data Aquisition - Controle Supervisório e Aquisição de Dados.

SDCD - Sistema Digital de Controle Distribuído.

SOM - Soma.

SPG - Set-point Generator - Gerador de Set-point.

SUB - Subtrai.

SV - Solenoide Valve - Válvula Solenoide.

RM - Rádio-modem.

RT- Roteador.

SNIS - Sistema Nacional de Informações Sobre Saneamento.

TAG - Sigla referente à codificação (que, por sua vez, faz referência ao tipo) de equipamentos ou dispositivos de campo em processos industriais.

TCP - Transfer Control Protocol - Protocolo de controle de transferência.

TEE - Temporizador para acionar.

VFD - Virtual Fieldbus Block - Bloco Virtual Fieldbus.

VP - Válvula Piloto.

VRP - Válvula Redutora de Pressão.

$\% \mathrm{~A}-$ Memória auxiliar discreta.

$\% \mathrm{E}$ - Memória de saída física. 
$\% \mathrm{KM}$ - Constante numérica.

\%M - Memória auxiliar inteira. 


\section{LISTA DE SÍMBOLOS}

FIT - Flow Indicator Transmitter - Transmissor Indicador de Vazão.

FT - Flow Transmitter - Transmissor de Vazão.

pH - Símbolo para a grandeza físico-química 'potencial hidrogeniônico'.

PI - Pressure Indicator - Indicador de Pressão.

PIC - Pressure Indicator Controller - Controlador Indicador de Pressão.

PIT - Pressure Indicator Transmitter - Transmissor Indicador de Pressão.

PT - Pressure Transmitter - Transmissor de Pressão.

SW - Switch - Chave.

Vdc - Voltage Direct Current - Tensão de corrente continua.

Z - Impedância.

ZAL - Alarme de posição.

ZSL - Chave de posição. 


\section{LISTA DE UNIDADES}

$\%$ - Porcentagem.

$\mu \mathrm{s} / \mathrm{km}$ - Micro Segundo por Quilômetro.

$\Omega-\mathrm{Ohm}$.

$\Omega / \mathrm{km}$ - Ohm por Quilômetro.

dB/km - Decibel por Quilômetro.

kbit/s - Quilo Bits por Segundo.

kHz - Quilo Hertz.

km - Quilômetro.

$\mathrm{kPa}$ - Quilo Pascal.

mA - Mili Amperes.

mca - Metros de Coluna D’água.

$\mathrm{mm}^{2}$ - Milímetro Quadrado.

ms - Mili Segundo.

Mbit/s - Mega Bits por Segundo.

nf - Nano Faraday. 


\section{RESUMO}

A diminuição das perdas hídricas com a redução das pressões de operação das redes de distribuição é um fenômeno conhecido há muito tempo pelas companhias de saneamento e distribuição de água. Entre as técnicas empregadas para esta finalidade, a setorização apresenta-se, atualmente, como um dos instrumentos mais efetivos de melhoria e otimização dos serviços de abastecimento. A setorização consiste na separação do sistema de abastecimento hídrico urbano em distritos denominados zonas pitométricas, com o objetivo geral de estabelecer um controle mais efetivo das pressões e das vazões de água destas zonas. A ampla difusão desta técnica, no entanto, não seria possível sem a evolução tecnológica dos elementos chave, necessários à implementação deste método de controle de abastecimento hídrico urbano. Visando subsidiar o desenvolvimento de técnicas para problemas enfrentados na setorização de redes de abastecimento hídrico, neste trabalho é relatado um estudo de caso realizado nas dependências da Companhia de Saneamento Básico do Estado de São Paulo (SABESP) por meio do qual são apresentadas soluções implementadas por esta Companhia no decorrer de mais de cinco anos. Este tempo permitiu que os métodos apresentados atingissem o grau de maturação necessário para que fosse estabelecido um modelo de setorização funcional e cada vez mais confiável. Por meio deste estudo são apresentadas, como contribuição original, soluções orientadas à utilização de recursos do protocolo digital Foundation Fieldbus, visando agregar ainda mais autonomia e disponibilidade às instalações do sistema de abastecimento hídrico da superintendência do litoral da referida Companhia e incorporando a este sistema características diferenciais como interoperabilidade, flexibilidade e redundância dos elementos críticos que o compõem.

Palavras chave: setorização, automação de sistemas de saneamento, válvulas redutoras de pressão, protocolo Foundation Fieldbus. 


\begin{abstract}
The decrease of the hydric losses with the reduction of the operation pressures of the distribution nets is a phenomenon a long time known for the sanitation and water distribution companies. Among the used techniques for this purpose, the division in sectors technique comes, now, as one of the more effective instruments of improvement and optimization of the supplying services. The division in sectors technique consists in the separation of the hydric urban provisioning system in districts denominated pitometric zones, with the general objective of establishing a more effective control of the water pressures and flows of these zones. The wide diffusion of this technique, however, would not be possible without the technological evolution of the key elements, necessary to carry out this control method of urban hydric supplying. Looking for subsidize the development of techniques for problems faced in the division in sectors technique of hydric provisioning nets, in this work is described a case study, accomplished in the dependences of the Company of Basic Sanitation of the State of São Paulo (SABESP) through which are presented solutions implemented by this Company which has been carried out for more than five years. This time allowed that the methods presented reach the necessary maturation degree so that a functional and each more reliable model of the division in sectors technique would be established. Through this study are presented, as original contribution, proposals guided to the use of resources of the digital protocol Foundation Fieldbus, looking for aggregate yet more autonomy and availability to the facilities of the hydric provisioning system of the coast superintendency of the referred Company and incorporating to this system differentiates characteristics as interoperability, flexibility and redundancy of the critical elements that composes it.
\end{abstract}

Key words: Division in sectors technique, sanitation automation systems, pressure reduction valves, Foundation Fieldbus protocol. 


\section{INTRODUÇÃO}

Muitas são as razões para as deficiências encontradas no controle do abastecimento hídrico urbano no Brasil. Muitas destas razões, no entanto, encontram convergência em um motivo comum: a falta de planejamento na implantação e na expansão das redes e dos sistemas de controle de abastecimento de água, fato que, infelizmente, é recorrente e independe do porte destes sistemas, sejam eles aplicados a pequenos, médios ou grandes municípios.

Com o crescimento demográfico, os agrupamentos urbanos tornaram-se cada vez mais densos e com atividades que exigem, a cada dia, maior quantidade de água. Da crescente consciência sobre o caráter esgotável dos recursos hídricos infere-se a necessidade de gestão eficiente e efetiva destes bens, o que se já era evidente torna-se, nos dias atuais, imperativo.

Previsões baseadas em estudos citados no Almanaque Brasil Socioambiental (2005) indicam que, em questão de algumas décadas, a água consistirá na principal causa de conflitos entre dezenas de nações no mundo. Em áreas do planeta como o Oriente Médio e a África, esses conflitos já existem há vários anos. Mesmo no Brasil, país considerado privilegiado por possuir $11 \%$ da água doce superficial no mundo, muitas cidades sofrem pela falta de água.

A distribuição desigual e a escassez dos recursos hídricos são as principais causas dos problemas de abastecimento. Outro foco de dificuldades é a distância entre mananciais e centros consumidores. É o caso, por exemplo, do estado da Califórnia (EUA) que utiliza, para abastecimento de algumas de suas cidades, neve derretida do distante estado do Colorado. É também o caso da cidade de São Paulo que, embora nascida na confluência de vários rios, viu a poluição tornar inutilizável para o consumo a água de muitos deles tendo, portanto, que 
captar água de mananciais distantes para complementar os recursos hídricos potáveis que ainda existem na região.

Dados do Sistema Nacional de Informações Sobre Saneamento - SNIS (BRASIL, 2004), indicam que, na última década, a quantidade de água distribuída aos brasileiros cresceu 30\%. Entretanto, o volume de água sem tratamento utilizada para consumo quase dobrou (de 3,9\% para 7,2\%) e o índice de perdas dos recursos hídricos tratados e distribuídos supera o impressionante número de $40 \%$.

De acordo com a Associação Brasileira das Concessionárias Privadas de Serviços Públicos de Água e Esgoto - ABCON, o índice de desperdício de água com vazamentos e ligações clandestinas foi de 38\% em 2005 e 45\% em 2009. O alto índice de perdas hídricas e a intermitência no abastecimento de água são, infelizmente, problemas amplamente encontrados tanto em regiões mais afastadas quanto nos grandes centros, e tendem a crescer com a implantação não planejada de redes de abastecimento.

Neste contexto, no SNIS é citada a setorização das redes de abastecimento como requisito básico para o controle de sistemas de fornecimento de água e para a diminuição das perdas hídricas. Em TSUTIYA (2004) é reafirmada essa necessidade quando são sugeridos os distritos pitométricos como unidades de controle operacionais, enfatizando, entre outros fatores, a necessidade de isolamento das redes.

Apesar destas recomendações e do bom desempenho verificado no controle dos sistemas de abastecimento hídrico urbano de localidades em que se adotaram a setorização, alguns gestores ainda resistem à adoção desta técnica, pois ela requer estudos e, por vezes, 
substanciais investimentos. Desta forma, a setorização, quando não estabelecida durante a etapa de projeto do sistema, acaba posteriormente por concorrer com os investimentos demandados pela própria expansão das redes de abastecimento, sendo então relegada a uma ação secundária.

Contudo, o relevante impacto positivo apresentado nos sistemas de abastecimento urbano onde se optou pela implantação desta técnica, compele os gestores ligados ao setor de saneamento básico ${ }^{1}$ considerarem a utilização da setorização como instrumento de melhoria e otimização dos serviços oferecidos. Esta ação tende a acarretar maior disponibilidade do sistema de abastecimento à população e grande redução do desperdício de recursos hídricos, fator que encabeça a lista de preocupações das empresas de saneamento básico.

\subsection{Justificativa da pesquisa e objetivo}

O cenário de inefíciência das companhias de saneamento básico decrementa a capacidade de investimento destas empresas, o que, por sua vez, acaba por tornar morosa a expansão e a melhoria dos sistemas de abastecimento hídrico. Este fator, somado ao agravamento do quadro de escassez de recursos hídricos devido à poluição dos mananciais, à irregularidade na distribuição demográfica e à indisponibilidade de água em certas regiões do país, ocasiona grande impacto negativo na sociedade, comprometendo suas necessidades mais básicas.

\footnotetext{
1 Saneamento básico é aqui entendido como conjunto de condições urbanas essenciais para a preservação da saúde pública e conexa com águas, esgotos, poluição e afins.
} 
De acordo com a Organização Mundial da Saúde (OMS), cada real investido em saneamento leva à economia de quatro reais em tratamento de doenças, uma vez que um elevado número de patologias é de veiculação hídrica.

Além disto, a redução dos índices de perdas em sistemas de abastecimento acarreta a redução dos custos de produção para a mesma quantidade de água entregue aos consumidores, considerando que o volume hídrico captado, tratado e transportado diminui, possibilitando a diminuição, também, da quantidade de produtos químicos utilizados no tratamento deste recurso, além da evidente vantagem da diminuição da quantidade de água captada dos mananciais, cada vez mais escassos.

Ações que vislumbrem a melhoria da eficiência das distribuidoras tornaram-se, portanto, prioridade e já fazem parte das atividades de maior importância das principais companhias de saneamento. Tais atividades, no entanto, exigem o envolvimento de mão-de-obra técnica especializada e, muitas vezes, grandes investimentos em intervenções nas redes de abastecimento.

Considerando a grande dimensão dos sistemas automáticos que controlam essas redes, características tais como supervisão remota, autonomia e redundância automática dos dispositivos que os compõem tornam-se imprescindíveis, uma vez que possibilitam o seu gerenciamento com reduzida necessidade de intervenções humanas e a contenção automática de eventuais falhas que os seus dispositivos possam vir a apresentar.

A automação dos sistemas de abastecimento hídrico consiste, basicamente, em coletar, concentrar e analisar as informações do processo com o uso da tecnologia da informação. 
Baseados nos resultados obtidos, os sistemas de automação agem de forma autônoma monitorada sobre os estados e as grandezas do processo para obtenção dos resultados desejados.

A autonomia destes sistemas é possibilitada, principalmente, pela inserção de parâmetros pré-determinados nos dispositivos de controle que os compõem. Estes parâmetros, por sua vez, baseiam-se em estudos e dados empíricos, obtidos por meio da coleta de informações em diversos pontos do sistema de abastecimento. Uma vez parametrizados, os dispositivos adquirem a capacidade de tomar decisões e de controlar, de forma autônoma, a malha da qual fazem parte. O gerenciamento efetivo de variáveis como pressão e vazão, massivamente presentes nas diversas zonas pitométricas que compõem um sistema de abastecimento hídrico, bem como o controle ativo de vazamentos é, então, viabilizado.

A manutenção da infraestrutura do sistema de controle de abastecimento, por sua vez, é auxiliada de forma bastante significativa pelo uso de tecnologias que possibilitam a redundância automática de dispositivos instalados nos pontos críticos do processo. Estas tecnologias proporcionam a comutação, independentemente de intervenção, dos dispositivos de controle e da instrumentação, de forma a estabelecer condições mínimas de operação enquanto a falha no sistema automático principal é sanada. A utilização de redundância, portanto, interfere diretamente na disponibilidade do sistema de abastecimento alocando tempo para execução de reparos.

A quantidade de falhas nos equipamentos é reduzida de forma significativa, por meio do acesso a dados sobre o desempenho e o estado dos instrumentos que fazem parte do sistema de controle. A utilização de tecnologias que viabilizem a monitoração do estado dos 
componentes que compõem os instrumentos, além dos dados de processo, possibilita a integração dos dispositivos de campo diretamente a sistemas de diagnóstico e manutenção. Esta tecnologia, referida em CASTRO, CASSIOLATO, AGUIAR, GIMENES, PAGANO e RIBEIRO (2005) como gerenciamento online de ativos, oportuniza a implantação de um sistema digital de manutenção preventiva conectado diretamente à rede de instrumentos, possibilitando o monitoramento contínuo das suas condições e notificando a equipe técnica sobre possibilidades de falhas ou quando a manutenção programada é necessária.

A convergência de características como redundância automática de dispositivos, autonomia e gerenciamento online de ativos em uma mesma tecnologia aplicada a sistemas de controle industriais é relativamente recente, surgiu, de acordo com SOUZA (2006, p.38), nas últimas duas décadas com o advento dos instrumentos industriais micro-processados operando por meio de protocolos digitais de comunicação.

Contudo, o aumento substancial da base instalada de instrumentos que fazem uso desta tecnologia só ocorreu recentemente, com a adoção dos protocolos digitais abertos pelos grandes fabricantes de instrumentos industriais, e pela organização destes fabricantes em comitês e associações que têm por função estabelecer e difundir os padrões referentes a estes protocolos.

Entretanto, percebe-se ainda a escassez de pesquisas voltadas à exploração de recursos avançados disponibilizados por essa tecnologia, e a ainda incipiente utilização destes recursos na resolução de deficiências e na melhora da eficácia dos sistemas automáticos utilizados para controle do abastecimento hídrico urbano, aspectos os quais esta pesquisa se propõe a dirimir. 
Por meio deste estudo são apresentadas soluções orientadas à automação de sistemas de abastecimento hídrico, aplicadas à setorização das redes que compõem estes sistemas, fazendo-se uso de recursos disponibilizados pelo protocolo digital para aplicações industriais Foundation Fieldbus. Estas soluções, que se baseiam em um estudo de caso realizado em instalações da Companhia de Saneamento Básico do Estado de São Paulo (SABESP), por serem percebidas como ímpares e peculiares a sistemas dessa natureza, constituem a contribuição original deste trabalho.

Almeja-se, com a descrição dessas soluções, fornecer subsídios para a atualização tecnológica do sistema digital com base em instrumentação eletrônica (DCS), ora utilizado pela SABESP por consistir na opção de melhor custo-benefício na época em que o sistema foi concebido, e estimular sua implantação em regiões em que os sistemas de abastecimento não foram, ainda, objeto de setorização.

\subsection{Estrutura do trabalho}

Com o objetivo de apresentar soluções de automação aplicadas à setorização de redes de abastecimento hídrico, este trabalho está estruturado de forma a, primeiramente, se estabelecer a conceituação básica relacionada à setorização de redes de abastecimento, enfatizando-se as melhorias proporcionadas pelo uso de recursos de automação aplicados à técnica de controle das pressões e vazões de água destas redes. Essa conceituação é seguida pela descrição das vantagens relacionadas à implementação de sistemas de controle baseados em protocolos digitais de aplicações industriais na setorização de redes de abastecimento hídrico, em especial, os sistemas baseadas no protocolo Foundation Fieldbus, que constitui a base das soluções propostas neste trabalho. 
Estabelecidas as bases conceituais, define-se a metodologia de obtenção, análise e validação dos dados que subsidiaram a descrição do sistema de automação apresentado, que é orientada, primeiramente, a uma visão geral do projeto que evidenciou as necessidades às quais as soluções descritas neste trabalho se propõem a atender. Esta exposição tem o intuito de estabelecer um panorama de aplicação das soluções apresentadas.

Posteriormente às definições metodológicas, é exposta a descrição dos componentes que fazem parte do sistema de automação proposto, detalhando-se o funcionamento dos dispositivos que o compõem e os recursos destes dispositivos utilizados para composição do resultado final da pesquisa. Estabelece-se, por conseguinte, as conclusões e a avaliação de parte do sistema proposto que já se encontra aplicado pela companhia cujo caso subsidiou esta pesquisa. 


\section{SETORIZAÇÃO DE REDES DE ABASTECIMENTO HÍDRICO}

Em MÀRIO FILHO (2001) é explicado que o conceito de automação em sistemas de abastecimento de água assemelha-se muito ao que acontece no setor elétrico. Da mesma forma que esse segmento pode ser dividido em geração, transmissão e distribuição de energia, o setor de saneamento envolve o tratamento da água, o transporte para os reservatórios e a distribuição aos consumidores.

Neste capítulo são demonstrados aspectos regulamentares sobre o uso e a exploração dos recursos hídricos e é descrita a infraestrutura envolvida em um sistema de abastecimento, relacionando-se a automação deste sistema com a contenção das perdas hídricas por meio da técnica de setorização.

\subsection{Uso e exploração dos recursos hídricos}

A partir de janeiro de 1997, com a instituição da Política Nacional de Recursos Hídricos por meio da Lei Federal 9433/97, aspectos relacionados à gestão do uso da água no Brasil têm sido tratados sob um aporte regulamentar atualizado e que considera de forma ampla as necessidades impostas pela utilização em grande escala da água.

Em consonância com essa medida, os estados brasileiros têm atualizado e aprovado suas respectivas leis, instituindo os Sistemas Estaduais de Recursos Hídricos e trazendo à pauta a discussão sobre a aplicação dos diversos instrumentos de gestão como a outorga do direito de uso dos recursos hídricos, o planejamento deste uso e a cobrança pela sua exploração. 
Dentre as medidas adotadas pelos estados, convergem àquelas relacionadas aos princípios de aproveitamento e uso da água que determinam que "todas as utilizações dos recursos hídricos que afetem sua disponibilidade qualitativa ou quantitativa, ressalvadas aquelas de caráter individual, para satisfação de necessidades básicas da vida, ficam sujeitas à prévia aprovação do órgão competente" (Lei Federal 9433/97 apud FREIRE, PEREIRA, RIBEIRO, KIRCHHEIN e LANNA, 1998). Estes princípios embasam as diretrizes gerais para exploração da água nos estados brasileiros, quais sejam:

a) O desenvolvimento de programas permanentes de conservação e proteção das águas contra a poluição e a exploração excessiva ou não controlada;

b) O estabelecimento de cadastro de poços, inventário de mananciais e de usuários, com vistas à racionalização do uso da água;

c) A utilização racional dos recursos hídricos superficiais e subterrâneos, assegurado o uso prioritário de medidas que garantam o uso múltiplo racional dos recursos hídricos protegendo-os contra a exploração excessiva e outras ações que possam comprometer a perenidade das águas;

d) O desenvolvimento de programas conjuntos com os municípios mediante convênios de mútua cooperação e assistência técnica e econômico-financeira, com vistas a zoneamento das áreas de mananciais, com restrições a usos incompatíveis. 
Nos anos setenta, o Governo Federal criou o Plano Nacional de Saneamento (PLANASA), que possibilitou que fossem criadas empresas estaduais que se tornaram concessionárias dos serviços de água e esgoto de muitos municípios que, na época, contavam com uma infraestrutura precária para prestação destes serviços. Os contratos foram firmados sem licitação prévia em razão de previsão legal de dispensa de licitação vigente na legislação da época, o Decreto-Lei 200/67.

No estado de São Paulo foi criada a SABESP, com a qual os municípios paulistas firmaram contrato de concessão de serviços público de saneamento básico pelo prazo de 30 anos. Com o vencimento destes contratos, os municípios têm decidido sobre assumir a prestação de serviços de água e esgoto ou outorgar a concessão destes serviços por um novo período mediante licitação, uma vez que a eventual prorrogação do prazo de concessão é explicitamente vedada pelo $\S 3^{\circ}$, da Lei de Licitações 8.666/93, subsidiária da Lei de Concessões (ANTUNES, 2006).

Fatores como a qualidade dos serviços prestados, os custos de manutenção destes serviços além da expertise e da infraestrutura necessárias para realizá-los, têm sido considerados pelos municípios na tomada desta decisão.

\subsection{Sobre os sistemas de abastecimento hídrico}

A infraestrutura de um sistema abastecimento hídrico é composta por diversas estações, desde a origem da água - que constitui a estação de captação - até o local de monitoração do macro-consumo. São elas, na totalidade dos casos, as estações de captação, de elevação, de 
tratamento, de adução hídrica, de armazenamento e de distribuição pública. Um modelo simplificado desta infraestrutura pode ser visto na Fig. 1:

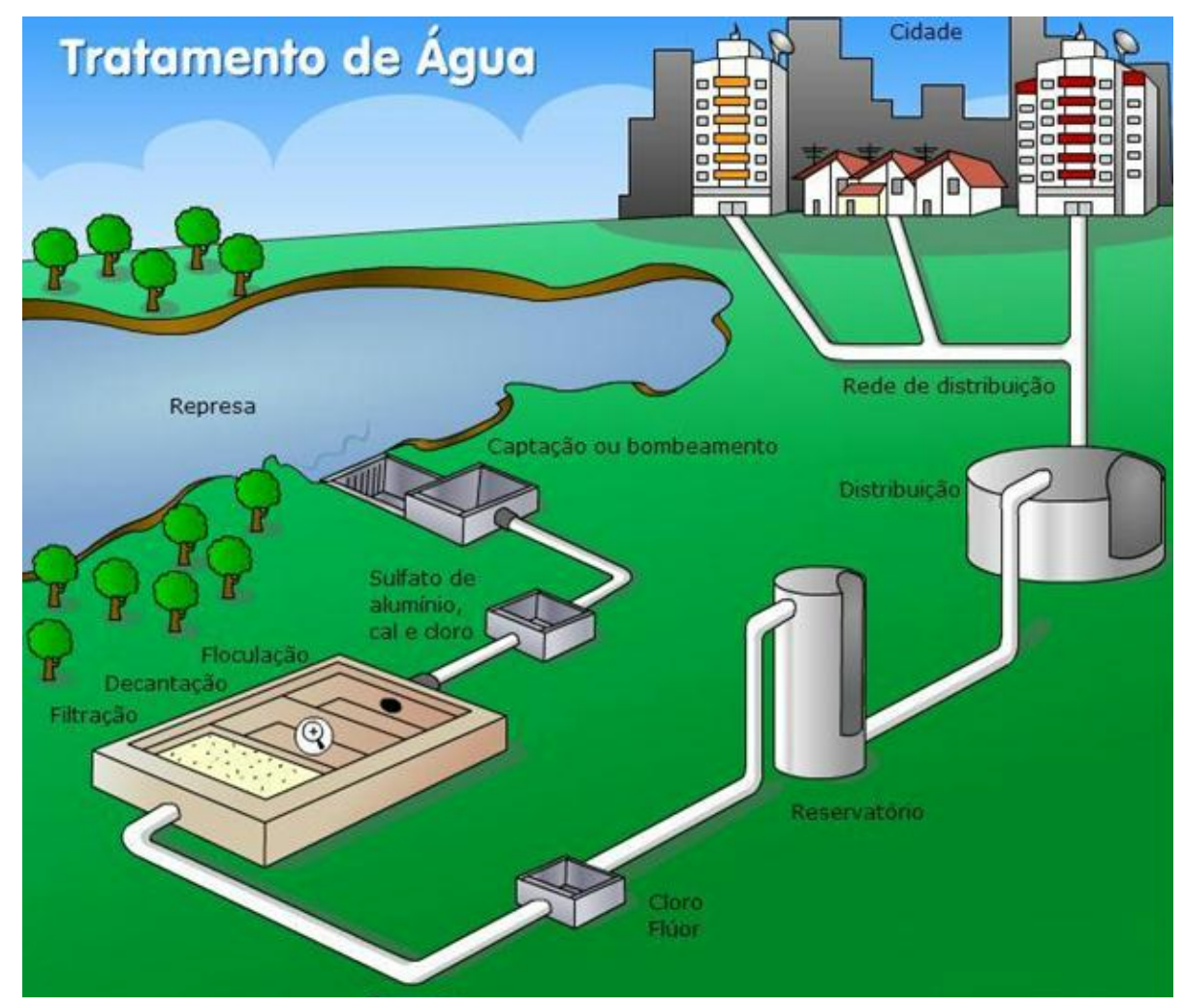

Figura 1 - Ilustração simplificada de um sistema de abastecimento hídrico - Disponível em < http://www.sabesp.com.br/CalandraWeb/ >. Acesso em: 02 Jul. 2008, 23h12min

O sistema de captação tem por função recolher, em qualquer meio hídrico superficial ou subterrâneo, água em quantidade suficiente e com características físicas, químicas e bacteriológicas minimamente aceitáveis em função da legislação vigente.

O sistema de elevação tem por função transmitir energia à água, de modo a que ela passe não só a circular a uma pressão conveniente, como também a ter a possibilidade de vencer desníveis topográficos e a garantir as pressões necessárias nos pontos de consumo. 
O sistema de tratamento tem por função conferir à água características físicas, químicas e bacteriológicas compatíveis com as exigências do Ministério da Saúde, em sua portaria ${ }^{\circ}{ }^{\circ}$ 518, de 25 de março de 2004, aplicável em todo o território nacional.

O sistema de adução tem por função transportar a água para as zonas de consumo, por vezes muito afastadas do local de captação.

O sistema de armazenamento tem por função acumular a água por períodos variáveis e em locais especialmente destinados a isso, seja para regularização dos mananciais, seja para garantir reservas de incêndio e de avaria.

O sistema de distribuição pública tem por função fazer a distribuição na zona a abastecer, garantindo que diversos pontos de consumo recebam água com pressões convenientes. Este sistema é o que apresenta a maioria dos casos de vazamento que aumentam substancialmente as estatísticas das perdas hídricas, fato que o fez se constituir em foco das pesquisas que originaram este trabalho.

\subsection{A automação e o controle das perdas hídricas}

A diminuição das perdas hídricas com a redução das pressões de operação da rede de distribuição é um fenômeno conhecido há muito tempo pelas companhias de saneamento e distribuição de água. Em 1980 foi publicado um extenso relatório sobre controle de pressão como parte da National Leakage Initiative - Inglaterra, que se tornou uma referência tradicional da relação entre pressão e volume de vazamento em sistemas de abastecimento urbano. 
O efetivo controle de perdas hídricas é feito por meio de quatro atividades citadas pelo documento técnico de apoio D1 do Programa Nacional de Combate ao Desperdício de Água (PNCDA - D1, 1999, p.11):

(a) gerenciamento da pressão das zonas pitométricas;

(b) controle ativo de vazamentos;

(c) velocidade e qualidade dos reparos; e

(d) gerenciamento da infraestrutura.

Considerando a natureza destas atividades, a automação surge como uma ferramenta poderosa na melhoria da gestão do saneamento, pois além de aumentar a qualidade do processo, possibilita o controle preciso da redução das pressões de operação da rede de distribuição.

O gerenciamento de pressões das zonas pitométricas visa controlar as pressões destas zonas e assegurar padrões mínimos de abastecimento aos ramais consumidores. Estes objetivos duais são atingidos pelo projeto específico de setorização dos sistemas de distribuição, que envolve o controle de bombeamento direto na rede por meio de estações de de reforço (boosters) ou pela introdução de válvulas redutoras de pressão (VRPs) em pontos estratégicos da rede de distribuição. 
O controle ativo de vazamentos contrapõe o controle passivo que é, basicamente, a atividade de reparar os vazamentos apenas quando se tornam visíveis. A metodologia mais utilizada no controle ativo de vazamentos é a pesquisa de vazamentos não visíveis, realizada por meio da sua escuta por geofones mecânicos ou eletrônicos e correlacionadores. Essa atividade reduz o tempo da perda hídrica, ou seja, quanto maior for a frequência da pesquisa, maior será a taxa de vazão anual recuperada. Uma análise de custo-benefício pode definir a melhor frequência de pesquisa a ser realizada em cada área.

Desde o conhecimento da existência de um vazamento, o tempo gasto para sua efetiva localização e seu estancamento é um ponto chave do gerenciamento de perdas hídricas.

A prática das atividades mencionadas já traz melhorias à infraestrutura do sistema de abastecimento. Portanto, a substituição de trechos da rede de água é realizada apenas quando, após a realização das outras atividades, ainda se detectar índices de perdas elevados na área, evitando-se assim custos mais altos. No entanto, para que seja possível a implementação efetiva destas atividades, é necessária a segmentação da rede de abastecimento em setores, técnica denominada setorização.

\subsection{Estado da arte da técnica de setorização}

Como exposto em THOMTON (2003, p.1), em alguns países como o Japão e o Reino Unido é notória a relação entre a administração efetiva das pressões nas redes de abastecimento hídrico e o sucesso na redução de vazamentos nestas redes. Essa administração 
é alcançada por meio da implementação da técnica de setorização dos sistemas de distribuição.

A setorização consiste na separação do sistema de abastecimento hídrico urbano em distritos denominados zonas pitométricas, com o objetivo geral de estabelecer um controle mais efetivo das pressões e das vazões de água destas zonas. Dentre os benefícios obtidos pela utilização desta técnica estão:

(a) o domínio do consumo dos setores, de forma individualizada, permitindo seu controle e acompanhamento;

(b) flexibilidade no direcionamento dos recursos hídricos para áreas que apresentem pressões abaixo do demandado para o seu abastecimento ou de regiões que apresentem pressões acima do necessário;

(c) rapidez no descobrimento das necessidades de intervenção no sistema, por meio da rápida detecção de rompimento ou obstrução de linhas de abastecimento;

(d) visão estruturada e sistêmica da rede de abastecimento hídrico e dos seus componentes;

(e) economia de recursos financeiros com a minimização dos danos causados pelas perdas hídricas e usos excedentes indicados pelo levantamento do perfil de consumo de cada setor controlado, também definido como "zona pitométrica". 
A relação entre a redução da pressão das redes de abastecimento e a diminuição das taxas de vazamento das tubulações das zonas pitométricas é demonstrada em LAMBERT (2000), por meio da seguinte equação:

$$
\mathrm{L}=\mathrm{Cd} \times \mathrm{A} x(2 \mathrm{gP})^{\mathrm{N}}
$$

Onde:

L: Taxa de vazão por uma determinada área;

Cd: Coeficiente de descarga relacionado ao escoamento do fluido da tubulação representado pelo número de Reynolds (ANEXO 1);
A: Área da ruptura na tubulação;
g: Aceleração da gravidade;
P: Pressão na tubulação;

$\mathrm{N}$ : Coeficiente de variação da área de vazamento: 0,5 para tubos de metal.

Cada zona pitométrica é definida pela área suprida por um reservatório de distribuição (apoiado, semi-enterrado ou enterrado), destinado a regularizar as variações de adução e condicionar as pressões na rede de distribuição. Alguns projetistas optam pelo abastecimento da rede de distribuição por derivação direta da adutora ou por meio da saída de boosters com bombas de rotação fixa. Esta técnica, porém, é altamente condenável, pois o controle das pressões dos setores torna-se impraticável diante da variedade das oscilações ocorridas. 
Uma vez que o reservatório principal situe-se dentro da zona pitométrica, na setorização é necessária a existência de um reservatório elevado, externo ao setor controlado, cuja principal função é condicionar as pressões nas áreas de cotas topográficas mais altas que não podem ser abastecidas pelo reservatório principal. Nesse caso, o setor é dividido em zonas de pressão, na qual as pressões estática e dinâmica obedecem a limites prefixados. Segundo a Norma Técnica NBR 12218/1994 a pressão estática máxima nas tubulações distribuidoras deve ser de $500 \mathrm{kPa}(50 \mathrm{mca})$, e a pressão dinâmica mínima, de $100 \mathrm{kPa}(10 \mathrm{mca})$. Valores fora dessa faixa podem ser aceitos desde que justificados técnica e economicamente.

Para que toda a zona pitométrica possa ser abastecida por apenas um reservatório é necessário que este seja elevado ou se localize fora desta zona, encontrando-se numa cota de, pelos menos, 10 metros acima da cota mais elevada do setor.

Na implantação de um sistema de setorização, a definição das zonas de pressão é feita tomando-se como base a limitação da pressão estática máxima em 50 mca no ponto mais baixo da zona pitométrica e a limitação da pressão dinâmica mínima em 10 mca no ponto extremo desta zona.

O ponto extremo ou crítico é aquele, dentro da zona pitométrica, onde se verifica a menor pressão dinâmica, isto é, o ponto mais elevado ou o mais distante. Com o passar do tempo, o ponto crítico pode se deslocar devido ao aumento de rugosidade em função da idade da tubulação, tendendo a se localizar, inicialmente, no ponto mais alto da zona de controle e, futuramente, nos pontos mais distantes em relação ao referencial de pressão (reservatório, booster ou VRP). Este ponto é utilizado para se estimar o potencial de redução de pressão da área, além de ser o ponto referencial para controle do abastecimento. A mínima pressão 
aceitável neste ponto pode variar entre as companhias abastecimento hídrico, entretanto, na maioria das áreas, a manutenção da pressão mínima das redes de distribuição entre 10 e 15 mca é suficiente para manutenção do abastecimento de forma satisfatória.

O documento técnico de apoio do programa nacional de combate ao desperdício de água (PNCDA - D1, 1999, p.21) exemplifica uma região abastecida por um reservatório apoiado e um elevado com uma variação de pressão dinâmica máxima de 10 mca. Neste sistema se pode demarcar a área de influência dos reservatórios por meio de curvas de nível que definam pressões estáticas de 20 mca e 50 mca, para ambos os reservatórios.

A Fig. 2 demonstra que isso irá definir uma área de abastecimento redundante, que tanto pode ser abastecida pelo reservatório apoiado (pressões mais próximas de 20 mca) como pelo reservatório elevado (pressões mais próximas de $50 \mathrm{mca}$ ).

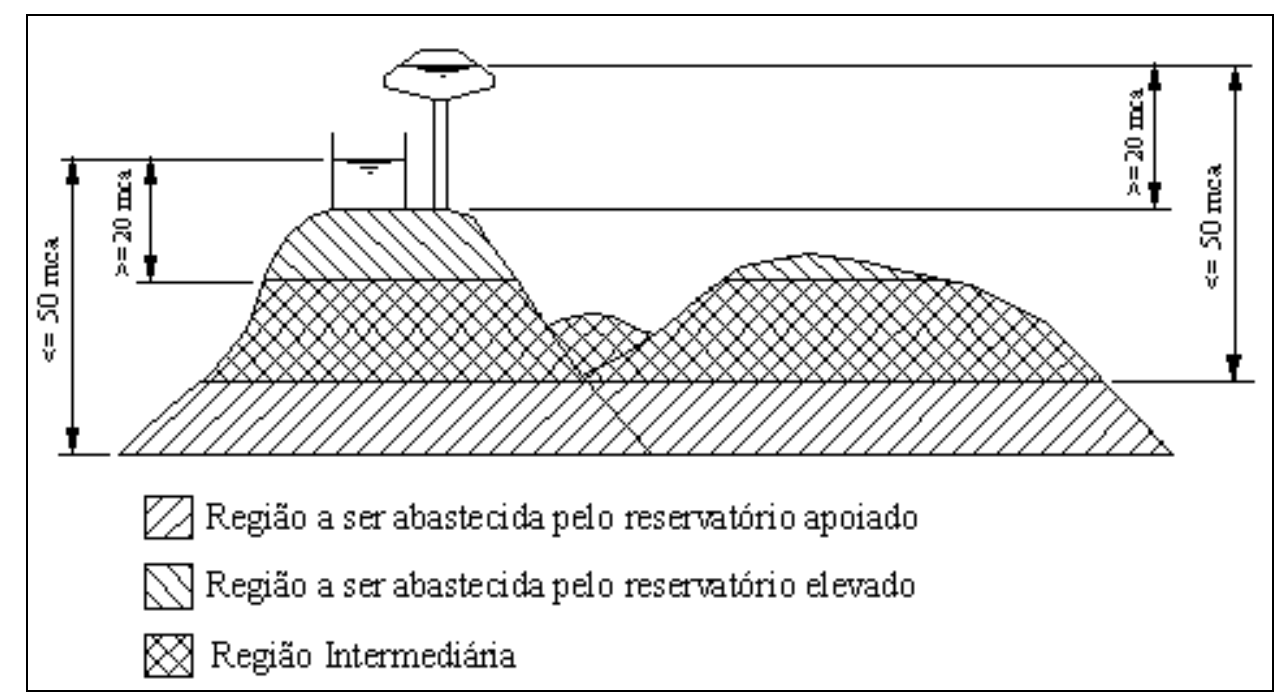

Figura 2 - Esquema de setorização com área de abastecimento redundante - Fonte: Documento técnico de apoio do programa nacional de combate ao desperdício de água - D1 - Secretaria Especial de Desenvolvimento Urbano, Brasília, 1999. 
Uma vez que, para a redução de perdas hídricas, é desejável submeter a rede a baixas pressões, a maior parte dessa área deve ser abastecida pelo reservatório apoiado, o que reduz também a vazão recalcada para o reservatório elevado, trazendo, assim, redução no consumo de energia elétrica.

O documento técnico de apoio do programa nacional de combate ao desperdício de água (PNCDA - D1, 1999) recomenda que o desnível geométrico máximo para a setorização de terrenos com baixa variação topográfica seja de 50 metros. Em regiões de topografia mais acidentada, é necessária a utilização de um reservatório intermediário. Os altos custos de implantação e manutenção de reservatórios (principalmente os elevados) conduziram os projetistas à elaboração de soluções alternativas, disponíveis apenas após o desenvolvimento tecnológico dos dispositivos de controle e automação. Desta forma, hoje é comum a utilização de boosters de rotação variável e de VRPs para o controle da pressão no setor, mantendo-se como função básica do reservatório a regularização de variações horárias de demanda e reserva de incêndio.

\subsection{Planejamento da automação dos sistemas de abastecimento}

O ciclo de vida dos sistemas de abastecimento de água é composto por diversas fases, algumas das quais constituem aquilo que pode ser designado por vida útil do sistema. Nesse sentido, o início do ciclo de vida corresponde ao planejamento do sistema, fase em que ele é imaginado em termos gerais, tendo em conta o contexto físico em que ele irá se inserir e os objetivos que se pretende alcançar. 
Após o planejamento, segue-se a fase de elaboração do projeto, em que se detalha e especifica o sistema idealizado. Ela é constituída por diversas etapas, compreendendo, de acordo com a legislação atual, o programa preliminar, o programa base, o estudo prévio, o anteprojeto e o projeto de execução. Aprovado o projeto, efetiva-se então a construção do sistema, a que se segue a sua exploração, compreendendo sua operação e manutenção, permitindo colocá-lo ao serviço dos consumidores, e com uma duração prevista tão longa quanto possível, da ordem das muitas décadas.

Se não houver nenhuma intervenção, o envelhecimento natural e inevitável do sistema e/ou eventualmente o seu envelhecimento acelerado resultante de planejamento, projeto, construção ou exploração inadequados, tenderá gradualmente a dificultar e mesmo a impossibilitar o cumprimento dos seus objetivos de uma forma técnico-economicamente aceitável, conduzindo ao fim do seu ciclo de vida.

É, no entanto, possível recorrer à reabilitação de toda a infraestrutura, com o objetivo de melhorar o seu desempenho por meio da alteração da sua condição física e/ou da sua especificação técnica. Essa fase corresponde, na prática, ao retorno às fases de projeto e construção do sistema, permitindo mantê-lo em exploração por um período de tempo significativamente maior. Este processo envolve a constante atualização tecnológica dos sistemas de automação e considerações sobre modificações nas tecnologias utilizadas na gestão dos cada vez mais preciosos recursos hídricos.

Considerando a dimensão dos sistemas de abastecimento hídrico, em especial os relacionados à setorização das redes de distribuição, e o considerável custo envolvido no processo contínuo de atualização tecnológica destes sistemas, é natural que a sua 
modernização ocorra de forma progressiva, por meio da integração das novas tecnologias às já implantadas e da priorização de sistemas críticos.

Com o objetivo de se estabelecer um plano de modernização gradual do sistema de automação das zonas pitométricas, pautado na priorização zonas mais críticas, propõe-se a organização de um ranking por intermédio da utilização do Quadro1 a seguir:

\begin{tabular}{|c|c|c|c|c|c|c|}
\hline \multirow[b]{2}{*}{ Características } & \multirow[b]{2}{*}{ Pontuação } & \multirow[b]{2}{*}{ Observações } & \multicolumn{4}{|c|}{ Zonas Pitométricas } \\
\hline & & & Centro & Praias & $\begin{array}{c}\text { Ilha } \\
\text { Porchat }\end{array}$ & Horto \\
\hline Setor não automatizado. & 4 & - & - & - & - & - \\
\hline $\begin{array}{l}\text { Setor com maior índice de } \\
\text { necessidade de intervenção } \\
\text { em instrumentos e } \\
\text { dispositivos. }\end{array}$ & 3 & $\begin{array}{l}\text { Priorização por } \\
\text { custos com } \\
\text { manutenção }\end{array}$ & - & - & 3 & - \\
\hline $\begin{array}{l}\text { Setor com maior número de } \\
\text { ramais consumidores. }\end{array}$ & 2 & $\begin{array}{l}\text { Priorização por } \\
\text { escala de } \\
\text { atendimento }\end{array}$ & 2 & - & - & - \\
\hline $\begin{array}{l}\text { Setor com maior pressão } \\
\text { manométrica de entrada. }\end{array}$ & 2 & $\begin{array}{c}\text { Priorização por } \\
\text { desgaste dos } \\
\text { equipamentos }\end{array}$ & - & 2 & - & - \\
\hline $\begin{array}{l}\text { Setor com tubulações mais } \\
\text { antigas ou com maior } \\
\text { suscetibilidade histórica à } \\
\text { corrosão. }\end{array}$ & 3 & $\begin{array}{l}\text { Priorização por } \\
\text { risco de } \\
\text { vazamentos }\end{array}$ & 3 & - & - & - \\
\hline $\begin{array}{l}\text { Setor com variações de } \\
\text { pressão de amplitude } \\
\text { superior a } 20 \text { mca em sua } \\
\text { entrada. }\end{array}$ & 1 & $\begin{array}{c}\text { Priorização por } \\
\text { desgaste dos } \\
\text { equipamentos }\end{array}$ & - & - & - & 1 \\
\hline $\begin{array}{l}\text { Setor submetido a variações } \\
\text { de pressão de amplitude } \\
\text { superior a } 15 \text { mca devido à } \\
\text { sazonalidade. }\end{array}$ & 1 & $\begin{array}{l}\text { Priorização por } \\
\text { desgaste dos } \\
\text { equipamentos }\end{array}$ & - & - & - & 1 \\
\hline Total & & & 5 & 2 & 3 & 2 \\
\hline
\end{tabular}

Quadro 1. Características consideradas na priorização da modernização dos sistemas de automação das zonas pitométricas. 
Por meio da comparação entre as zonas pitométricas dispostas no Quadro 1, atribui-se pontos aos sistemas de distribuição destas zonas cujas propriedades corresponderem às descritas na coluna "Características". Ao término desta análise, os sistemas que possuírem maior pontuação devem ter a sua modernização priorizada.

\subsection{Sistemas de controle Fieldbus aplicados à setorização}

A implantação de um sistema de automação baseado em protocolos digitais de comunicação, segundo COELHO (2006), requer um estudo para determinar qual tipo de tecnologia possui as maiores vantagens de implementação ao usuário final. Este, por sua vez, deve buscar, entre outros aspectos, uma plataforma compatível com a base tecnológica instalada no processo industrial do qual esse sistema fará parte, além de uma tecnologia que conte com uma gama variada de fornecedores de equipamentos e dispositivos que atendam às necessidades da aplicação considerada.

Impõe-se, portanto, a opção pela utilização de uma arquitetura de sistema industrial aberta que, ao contrário das arquiteturas proprietárias, proporciona aos projetistas e desenvolvedores encontrar, em uma gama de fabricantes, soluções para as especificidades que um sistema de automação aplicado à setorização de redes de abastecimento hídrico possa vir a apresentar. Além disso, a maioria dos protocolos de comunicação que compõe arquiteturas abertas possui organizações de usuários e fornecedores que podem oferecer subsídios ao desenvolvimento de projetos e oportunizar trocas de experiências a respeito de soluções implementadas com estes protocolos. 
Dentre os benefícios do uso de protocolos digitais de comunicação em aplicações industriais, incluindo a de setorização de redes de abastecimento hídrico, destacam-se:

a) A melhoria da qualidade e o aumento da quantidade de informações sobre o processo controlado e os dispositivos que o compõe;

b) A possibilidade de troca de informações entre esses dispositivos, possibilitando a percepção do próprio sistema da perda de algum dos seus componentes;

c) A distribuição das funções de controle e comunicação;

d) A redundância dessas funções.

Com base nestas características foram selecionadas, dentre as tecnologias disponíveis no mercado, os protocolos Profibus PA e Foundation Fieldbus como opções promissoras ao atendimento da proposta idealizada neste trabalho. Nesta seleção, além dos aspectos supracitados, considerou-se também o fato desses protocolos constituírem redes industriais idealizadas e concebidas para comunicação entre dispositivos destinados ao controle de processos contínuos.

As características desses dois protocolos foram então confrontadas e analisadas por meio de um estudo investigativo sobre seus recursos, arquiteturas, quantidades máximas de dispositivos e distribuição das funções de controle. 
Considerando as particularidades evidenciadas nos sistemas de automação aplicados à setorização de redes de abastecimento, a análise comparativa entre os dois protocolos conduziram à escolha da solução oportunizada pela utilização de uma arquitetura baseada no protocolo Foundation Fieldbus (APÊNDICE 1).

\subsection{Redes baseadas no protocolo Foundation Fieldbus}

Dentre as características que permitiram a escolha do protocolo Foundation Fieldbus como plataforma para desenvolvimento do sistema de automação proposto neste trabalho, destacam-se:

a) Trata-se de um protocolo aberto que não pertence a nenhuma empresa ou é regulado por um único organismo ou nação e que, portanto, conta com diversos fornecedores;

b) Apresenta interoperabilidade, característica pela qual um dispositivo da rede pode ser substituído por outro dispositivo similar de outro fornecedor, mantendo as funções do dispositivo original. Isto permite aos usuários mesclar dispositivos de campo e sistemas de vários fornecedores;

c) É flexível, permite a implementação de novas estratégias de controle ou otimização das já existentes por meio de programação remota, permitindo o comissionamento do sistema a partir do $\mathrm{CCO}$ ou de qualquer outra localidade remota interligada à rede por meio de rádio ou link físico de dados. Características 
especialmente interessantes quando aplicadas a sistemas da dimensão geográfica do estudado neste trabalho;

d) Possui redundância de controle. O algoritmo de controle de uma determinada malha pode estar localizado, de forma redundante, em vários dispositivos desta malha, característica inerente ao protocolo Foundation e não presente do protocolo Profibus PA. Na ocorrência de falha de um dos dispositivos, outro dispositivo pode apropriar-se automaticamente desta função ou assumir, também automaticamente, valores de contenção até que a falha seja sanada.

Além destas características, em COELHO e LOBUE (2006) é destacado que nos sistemas de automação baseados em protocolos de comunicação analógicos, o volume de dados disponíveis ao usuário compreende poucas informações além das destinadas às funções de controle, como valores de variáveis e status de alarmes. Em sistemas baseados no protocolo Foundation Fieldbus, o volume de informações disponibilizado é bem maior, devido às facilidades proporcionadas, principalmente, pela comunicação digital. Essas informações envolvem status de funcionamento dos dispositivos de campo e de seus componentes, além de informações sobre a rede de controle e de supervisão.

Esta característica tem especial importância quando empregada em sistemas de grandes dimensões e que cobrem grandes extensões geográficas, como os de abastecimento hídrico, que se caracterizam por ter suas plantas industriais distribuídas em cidades ou, até mesmo, em regiões metropolitanas. $\mathrm{O}$ acesso a dados sobre o funcionamento dos componentes de sistemas de controle desta natureza oportuniza à equipe de gestão e manutenção destes sistemas se antecipar a falhas a que eles estão sujeitos, o que a afeta diretamente a sua 
disponibilidade operacional. A linha pontilhada da Fig. 3 a seguir delimita as visões dos dispositivos proporcionadas pelos sistemas de controle Fieldbus (FCS) e digital com base em instrumentação eletrônica (DCS).
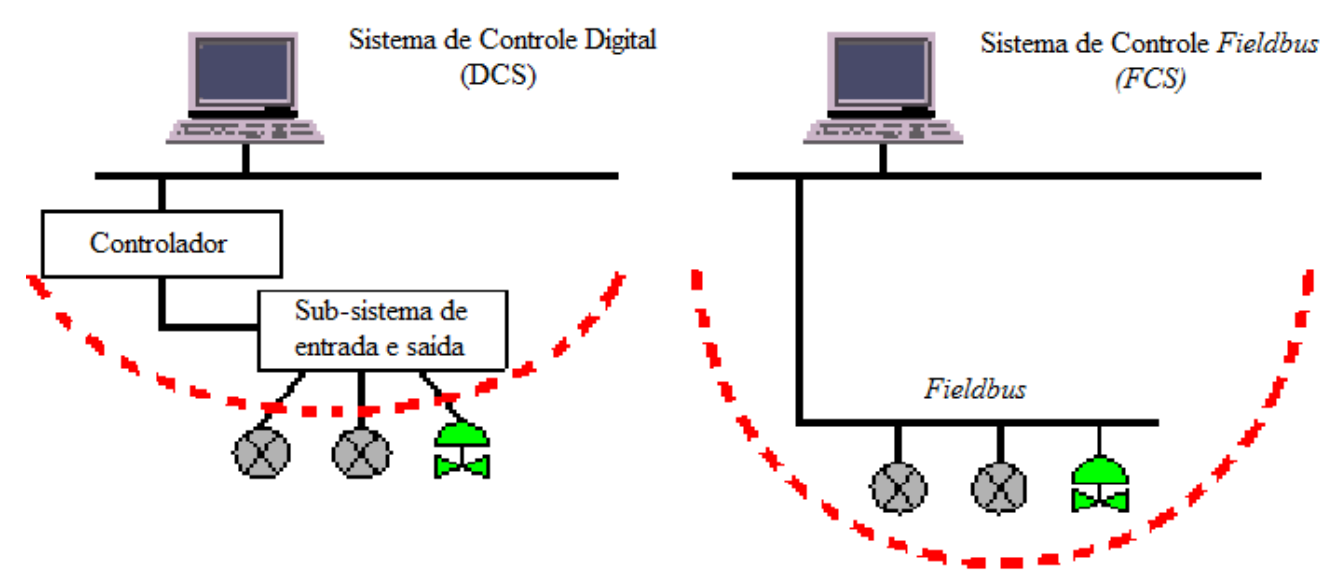

Sistema de controle baseado em instrumentação eletrônica (4-20mA)

Sistema de controle baseado em instrumentação digital

Figura 3 - Diagrama ilustrando a visão expandida proporcionada pelos sistemas de controle Fieldbus.

Os sistemas baseados no protocolo Foundation Fieldbus funcionam a partir da comunicação digital bidirecional entre os dispositivos que os compõem, permitindo a interligação em rede de múltiplos instrumentos destinados ao controle e à monitoração das estações de controle que compõem uma planta industrial.

Como exposto em BERGE (1998), o protocolo Foundation Fieldbus foi desenvolvido com base no padrão ISO / OSI embora não contenha todos os seus níveis. Pode-se, em uma primeira análise, dividi-lo no nível físico, que trata das técnicas de interligação dos instrumentos e nos níveis de software, que tratam da comunicação digital entre os equipamentos (APÊNDICE 2). 
Na camada básica do modelo do protocolo é definida a estrutura física do barramento e das interfaces de comunicação que determinam as possibilidades relacionadas às topologias que a rede do sistema de controle poderá dispor.

O protocolo Foundation Fieldbus contempla, em suas especificações de nível físico, dois padrões:

- O H1, com velocidade de comunicação de $31,25 \mathrm{kbit} / \mathrm{s}$ e que tem por função conectar os equipamentos de campo, com ou sem alimentação dos instrumentos pelo próprio barramento de dados. Este barramento pode ser intrinsecamente seguro, por meio do uso de acopladores de impedância, e pode chegar a até 1900 metros de comprimento.

- O High Speed Ethernet (HSE), com velocidade de $100 \mathrm{Mbit} / \mathrm{s}$ e que tem por função a integração entre os dispositivos da rede Foundation com equipamentos baseados em outras tecnologias, utilizando o padrão Ethernet com base no protocolo de encapsulamento TCP/IP. Este padrão permite, ainda, a expansão da rede Foundation por meio do uso de roteadores ou switches possibilitando, desta forma, a implantação de topologias de rede de extensões ilimitadas, o que é determinante para que o protocolo Foundation seja aplicado ao controle de redes de abastecimento hídrico. Estas características permitem a implementação dos padrões físicos contemplados no modelo Foundation em diferentes topologias de rede (APÊNDICE 3).

A alimentação dos dispositivos Foundation pode ser realizada, opcionalmente, através dos mesmos condutores de comunicação ou separadamente. Um instrumento com alimentação através de condutores distintos dos de comunicação, pode ser conectado a outros instrumentos 
com alimentação pelos condutores de comunicação. A utilização de instrumentos alimentados pelo próprio barramento de dados, por permitir a economia com condutores, reduz significativamente a quantidade de instrumentos que pode ser conectada neste barramento.

O padrão de comunicação definido nos níveis físico e de link de dados estipula que, no nível H1 e na velocidade de comunicação de $31,25 \mathrm{kbit} / \mathrm{s}$ são determinadas regras de interconexão dos instrumentos que, segundo SMAR (1998) leva em consideração o consumo de 9 mA por instrumento, com uma variação de +/- 1 mA, e com tensão de alimentação de 24 Vdc, além do uso de barreiras de segurança intrínseca com alimentação de 11Vdc a 21Vdc de saída e $80 \mathrm{~mA}$ máximos de corrente para os instrumentos localizados na área de segurança intrínseca (APÊNDICE 4).

Os principais componentes, comumente encontrados em redes baseadas no protocolo Foundation Fieldbus, são descritos a seguir:

a) Servidor: é um equipamento que, ligado à rede Foundation, tem a capacidade de configurar, monitorar e interagir com o processo sem a necessidade de permanecer no campo, tipicamente pode ser um Sistema Digital de Controle Distribuído (SDCD), um sistema de aquisição de dados ou um computador industrial.

b) Repetidor: é um equipamento com barramento energizado ou não, utilizado para estender um segmento Fieldbus. Como exposto anteriormente, é possível ser utilizado no máximo quatro repetidores ou acopladores ativos em um segmento de rede Foundation. Utilizando quatro repetidores, a distância entre qualquer segmento pode chegar a $9500 \mathrm{~m}$. 
c) Bridge: é um equipamento com barramento energizado ou não, utilizado para conectar segmentos Fieldbus de diferentes velocidades a fim de formar uma rede mais extensa e com diferentes segmentos. Normalmente são utilizados Bridges como interfaces entre os níveis HSE e H1 de uma aplicação.

d) Gateway: é um equipamento com barramento energizado ou não, utilizado para conectar um ou mais segmentos da rede Foundation a redes baseadas em outros tipos de protocolos de comunicação.

e) Cabos: de acordo com a norma ISA-S50.02 apud COELHO (2006), o cabo utilizado para ligar equipamentos de uma rede Foundation, operando na velocidades de 31,25 $\mathrm{kbit} / \mathrm{s}$, pode ser um simples par de fios trançados com blindagem atendendo à requisitos físicos e elétricos (APÊNDICE 5).

Um importante aspecto na concepção de um projeto de rede baseado no protocolo Foundation Fieldbus é a determinação de como serão instalados os equipamentos que farão parte desta rede. Várias topologias podem ser aplicadas em projetos Foundation. A Fig. 4, a seguir ilustra quatro topologias possíveis. De forma a simplificá-la, as fontes de alimentação e os terminadores foram omitidos do esquema mostrado. 


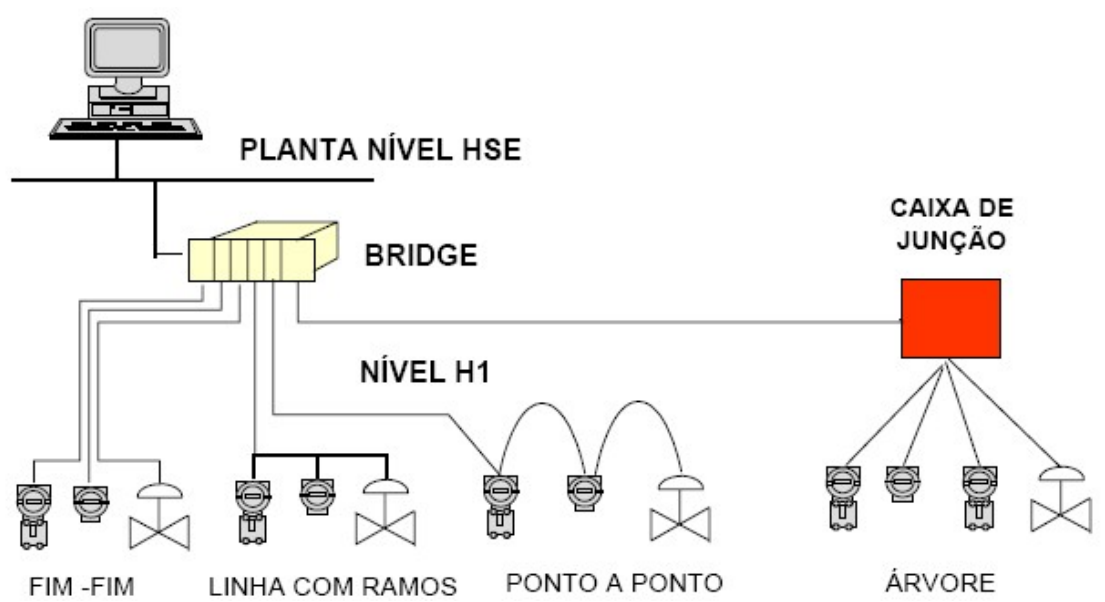

Figura 4 - Esquema ilustrando as possíveis topologias aplicáveis a projetos baseados em instrumentos Foundation Fieldbus.

O Quadro 2 a seguir relaciona as características, vantagens e desvantagens de cada topologia:

\begin{tabular}{|c|c|c|c|}
\hline Topologia & Característica & Vantagem & Desvantagem \\
\hline Fim-Fim & $\begin{array}{l}\text { Conexão direta entre a } \\
\text { fonte do barramento e o } \\
\text { dispositivo de campo. }\end{array}$ & Simplicidade. & $\begin{array}{l}\text { Grande quantidade de } \\
\text { cabos e subutilização dos } \\
\text { canais de rede. }\end{array}$ \\
\hline Linha com ramos & $\begin{array}{l}\text { Um barramento único } \\
\text { onde os dispositivos são } \\
\text { ligados de forma direta } \\
\text { (por meio de derivações), } \\
\text { ou indireta (via ramos } \\
\text { secundários). }\end{array}$ & $\begin{array}{l}\text { Ideal para ampliação do } \\
\text { alcance do barramento em } \\
\text { relação à fonte (máximo de } \\
90 \mathrm{~m}) \text { e para distribuição da } \\
\text { rede em locais afastados do } \\
\text { barramento principal. }\end{array}$ & $\begin{array}{l}\text { Os ramos devem possuir } \\
\text { uma distância limitada em } \\
\text { relação à derivação } \\
\text { (máximo de } 1 \mathrm{~m} \text { ). } \\
\text { Quanto maior a quantidade } \\
\text { de ramos, maior a } \\
\text { quantidade de emendas no } \\
\text { barramento, aumentando o } \\
\text { risco de oxidações e curtos- } \\
\text { circuitos. }\end{array}$ \\
\hline Ponto a ponto & $\begin{array}{l}\text { Ligação dos dispositivos } \\
\text { em série. }\end{array}$ & $\begin{array}{l}\text { Facilidade de distribuição da } \\
\text { rede em torno de uma planta } \\
\text { e diminuição dos pontos de } \\
\text { conexão por meio da } \\
\text { utilização dos conectores } \\
\text { dos próprios dispositivos. }\end{array}$ & $\begin{array}{l}\text { As instalações que utilizam } \\
\text { esta topologia devem usar } \\
\text { conectores duplos de forma } \\
\text { que a desconexão de um } \\
\text { simples equipamento não } \\
\text { interrompa a continuidade } \\
\text { do segmento de rede. }\end{array}$ \\
\hline Árvore & $\begin{array}{l}\text { Ligação dos } \\
\text { equipamentos por meio } \\
\text { de concentradores. }\end{array}$ & $\begin{array}{l}\text { Concentração do ponto de } \\
\text { conexão implicando a } \\
\text { diminuição de riscos de } \\
\text { curtos-circuitos e oxidação. } \\
\text { Facilidade de manutenção. } \\
\text { Simplificação da rede por } \\
\text { meio da organização desta } \\
\text { em núcleos. }\end{array}$ & $\begin{array}{l}\text { Diminuição significativa da } \\
\text { derivação máxima } \\
\text { permitida em relação ao } \\
\text { barramento principal se } \\
\text { comparada à topologia } \\
\text { linha com ramos (de } 90 \mathrm{~m} \\
\text { para } 60 \mathrm{~m}) .\end{array}$ \\
\hline
\end{tabular}

Quadro 2. Comparação entre vantagens e desvantagens relacionadas às diferentes topologias possibilitadas pelo protocolo Foundation Fieldbus. 
Há de se considerar, na implementação destas topologias, as distâncias máximas permitidas entre os equipamentos. Desta forma, é recomendada uma análise prévia do projeto do processo industrial onde o sistema de controle será implementado, para que sejam determinados os melhores pontos para instalação dos equipamentos, aperfeiçoando-se ao máximo o comprimento do barramento ou e das derivações da rede (APÊNDICE 6).

Os segmentos do barramento Foundation não devem exceder 90 metros, caso existam dois equipamentos ligados a este segmento, 120 metros caso exista um e 60 metros caso existam três. As derivações dos segmentos não devem exceder a 1 metro.

Além dessas regras, características como: o número máximo de equipamentos ligados a mesma rede, a topologia e os tipos de equipamentos utilizados na rede Foundation, por razões já expostas, devem ser considerados.

Os níveis de especificação do protocolo Foundation relacionados aos algoritmos de comunicação (APÊNDICE 7) funcionam de forma transparente ao usuário. A camada de link de dados garante a integridade da mensagem por meio do controle das informações que trafegam na rede. Esta garantia é concretizada por meio do cálculo de um polinômio aplicado a todos os bytes das mensagens enviadas. O resultado deste cálculo é acrescentado no final das mensagens e confirmado no endereço de destino. A obtenção do mesmo resultado garante a integridade da mensagem. Em caso de discrepância entre o resultado esperado e o obtido no endereço de destino, a mensagem é descartada e o dispositivo de origem da mensagem é incumbido de um novo envio. 
O nível de aplicação da especificação do protocolo Foundation é onde são estabelecidas as regras da interface da rede para com o software aplicativo de configuração, comunicação e programação dos dispositivos do barramento. Basicamente, estas regras definem como ler, escrever ou disparar uma tarefa a um dispositivo. Além disto, regras estabelecem uma sintaxe para mensagens, além de definir em qual modo a mensagem deve ser transmitida: ciclicamente, imediatamente, somente uma vez ou quando requisitada pelo consumidor.

As definições de nível de usuário do protocolo Foundation estabelecem o modo para acessar a informação dentro dos equipamentos presentes no barramento e como esta informação pode ser distribuída para outros equipamentos da rede. A base para a arquitetura de um equipamento Foundation são blocos funcionais, alguns dos quais são programáveis, outros que já se encontram, por padrão, ativos nos dispositivos e que executam as tarefas necessárias às aplicações às quais estes dispositivos se destinam. Cada um destes blocos funcionais contém um algoritmo, uma base de dados de entradas e saídas e um nome definido pelo usuário, o TAG do bloco, que deve ser único no sistema de automação no qual ele está programado. 


\section{METODOLOGIA}

O desenvolvimento deste trabalho foi orientado à proposição de um sistema automatizado que visa subsidiar a desenvolvedores e projetistas o desenvolvimento de soluções para problemas enfrentados na setorização de redes de abastecimento hídrico.

Para a estruturação do modelo de sistema de automação aplicado à setorização de redes de abastecimento hídrico, optou-se pela organização de referenciais de pesquisa segmentados de acordo com a função que cada um destes referenciais exerce no referido modelo, contribuindo assim para a realização de um processo de tomada de decisões mais racional, eficiente e produtivo.

Para que o modelo estruturado seja aplicável a diferentes contextos é necessário que ele se caracterize, primeiramente, como abrangente e flexível. Essas características podem ser conseguidas mediante a identificação de critérios de decisão referentes aos componentes de um modelo dessa natureza. Nesse sentido, os componentes do modelo proposto estão representados no esquema da Fig. 5.

Sistema Integrado de Compartilhamento e Gestão de Informações de Abastecimento Hídrico

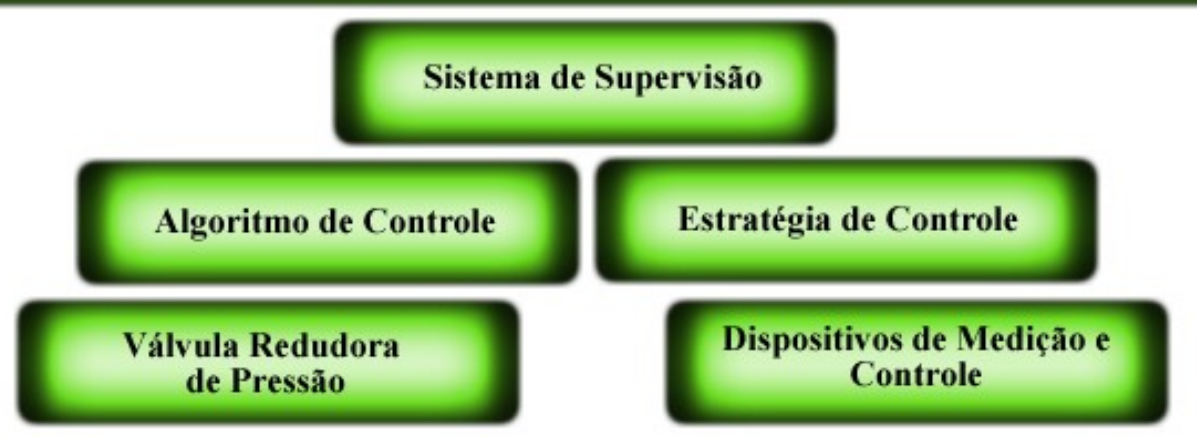

Figura 5 - Diagrama ilustrando os componentes do modelo de sistema de automação aplicado à setorização de redes de abastecimento hídrico 


\subsection{Referenciais da pesquisa}

Para elaboração do modelo proposto neste trabalho, optou-se por um estudo de caso realizado nas dependências da SABESP, por meio do qual se apresentam propostas orientadas à utilização de recursos do protocolo digital para aplicações industriais Foundation Fieldbus que possam vir a mitigar ou mesmo resolver problemas enfrentados na setorização de redes de abastecimento hídrico.

A SABESP é uma empresa de economia mista, de capital aberto, que tem como principal acionista o Governo do Estado de São Paulo. É uma concessionária de serviços sanitários, responsável pelo planejamento, construção e operação de sistemas de água e esgoto (doméstico e industrial) em 366 municípios paulistas.

A SABESP possui atualmente 1.357 unidades de produção, divididas em 198 Estações de Tratamento de Água, 1.078 Poços Profundos e 81 outros sistemas. Essas unidades são responsáveis pela geração de 100 mil litros de água potável por segundo (SABESP, 2010).

Estas unidades de produção estão espalhadas entre os municípios atendidos pela companhia, que são organizados em Unidades de Negócio, gerenciadas por superintendências. Além da região metropolitana da cidade de São Paulo, que possui sete Unidades de Negócio, há ainda os sistemas regionais, distribuídos em dez unidades.

O estudo de caso relatado neste trabalho faz referência a dados coletados na Unidade de Negócio da Baixada Santista, gerenciada pela Superintendência do Litoral, que abrange nove municípios: Cubatão, Santos, São Vicente, Praia Grande, Mongaguá, Itanhaém, Peruíbe, 
Guarujá e Bertioga. Estes sistemas têm a capacidade total de produção de 8.500 litros por segundo, o suficiente para abastecer a população fixa e flutuante da Baixada Santista e Litoral Sul, calculada atualmente em cerca de 3 milhões de pessoas. Fora da temporada de férias, a produção/consumo cai para 5.900 litros por segundo no atendimento a cerca de 1.500 .000 pessoas.

Os mananciais que compõem o sistema de abastecimento da Baixada Santista têm como característica a captação a fio d'água, ou seja, a captação que é feita diretamente no manancial abastecedor, inexistindo represas de acumulação. Para um melhor gerenciamento destes mananciais, a superintendência do litoral dividiu seus sistemas de abastecimento em gerências regionais, ora denominadas: Gerência Regional Norte, que gerencia os municípios de Guarujá, incluindo o distrito de Vicente de Carvalho, e Bertioga; Gerência Regional Centro, que abrange os municípios de Santos, São Vicente e Cubatão; e Gerência Regional Sul, para os municípios de Praia Grande, Mongaguá, Itanhaém e Peruíbe.

Estas gerências possuem autonomia operacional supervisionada, ou seja, cada gerência tem um Centro de Controle Operacional (CCO) regional responsável pelo controle operacional local das cidades que as compõem. Este CCO estabelece os parâmetros operacionais de válvulas redutoras de pressão, reservatórios e vazão de adutoras secundárias, de forma a administrar os recursos hídricos da sua área a partir das linhas principais de adução que são de responsabilidade do CCO principal, localizado na gerência regional Centro, na cidade de Santos.

Devido à grande dimensão do sistema de abastecimento da Unidade de Negócio da Baixada Santista, gerenciada pela Superintendência do Litoral, tornou-se necessária a 
delimitação de um contexto que oferecesse características amostrais típicas de um sistema de abastecimento setorizado. Essa delimitação permitiu indicar como foco o plano de setorização da cidade de São Vicente, por ser este um projeto que reúne condições de identificação e estudo de referenciais de análise significativos acerca de sistemas desta natureza.

A realização deste estudo está baseada nas informações coletadas em mais de cinco anos de vivência na Unidade da Baixada Santista da SABESP no desenvolvimento e na implementação de soluções voltadas a automação de sistemas abastecimento hídrico. Essas informações foram confrontadas com referenciais teóricos resultantes de estudos no campo da automação industrial, da análise de sistemas de controle, da arquitetura de sistemas distribuídos e foram ampliadas e aprofundadas por meio de estudo investigativo sobre novas técnicas de automação de sistemas que se apresentam como promissoras candidatas à superação de alguns dos problemas ainda existentes na setorização de sistemas de abastecimento hídrico.

Contou-se, ainda, com informações obtidas por meio de entrevistas com especialistas de diversas áreas da SABESP, como técnicos e engenheiros do setor de manutenção e operação do sistema de abastecimento hídrico, técnicos do setor de tecnologia da informação, engenheiros do setor de pitometria (macromedição) e também técnicos do departamento de análise e controle de perdas hídricas. 


\section{MODELO DE SISTEMA DE AUTOMAÇÃO APLICADO À SETORIZAÇÃO DE REDES DE ABASTECIMENTO HÍDRICO}

O modelo de sistema descrito neste trabalho foi baseado em soluções e tecnologias propostas para o projeto de automação aplicado à setorização da rede de abastecimento hídrico da cidade de São Vicente, município que possuía no primeiro semestre de 2010, segundo levantamento feito pelo Jornal A Tribuna de Santos (2010, pg.C4), 351.867 residentes fixos e 38.410 residentes flutuantes ${ }^{2}$.

Algumas destas soluções compuseram o memorial descritivo que subsidiou a implementação do referido projeto. Outras foram elaboradas posteriormente à sua implementação com o objetivo de atualizá-lo tecnologicamente, fazendo uso de recursos que conferissem a ele características como maior autonomia e robustez.

\subsection{Projeto de setorização da cidade de São Vicente}

O projeto de setorização do sistema de distribuição de água da cidade de São Vicente envolveu a separação do sistema de abastecimento hídrico urbano desta cidade em nove distritos denominados zonas pitométricas, com o objetivo geral de estabelecer um controle mais efetivo das pressões e das vazões de água destas zonas. A Fig. 6 a seguir mostra a delimitação desses distritos.

\footnotetext{
${ }^{2}$ Residentes temporários que mantêm casas na cidade que são habitadas apenas durante períodos de férias e finais de semana.
} 


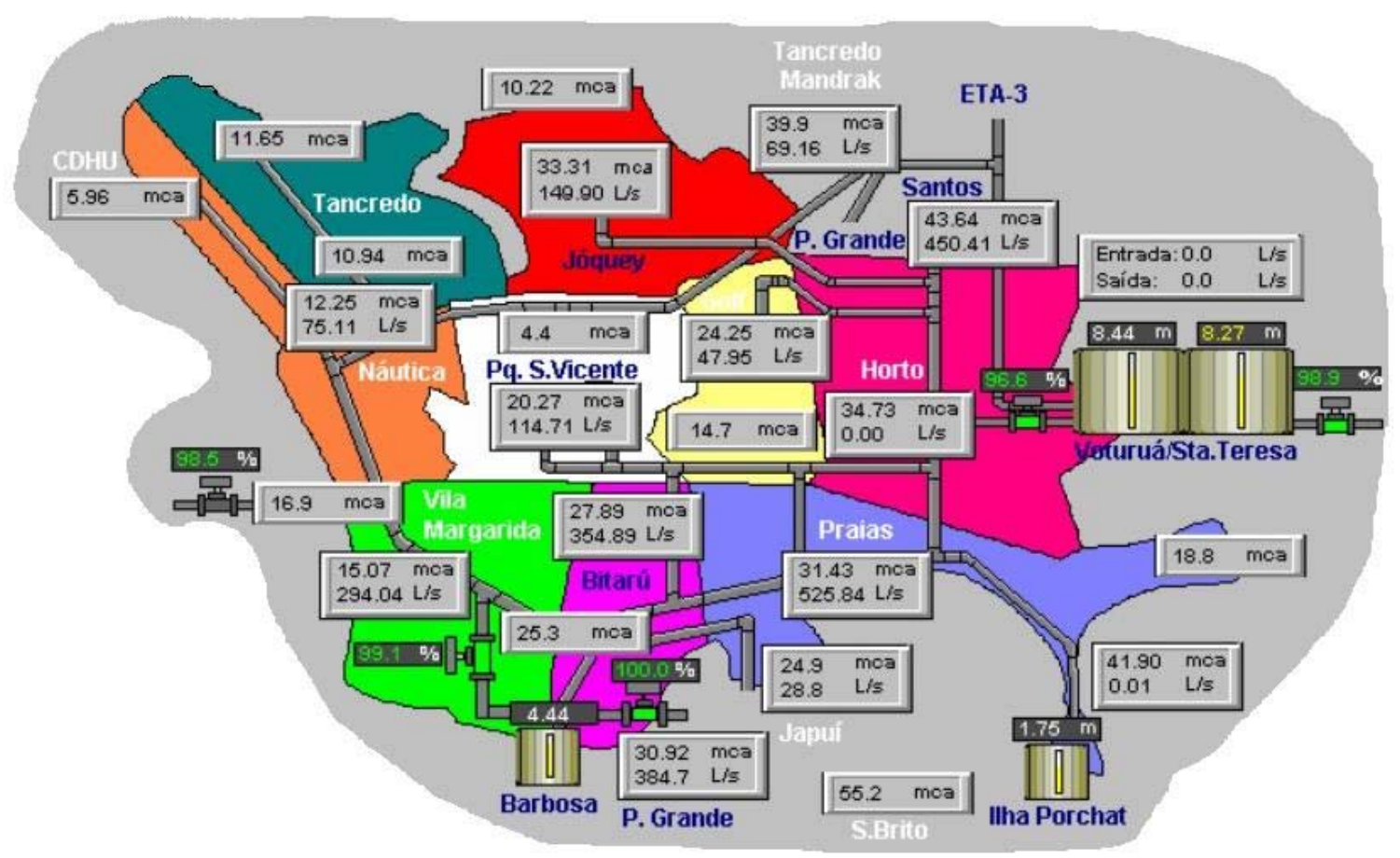

Figura 6 - Esquema da divisão da cidade de São Vicente em nove zonas pitométricas. - Projeto de setorização da cidade de São Vicente - Fonte: Companhia de Saneamento Básico do Estado de São Paulo - Superintendência do Litoral, 2008.

Nesse projeto de setorização, a definição das zonas de pressão foi feita tomando-se como base a limitação da pressão estática máxima em 35 mca no ponto mais baixo da zona pitométrica, valor 15 mca abaixo do valor máximo recomendado pela Norma Técnica NBR 12218/1994. Esta limitação deve-se ao fato da rede de abastecimento da cidade de São Vicente ser antiga e muito suscetível a vazamentos e rupturas.

A pressão a ser mantida nos pontos críticos foi estabelecida em no máximo 15 mca, com valor mínimo de 10 mca. O valor adotado é estabelecido pelo CCO, que considera a variação da demanda de água decorrente dos horários de maior consumo e da sazonalidade que acarreta maior quantidade de consumidores na cidade em períodos de férias, feriados prolongados e fins-de-semana. Como relatado anteriormente, o ponto extremo ou crítico é aquele, dentro da zona pitométrica, onde se verifica a menor pressão dinâmica, isto é, o ponto 
mais elevado ou o mais distante. Este ponto é utilizado para se estimar o potencial de redução de pressão da área, além de ser o ponto referencial para controle do abastecimento.

\subsection{Componentes do sistema de controle automático das zonas pitométricas}

A ampla difusão da técnica de setorização não seria possível sem a evolução tecnológica dos seus elementos chave, necessários à implementação deste método de controle de abastecimento hídrico urbano. Entre estes elementos estão as válvulas redutoras de pressão ou VRPs, os dispositivos de medição e controle automático e o sistema de supervisão e gerenciamento.

Estes elementos, trabalhando conjuntamente, formam um sistema de arquitetura distribuída que é referenciado a um ou mais Centro de Controle Operacionais (CCOs). Algumas abordagens de arquiteturas distribuídas são descritas na literatura científica em várias áreas de aplicação. Dentre os modelos de sistemas de automação e controle que fazem uso dessa arquitetura destacam-se mais fortemente os baseados em Sistemas Digitais de Controle Distribuído (SDCDs) ou nos sistemas de controle supervisório e aquisição de dados (SCADAs). O primeiro modelo vem ao encontro de sistemas de controle concentrados geograficamente como os encontrados em plantas industriais de produção. Já o segundo vem ao encontro de sistemas que possuem suas unidades geograficamente descentralizadas, ou seja, distribuídas em bairros ou cidades como é o caso dos sistemas de abastecimento hídrico. 


\subsection{Funcionamento das válvulas redutoras de pressão das zonas pitométricas}

As VRPs têm como propósito principal manter, no setor controlado, a pressão mínima necessária para o abastecimento satisfatório dos ramais consumidores. As características dinâmicas presentes nas modernas válvulas redutoras de pressão permitem manter, com mais precisão, o controle da vazão e da pressão de saída destas válvulas. Estas características, somadas às inúmeras possibilidades e estratégias disponibilizadas pelos dispositivos digitais de controle associados a estes equipamentos, viabilizam o controle preciso da pressão nas áreas setorizadas e, por conseqüência, a redução significativa das perdas hídricas existentes nestes setores.

As VRPs são utilizadas para gerar uma perda de carga controlada para que, em casos de instabilidade de pressão, se possa manter, à jusante da linha em que estão instaladas, uma pressão fixa.

O sistema envolvido na implementação de um controle por meio de VRPs é composto, além da própria válvula, de um conjunto de dispositivos que têm por função estabelecer o controle da pressão de acionamento deste equipamento.

A Fig. 7 apresenta, em um diagrama de blocos, os módulos que constituem o sistema de acionamento de uma VRP típica, utilizada pela SABESP para estabilização da pressão das zonas pitométricas: 


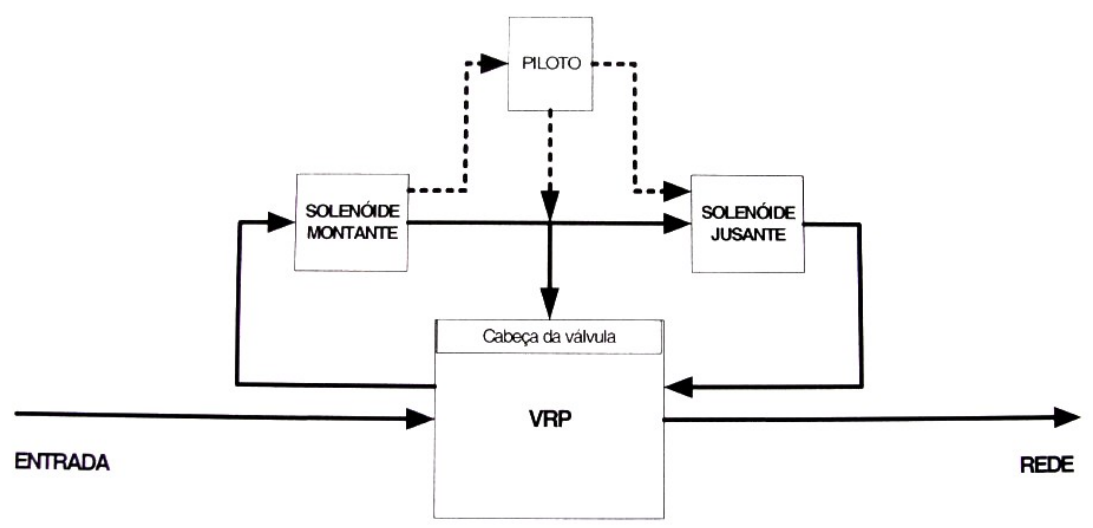

Figura 7 - Diagrama ilustrando os módulos do sistema de acionamento de uma VRP - Fonte: Memorial descritivo do projeto típico de automação de válvulas redutoras de pressão, SABESP - Superintendência do Litoral, 2006.

A maioria das VRPs, utilizadas na setorização dos distritos controlados é do tipo globo, operadas hidraulicamente por meio de acionamento direto de um diafragma através de uma válvula piloto que, por sua vez, é acionada por válvulas solenóides.

O circuito piloto permite o auto-ajuste da válvula, assegurando um controle preciso da pressão reduzida, dentro de extensas variações de vazão.

A válvula fica normalmente aberta quando a pressão da linha é aplicada em sua entrada (montante). Quando essa mesma pressão é aplicada à cabeça da válvula, o que ocorre por meio da válvula piloto, essa se fecha, pois a área do diafragma que compõe o acionador da válvula é maior que a área da sede da válvula. É o controle da pressão acima do diafragma que determina a posição da VRP, ou seja, aberta, fechada ou em uma posição intermediária. As Figs. 8 e 9 ilustram o circuito hidráulico de acionamento de uma VRP: 


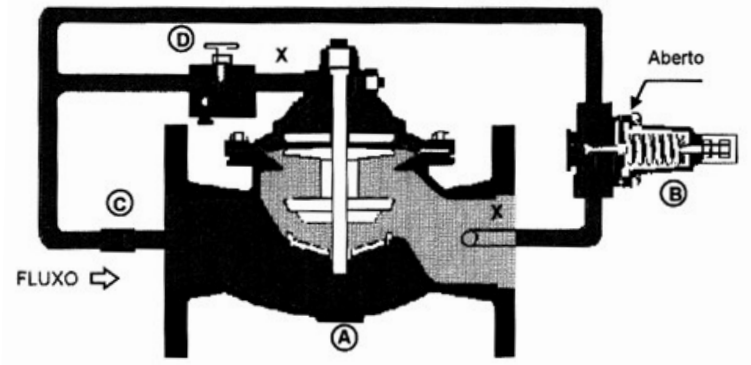

Figura 8 - Visão do circuito hidráulico de uma VRP aberta.

Documento técnico de apoio do Programa Nacional de Combate ao Desperdício de Água, Secretaria Especial de Desenvolvimento Urbano - Brasília, 1999.

Por princípio, o sistema mostrado nas Figs. 8 e 9 faz com que a válvula principal reproduza os movimentos da válvula piloto (B) sob a ação das pressões a montante e a jusante.

Quando a válvula piloto está aberta, a pressão presente no circuito de controle não exerce nenhuma força na membrana da válvula principal (A), o que faz com que o sistema de fechamento fique livre e a válvula abra.

A partir do fechamento da válvula piloto, a pressão contida no circuito de controle exerce uma força na membrana da válvula principal ocasionando o seu fechamento.

O orifício fixo (C) possibilita a condução da pressão à jusante da válvula ao circuito de acionamento, enquanto a válvula agulha (D) proporciona o ajuste da velocidade de atuação da VRP.

O controle por meio de uma válvula piloto é um acionamento ajustável, projetado para permitir o fluxo através da válvula principal quando a pressão à sua jusante fica abaixo da 
ajustada pela mola do atuador de pilotagem. O aumento na demanda de fluido produz, como resultado, a queda na pressão à jusante da VRP (pressão controlada). A válvula piloto "sente" esta queda na pressão ao passo que mola do seu atuador causa a abertura da válvula. Com a abertura da válvula piloto, a pressão é drenada da cabeça da válvula principal, permitindo à linha de pressão principal abrir a VRP. A válvula principal continua a abrir até que a pressão a jusante tenha retornado ao valor correspondente ao ajustado na válvula piloto.

O reverso acontecerá num incremento na pressão controlada (à jusante da válvula), resultante de uma redução da demanda de água, que ocasiona o fechamento proporcional da válvula piloto que, consequentemente, provoca a mesma reação na válvula principal.

As VRPs são instaladas nos pontos de entrada de cada zona pitométrica, que tem a sua delimitação estabelecida pela instalação de válvulas manuais em seus pontos limítrofes. A entrada da zona pitométrica tem o seu abastecimento proporcionado por um reservatório ou booster variável, que provêm água à montante da VRP.

As VRPs atuais possuem a capacidade de auto-regulação, com parâmetros de funcionamento estabelecidos remotamente por meio de vias digitais de telemetria e de instrumentos microprocessados, que constituem os dispositivos de medição e controle automático do sistema.

\subsection{Dispositivos de medição e controle das zonas pitométricas}

Segundo PEREIRA apud SOUZA (2006, p.28), “A automação (...) possibilita a coleta metodológica e precisa de dados que podem ser empregados para se obter a otimização do 
processo". Nesse sentido, os sistemas de automação possibilitam, portanto, a redução do custo de todo o sistema produtivo, com o consequente aumento dos lucros e a diminuição de perdas.

Do ponto de vista operacional, a Superintendência do Litoral da SABESP faz uso dos seguintes elementos nas estações remotas que compõem o sistema automático de controle das zonas pitométricas:

(a) Instrumentação: conjunto de instrumentos (transmissores de pressão e vazão) que permite monitorar parâmetros específicos das VRPs. Pela característica dos locais de instalação destes instrumentos, eles devem ter grau de proteção que os possibilitem trabalhar sob intensa umidade;

(b) Painéis locais: conjunto de componentes (relés, disjuntores, fontes, baterias, bornes e cabeamento) que permite interligar e alimentar os dispositivos da estação remota de controle das VRPs;

(c) Controlador: dispositivo que recebe os sinais dos instrumentos, processa estes sinais de acordo com uma programação interna e aciona as válvulas solenóides conjugadas à válvula piloto da VRP controlando a sua posição. Trabalha de forma autônoma, de acordo com parâmetros pré-estabelecidos e enviados remotamente pelo centro de controle operacional (CCO) do sistema.

Os outros instrumentos que compõem a estação (sensores adicionais e alarmes) visam dar subsídios aos operadores do sistema para a detecção de defeitos de funcionamento da VRP ou acesso não autorizado à estação remota. 
As estações remotas constituem a planta industrial do sistema de abastecimento hídrico. O sistema de automação e as variáveis monitoradas e controladas de cada estação variam de acordo com a função que ela exerce no sistema. As estações responsáveis pelo controle das zonas pitométricas apresentam estrutura semelhante entre si. O diagrama que ilustra a estrutura de uma estação desta natureza pode ser visualizado na Fig.10. O impacto ocasionado pela perda eventual de uma estação determina também a quantidade de redundâncias, sejam elas de comunicação ou de instrumentação nela presentes.

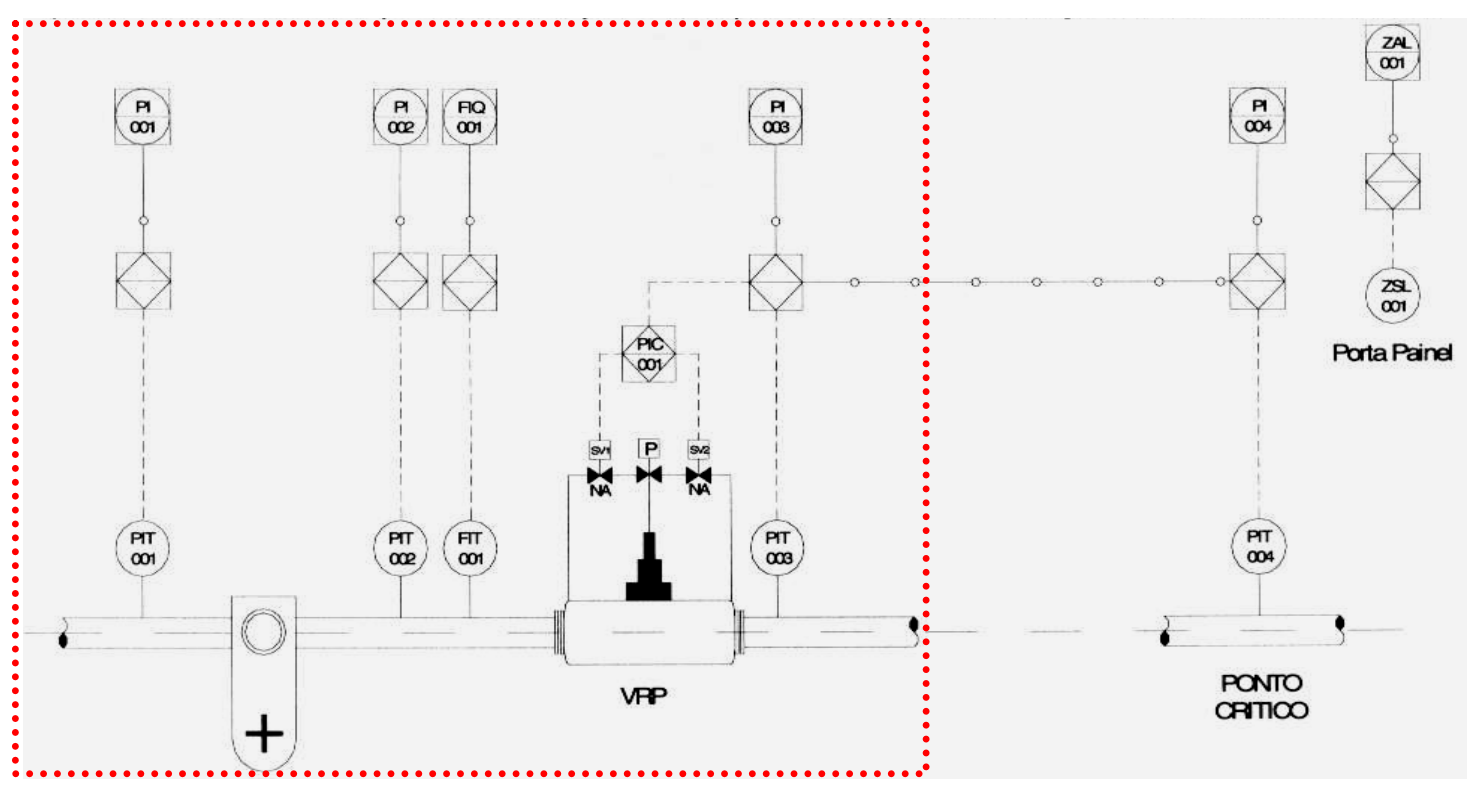

Figura 10 - Diagrama P\&I de uma estação remota de controle de uma VRP. Fonte: Memorial descritivo do projeto típico de automação de válvulas redutoras de pressão, SABESP - Superintendência do Litoral, 2006.

\subsection{Funcionamento do sistema de controle das zonas pitométricas}

O controle das zonas pitométricas é realizado com base nos sinais enviados pelos instrumentos das suas estações remotas (ERTs) e por parâmetros enviados pelo centro de controle operacional (CCO). A posição da VRP de cada zona varia entre totalmente aberta e 
parcialmente fechada. O estanqueamento total do ramal da VRP, quando necessário, é realizado por meio de válvulas manuais presentes neste ramal.

As ERTs de controle das zonas pitométricas podem assumir dois estados de operação automática:

a) Estado de operação normal: A posição da válvula é estabelecida em função da pressão do ponto crítico na zona pitométrica controlada. Este valor é transmitido ao controlador da estação pelo CCO. Pela comparação deste valor com um set-point parametrizado, o controlador gera o sinal de saída a partir da análise da diferença entre estes dois valores. A análise destas grandezas e a determinação do sinal de saída ocorrem a partir de um algoritmo interno programado no controlador. Este sinal de saída consiste em um valor de 0 ou $100 \%$, modulado no tempo, ou seja, o algoritmo estabelece o tempo em que o sinal permanece em seu nível máximo até que a válvula atinja a posição necessária para o estabelecimento da pressão desejada à sua montante e, por conseqüência, no ponto crítico.

b) Estado de contingência: A partir da perda de comunicação entre a estação remota de controle da zona pitométrica e o ponto crítico desta zona, o controlador assume o estado de controle de contingência, onde a posição da VRP é estabelecida pelo controlador a partir da medição da pressão à sua jusante e de uma tabela hora x pressão, previamente definida e programada. Esta tabela é resultado de um estudo aprofundado sobre o comportamento sazonal, diário e horário da região abastecida e estabelece as pressões demandadas a cada hora do dia para manutenção da pressão mínima necessária no ponto crítico da zona pitométrica. 
A lentidão inerente ao processo determina que o ganho do sistema de controle seja baixo, bem como a sua constante de integração, para que o sistema perceba o resultado de uma ação executada antes de decidir pela manutenção, acréscimo ou decréscimo da posição da válvula.

A posição da VRP é estabelecida, em condições ideais de funcionamento, em função da pressão no ponto crítico da zona pitométrica controlada. Este valor é transmitido a um controlador, presente na estação local da VRP, pelo CCO. Pela comparação e pela análise da diferença entre este valor e um set-point (valor desejado no ponto crítico) parametrizado, o controlador gera um sinal para um cartão de saídas discretas que irá manipular as válvulas solenóides da VRP.

Na ocorrência da perda do sinal proveniente do transmissor de pressão instalado no ponto crítico da zona pitométrica, o sistema de controle proposto assume um modo denominado estado de contingência. Nesse modo, a posição da VRP é estabelecida pelo controlador a partir da medição da pressão à sua jusante e de uma tabela hora x pressão, previamente definida e programada.

Em condições de equilíbrio da pressão desejada na saída da VRP, o controlador mantém sinais atuando em ambas as válvulas solenóides, o que faz a VRP permanecer na posição atual. Para fechar a VRP, o controlador retira o sinal enviado à válvula solenóide SV1 mostrada na Fig.10, abrindo-a e injetando, desta maneira, água pressurizada no atuador da VRP até que a pressão à jusante da válvula baixe para o valor desejado, momento em que a solenóide SV1 é fechada, confinando a pressão na cabeça da VRP. Se a pressão à jusante da válvula estiver abaixo do valor desejado, o controlador retira o sinal enviado à válvula 
solenóide SV2, esvaziando o atuador da VRP pela ligação entre este e a jusante da válvula e provocando a sua abertura, até que a pressão desejada à jusante seja alcançada, momento em que a solenóide SV2 é fechada.

O fato das válvulas SV1 e SV2 serem normalmente abertas possibilita que, na ausência de energia ou defeito no controlador, a VRP permaneça aberta, garantindo uma pressão à sua jusante determinada por um ajuste manual realizado previamente na válvula piloto que, nestas condições, deverá assumir o controle da VRP. Esta condição preserva o abastecimento do setor controlado em caso de falhas de natureza elétrica ou no sistema digital de controle.

A condição de auto-atuação inerente ao tipo de VRP utilizada acarreta benefícios e desafios. Dentre os benefícios, o principal é a não necessidade de um mecanismo de acionamento da válvula por meio de energia externa ao sistema como um motor, por exemplo, tornando mais barato os custos de implantação destes equipamentos e diminuindo as necessidades de manutenção ao sistema.

Dentre os desafios impostos pela auto-atuação da VRP utilizada pela SABESP, cuja energia para seu fechamento é provida pela pressão da própria linha em que ela encontra-se instalada, está a velocidade de fechamento deste dispositivo. Quando a pressão à montante da válvula está muito próxima da sua pressão à jusante, a força exercida no atuador da VRP, a qual proporciona seu fechamento, fica próxima à força presente na sede da válvula. Esta força exerce uma contrapressão à força exercida pelo atuador, ocasionando como resultado lentidão no fechamento da VRP nesta circunstância. 


\subsection{Proposta de um sistema de controle baseado no protocolo Foundation Fieldbus}

A proposta apresentada neste trabalho é a de utilização de recursos do protocolo digital de comunicação para dispositivos industriais Foundation Fieldbus, promovendo uma evolução em relação ao controle baseado em instrumentação analógica, atualmente utilizado pela SABESP, para controle das VRPs responsáveis pela manutenção das pressões nas zonas pitométricas obtendo-se, desta forma, ganhos em relação a este tipo de controle.

As implicações relacionadas à transposição de um DCS para um FCS envolvem, segundo BERGE (1998), a análise dos seguintes aspectos relacionados à documentação dos sistemas:

a) Documentação básica: Para a elaboração dos dois tipos de projetos, DCS e FCS, são gerados documentos com graus de complexidades diferentes, característicos de cada tecnologia. O Quadro 3 a seguir possibilita a comparação entre o grau de complexidade relacionado a cada documento de projeto gerado: 


\begin{tabular}{|l|c|c|}
\hline & Projeto DCS & FCS / Grau de Complexidade \\
\hline Revisão de fluxogramas de engenharia & Sim & Igual \\
\hline Diagrama de malhas & Sim & Menor \\
\hline Diagrama funcional & Sim & Igual \\
\hline Diagrama lógico & Sim & Igual \\
\hline Base de dados & Sim & Igual \\
\hline Planta de instrumentação & Sim & Menor \\
\hline Detalhe típico de instalação & Sim & Não tem \\
\hline Arranjo de painéis & Sim & Não tem \\
\hline Diagrama de interligações de Painéis & Sim & Menor \\
\hline Diagrama de alimentação & Sim & Menor \\
\hline Arranjo de armários & Sim & Menor \\
\hline Lista de cabos & Sim & Sim \\
\hline Lista de material & & \\
\hline
\end{tabular}

Quadro 3. Comparação entre o grau de complexidade relacionado aos documentos de projeto gerados no planejamento de um sistema DCS e FCS. Fieldbuses for Process Control: Engineering, Operation, Maintenance. Carolina do Norte, EUA: The Instrumentation, Systems, and Automation Society, 1998.

b) Revisão de fluxogramas de engenharia: que terão como principal mudança a redução no hardware por meio da implementação de transmissores "inteligentes" e o ocasional deslocamento das funções de processamento dos algoritmos de controle para os dispositivos de campo. 
c) Desenvolvimento de novos diagramas de malhas: Nos sistemas baseados em instrumentação analógica, existe a necessidade de representação dos condutores que compõem as malhas de envio de sinais entre os instrumentos. Uma representação deste tipo é mostrada na Fig. 11 a seguir.

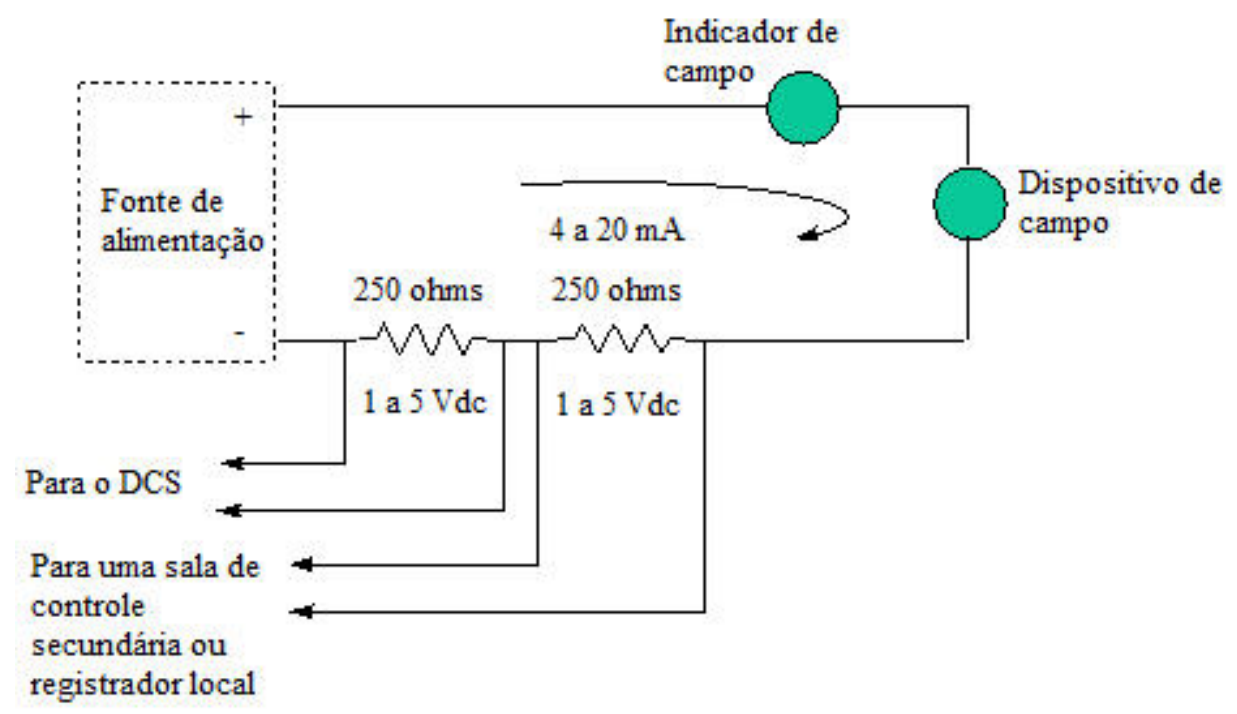

Figura 11 - Malha de um sistema de controle baseado em instrumentação eletrônica.

No FCS há a redução de trabalhos na elaboração dos diagramas de malhas, pois é apresentado, para cada malha, apenas a configuração de controle dos elementos de campo. A representação dos condutores é muito mais simples, não havendo a necessidade da representação bifilar das malhas, uma vez que a interligação dos instrumentos digitais por meio do barramento Fieldbus já é representada em um documento gerado pelo próprio software de configuração da rede.

d) Diagrama funcional: Este documento não sofrerá alterações. 
e) Diagrama lógico: Este documento não sofrerá alterações.

f) Base de dados de configuração de controle e supervisão: Para configuração do sistema de supervisão é previsto, praticamente, o mesmo volume de trabalho, uma vez que este módulo do DCS assemelha-se em relação ao FCS.

g) Diagrama de instalação da planta de instrumentação: a implantação de um FCS proporciona uma grande redução de trabalhos na confecção deste documento, pois reduz a quantidade de bandejas e cabos nele representados, uma vez que os instrumentos digitais comunicam-se em rede por meio de um par de condutores.

h) Detalhes típicos de instalação: Este documento não sofrerá alterações.

i) Arranjos de painéis: Em FCSs, não é gerado este documento.

j) Diagrama de interligação de painéis: Em FCSs, não é gerado este documento.

k) Diagrama de alimentação: Esse documento, em FCSs, tem a sua complexidade reduzida, uma vez que a alimentação dos instrumentos é realizada por lotes, e não individualmente. 
1) Arranjo de armários: documentação muito simplificada em FCSs e, por vezes, dispensável.

m) Lista de cabos: Em FCSs, esta lista pode chegar a 10\% da lista produzida em um DCS.

n) Lista de material: documento consideravelmente menor, considerando a redução dos componentes que a transposição do projeto de um DCS para um FCS implica.

Além das vantagens no desenvolvimento do projeto de um FCS em relação a um DCS, as premissas que orientaram a pesquisa de um sistema de controle que pudesse substituir o atualmente utilizado pela SABESP, com a vantagem da resolução ou mitigação das limitações por ele apresentadas, conduziram à solução oportunizada pelo uso do protocolo Foundation, pois este:

a) Possibilita redundância automática de dispositivos. Um dispositivo pode assumir automaticamente a função integral de outro idêntico presente na rede, na ocorrência de falha neste.

b) Possui dispositivos que permitem a programação de algoritmos customizados, a exemplo dos Controladores Lógico Programáveis (CLPs);

c) Além das informações necessárias ao controle, disponibiliza vários outros dados dos dispositivos de campo, permitindo o diagnóstico remoto de um eventual mau 
funcionamento em sensores, entradas/saídas, ou mesmo na configuração destes dispositivos, aumentando a eficácia e reduzindo o custo de intervenções e manutenção. Além disto, os dispositivos possuem funções de auto-diagnóstico que vão ao encontro da implementação de programas de manutenção preventiva e preditiva dos componentes do sistema de controle;

d) Apresenta possibilidade de integração com o atual sistema utilizado pela Superintendência do Litoral da SABESP, tanto no nível de campo, por meio da utilização de gateways, como no nível de gerenciamento, comunicando-se com o sistema de supervisão por meio do padrão de comunicação aberto OLE for Process Control (OPC).

Considerando estes aspectos, propõe-se a implantação do sistema de controle representado na Fig. 12 a seguir:

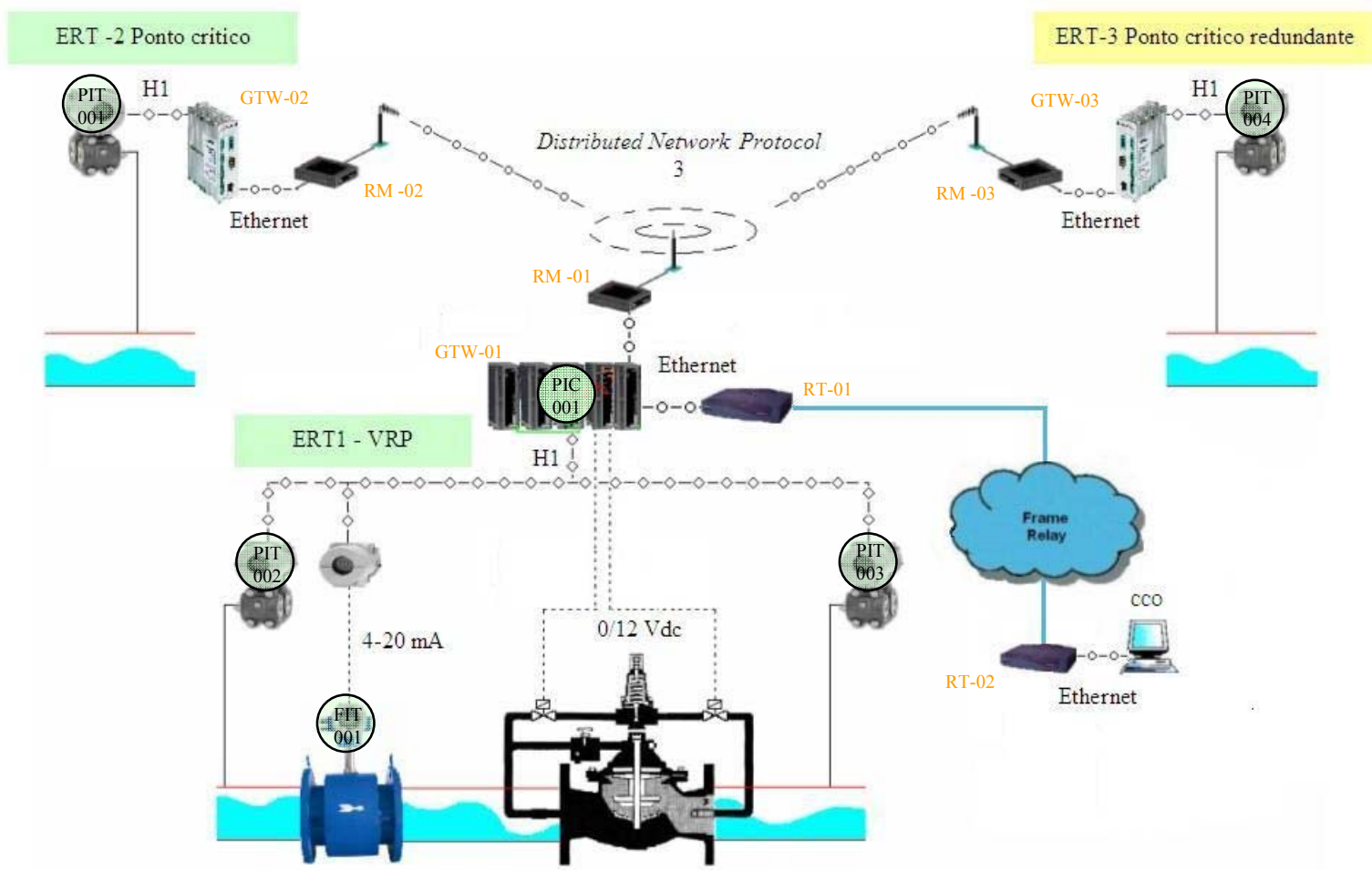

Figura 12 - Esquema da proposta de um sistema de automação baseado no protocolo Foundation Fieldbus para controle da pressão das zonas pitométricas. 
O sistema de controle mostrado na Fig. 12 baseia-se nos recursos oferecidos pelo protocolo Foudation para dirimir os problemas ocasionados pela perda do sinal do ponto crítico do setor controlado pela VRP. Na ocasião da perda do sinal proveniente da ERT-2, automaticamente os sub-status da rede Foundation, cuja camada física corresponde ao padrão H1 indicado na Fig.12, informam o bloco de controle presente no dispositivo PIC001, que passa a considerar o sinal do transmissor de pressão redundante presente na ERT-3, o ponto crítico redundante do setor controlado.

Os sub-status também alertam o CCO da ausência do sinal do ponto crítico principal, possibilitando a mudança do set-point da VRP, caso necessário, e o envio de uma solicitação de manutenção do ponto crítico principal ao setor competente.

A comunicação entre as ERTs é viabilizada, em locais onde existe infraestrutura disponibilizada por empresas de telefonia fixa, pelo uso de links Frame Relay, tecnologia baseada na comunicação por meio de pacotes digitais de informação, ideal para tráfego de dados por meio de protocolos de controle de transferência (TCPs). Em locais isolados, podese fazer uso de rádio-modems, equipamentos rádio transceptores com modems integrados.

Os gateways representados na Fig.15 pelas denominações GTW-01, GTW02 e GTW03 têm a função de converter o protocolo Foundation, que trafega no meio físico determinado pelo padrão $\mathrm{H}$, em um protocolo de controle de transferência (TCP), proporcionando a troca de dados entre as ERTs pelos rádio-modems RM-01, RM-02 e RM-03 e pelo roteador RT-01.

O gateway GTW-01 diferencia-se dos outros por incorporar também a função de bridge, além de possuir um módulo fonte, o que possibilita a ligação de vários dispositivos 
Foundation em até quatro barramentos Fieldbus distintos. Este dispositivo também agrega a função de controle, permitindo que nele sejam programados algoritmos customizados baseados em linguagens padronizadas pela norma IEC 61131-3.

O transmissor de vazão FIT001 é integrado à rede Fieldbus por um dispositivo transdutor, que converte o sinal padrão de 4 a $20 \mathrm{~mA}$ para o protocolo Foundation possibilitando, desta forma, o aproveitamento dos transmissores de vazão ora instalados na infraestrutura de abastecimento atualmente utilizada pela SABESP.

A manutenção da instrumentação já existente, enquanto proporciona considerável economia, principalmente com relação a equipamentos de grande porte e de difícil substituição como os transmissores eletromagnéticos de vazão, suprime, entretanto, um relevante recurso proporcionado pelo protocolo Foundation, que é o de disponibilização de informações online referentes ao desempenho e ao estado dos instrumentos. Estas informações constituem subsídio valioso para os departamentos de manutenção e de engenharia de processo, que podem fazer uso destes dados para implementação de programas de manutenção preditiva e para otimização do sistema de controle, respectivamente.

\subsection{Programação dos dispositivos Foundation}

A base da arquitetura dos equipamentos Foundation são os blocos funcionais, os quais executam as tarefas necessárias à aplicação de controle das zonas pitométricas. Estas tarefas incluem: aquisição de dados, processamento do algoritmo de controle e atuação nos elementos finais de controle. 
Todo bloco funcional contém um algoritmo básico, uma base de dados de entradas e saídas e um nome definido pelo usuário, o TAG do bloco, que deve ser único na planta do usuário. Os blocos podem ser divididos em três tipos:
a) Bloco Transdutor;
b) Bloco Resource (Recurso);
c) Blocos Funcionais.

O bloco Transdutor serve para desacoplar os blocos de função das funções de interface com o sensor do dispositivo. Eles possuem uma frequência de varredura superior à dos blocos de função. Apesar de visíveis, esses blocos não podem ser ligados por meio da ferramenta de configuração do sistema Foundation, mas seus parâmetros são passados internamente aos blocos funcionais de leitura das entradas analógicas.

O bloco Recurso descreve as características físicas do dispositivo. Ele contém configurações gerais como identificação do fornecedor do equipamento, sua versão e características, sua capacidade de memória, etc. que são repassadas a dois dispositivos virtuais da rede Foundation denominados Virtual Field Devices ou VFD.

Todo dispositivo da rede Foundation possui dois VFDs:

a) Um VFD Fieldbus Block (FB), para os blocos de função;

b) UmVFD Management Information Base (MIB) que gerencia as informações de comunicação do dispositivo na rede Foundation. 
Desta forma, os dados de cada dispositivo instalado no barramento também ficam disponíveis na rede Fieldbus. Esses blocos também são visíveis na interface de configuração, mas a exemplo do bloco Transdutor, não podem ser interligados a outros blocos.

Os blocos de função determinam o comportamento do sistema de controle. As entradas e saídas desses blocos podem ser interligadas para configurar uma estratégia de controle Foundation. Um bloco de Entrada Analógica (AI) (ANEXO 2), por exemplo, possui várias funcionalidades além de sua atribuição típica, que é a de disponibilizar um dado analógico de campo, normalmente fornecido por um bloco transdutor, e o encaminhar como um valor digital para outros blocos. Dentre as funções que podem ser executadas por um bloco AI, estão também a de geração de alarmes, caso o sinal analógico do bloco passe de um valor parametrizado, e a simulação de um sinal analógico de saída, caso o transdutor do equipamento esteja com problemas.

A Fig. 13 a seguir mostra a rede Foundation projetada para o controle de uma das nove zonas pitométricas nas quais foi dividida a cidade de São Vicente.

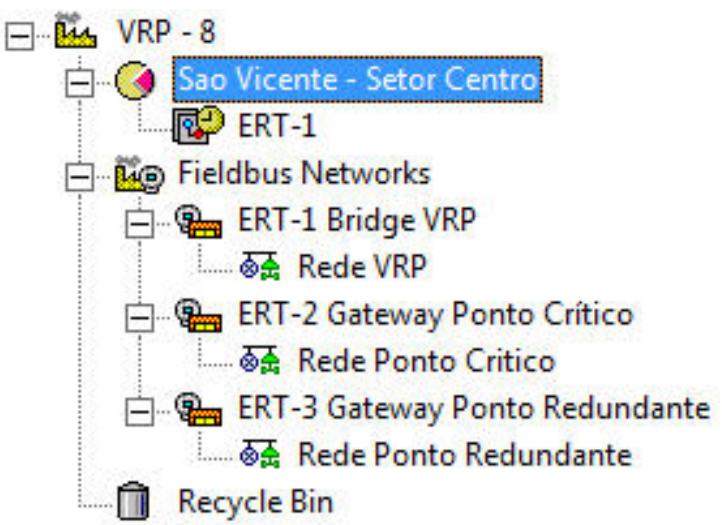

Figura 13 - Tela do software de configuração de sistemas Foundation Syscon, demonstrando o projeto da rede Foundation para o controle da zona pitométrica centro da cidade de São Vicente. 
O projeto de uma rede Foundation é segmentado no software de desenvolvimento em duas áreas: A área que representa a rede física e a área que representa o controle lógico do sistema.

A área que representa a rede física pode ser vista na Fig. 13, identificada como Fieldbus Networks. Sob a hierarquia desta área encontram-se três segmentos de rede distintos: O segmento de rede ERT-1, que consiste na rede Foundation localizada na ERT que controla a VRP do setor centro, e os segmentos ERT-2 e ERT-3, que consistem nas redes Foundation localizadas no ponto crítico e no ponto crítico redundante do setor, respectivamente. Ambos em localidades distintas, situados a $2 \mathrm{~km}$ da entrada do setor onde localiza-se a VRP.

Expandindo-se as redes de cada ERT, são visualizados os dispositivos e os blocos neles programados. Cada dispositivo possui um conjunto de blocos funcionais, além dos blocos Transdutor e Recurso, já descritos. Os blocos utilizados nos dispositivos dos segmentos de rede da ERT-1 são mostrados na Fig. 14 a seguir. 


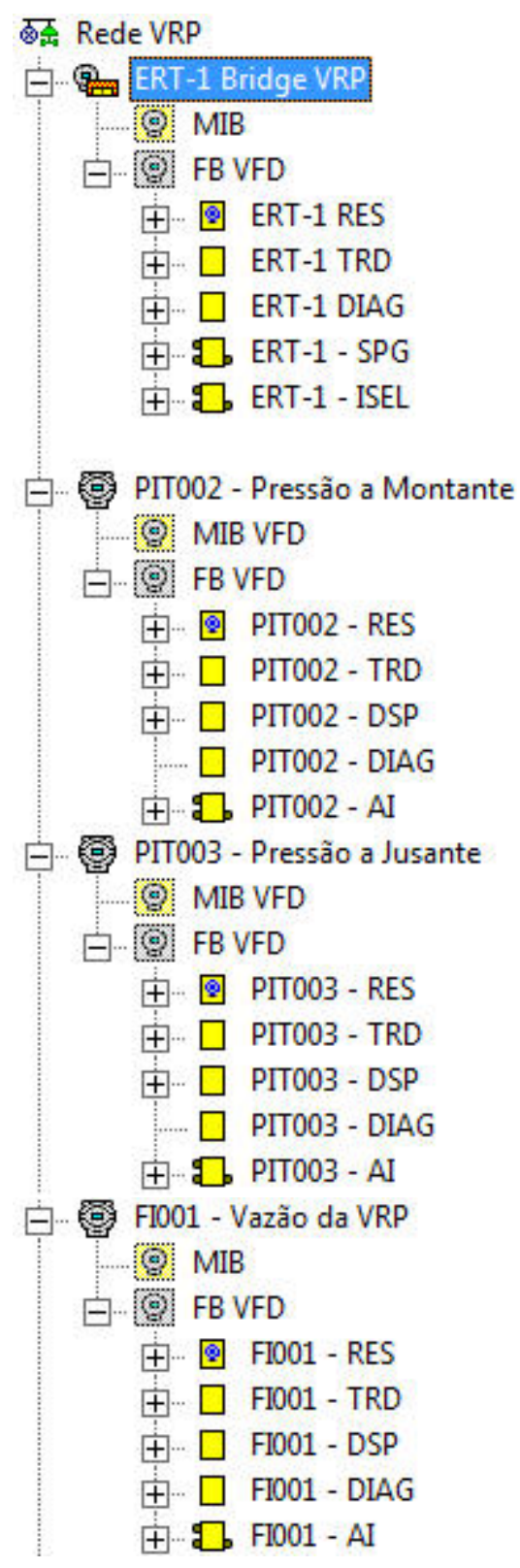

Figura 14 - Tela do software de configuração de sistemas Foundation Syscon demonstrando os blocos parametrizados no segmento da rede Foundation localizada na ERT-1- Controle da VRP.

Os dispositivos localizados nos segmentos de rede das ERTs 2 e 3, o ponto crítico da zona pitométrica e o ponto crítico redundante, respectivamente, têm programação semelhante, uma vez que um funciona como contenção do outro em caso de problemas. Os blocos programados nestes dispositivos são mostrados nas Figs. 15 e 16 a seguir: 


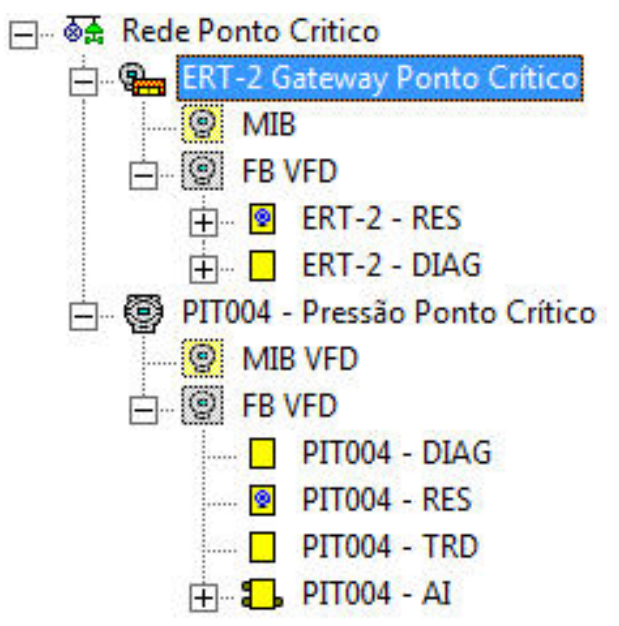

Figura 15 - Tela do software de configuração Figura 16 - Tela do software de configuração de sistemas de sistemas Foundation Syscon demonstrando Foundation Syscon demonstrando os blocos parametrizados os blocos parametrizados no segmento da no segmento da rede Foundation localizada na ERT-3- Ponto rede Foundation localizada na ERT-2- Ponto crítico redundante. crítico da zona pitométrica.

Os blocos de controle programados nos dispositivos têm funções específicas. Os blocos identificados como Diagnóstico (DIAG) permitem que os dados de diagnóstico do instrumento sejam disponibilizados na rede Foundation. Entre estes dados estão informações sobre o hardware e o firmware do dispositivo.

Os dados disponibilizados pelo bloco DIAG compõem as telas de informação dos instrumentos de campo. Esta tela é integrada ao módulo de manutenção do sistema de supervisão de abastecimento e serve de subsídio para elaboração de planos de manutenção preventiva dos equipamentos que compõem as ERTs. Esta tela é mostrada na Fig. 17, a seguir: 


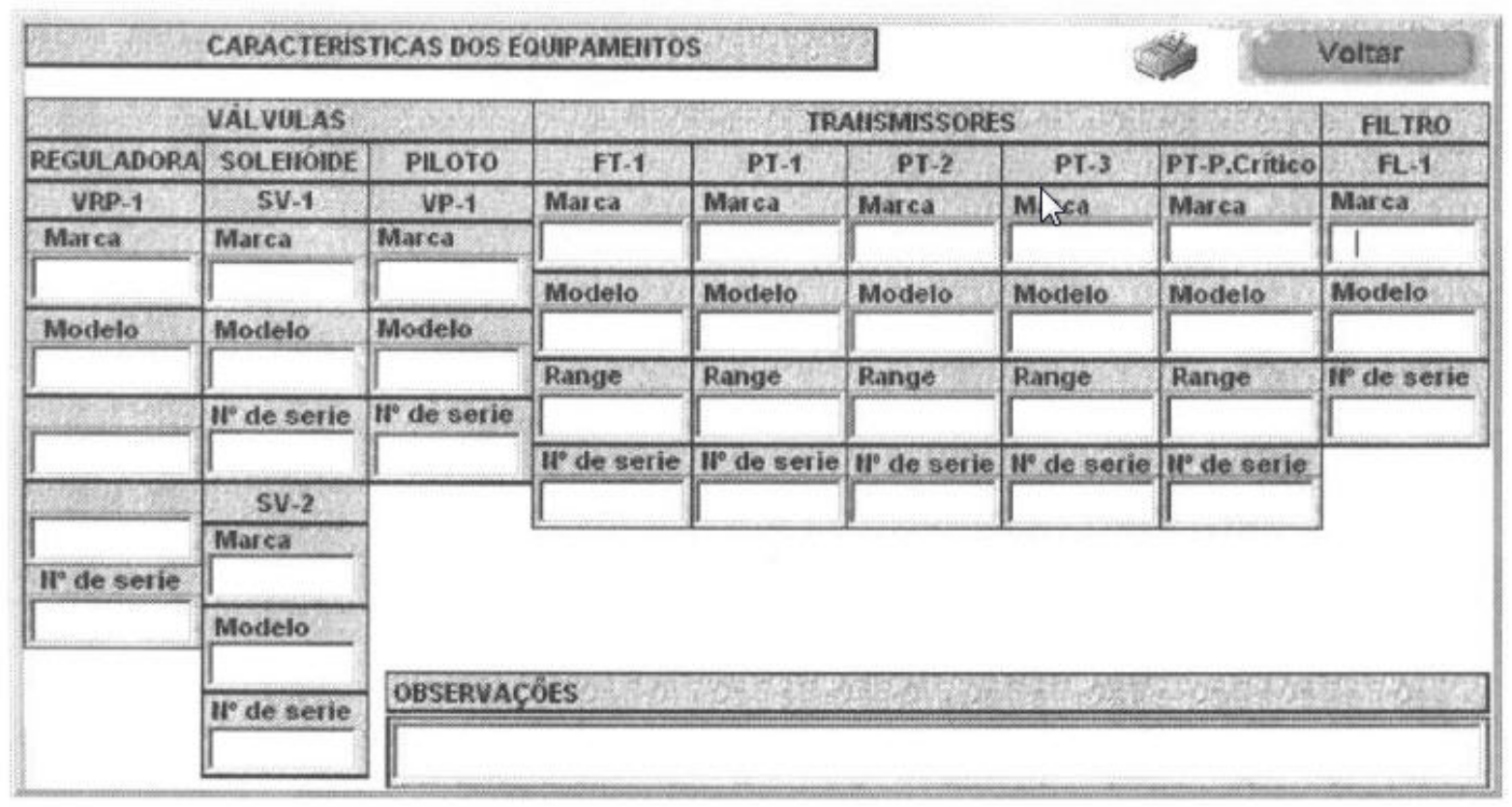

Figura 17 - Tela de informação dos instrumentos de campo que compõem o sistema de controle de uma zona pitométrica. Fonte: Sistema Integrado de Compartilhamento e Gestão de Informações de Abastecimento Hídrico da SABESP - Superintendência do Litoral, 2009.

O bloco Gerador de Set-point (SPG) (ANEXO 3) proporciona a geração de uma sequência pré-definida de valores em períodos determinados por um relógio atualizado pela rede Foundation. Este bloco tem a função de proporcionar uma das medidas de contenção do sistema de controle, gerando uma sequência de valores de set-point de pressão em substituição aos sinais dos pontos críticos, caso ocorram problemas com ambos os pontos.

Além da sequência de valores gerada, este bloco disponibiliza informações sobre em que ponto da curva de execução ele se encontra, e também permite a alteração remota dos parâmetros hora $\mathrm{x}$ pressão possibilitando a adequação do sistema de controle a fatores sazonais de demanda ou a mudanças nas características do processo em função de incrustações nas tubulações da rede abastecimento, por exemplo. 
Os blocos AI, como já exposto, possuem a atribuição de disponibilizar um dado analógico de campo, normalmente fornecido por um bloco transdutor, e o encaminhar como um valor digital para outros blocos. Além desta função, esses blocos também possuem a capacidade de geração de alarmes e de simulação de um sinal analógico de saída, caso o transdutor esteja com problemas.

Os blocos Display (DSP) são programados nos dispositivos que possuem display local em sua interface. Esses blocos são responsáveis por encaminhar ao display do instrumento as variáveis nele parametrizadas. Por meio de chaves magnéticas, é possível também alterar localmente alguns parâmetros de blocos programados no instrumento como, por exemplo, os parâmetros de ações de sintonia de um bloco de controle.

O bloco de Função Flexível (FFB) proporciona a interface entre os sinais provenientes da lógica de controle Foundation e o algoritmo programado no dispositivo controlador. Esses sinais são referenciados no algoritmo de controle por meio de memórias associadas ao nome dos parâmetros na lógica Foundation. A Fig.18 a seguir ilustra o bloco FFB referenciado às variáveis de controle da rede Foundation.

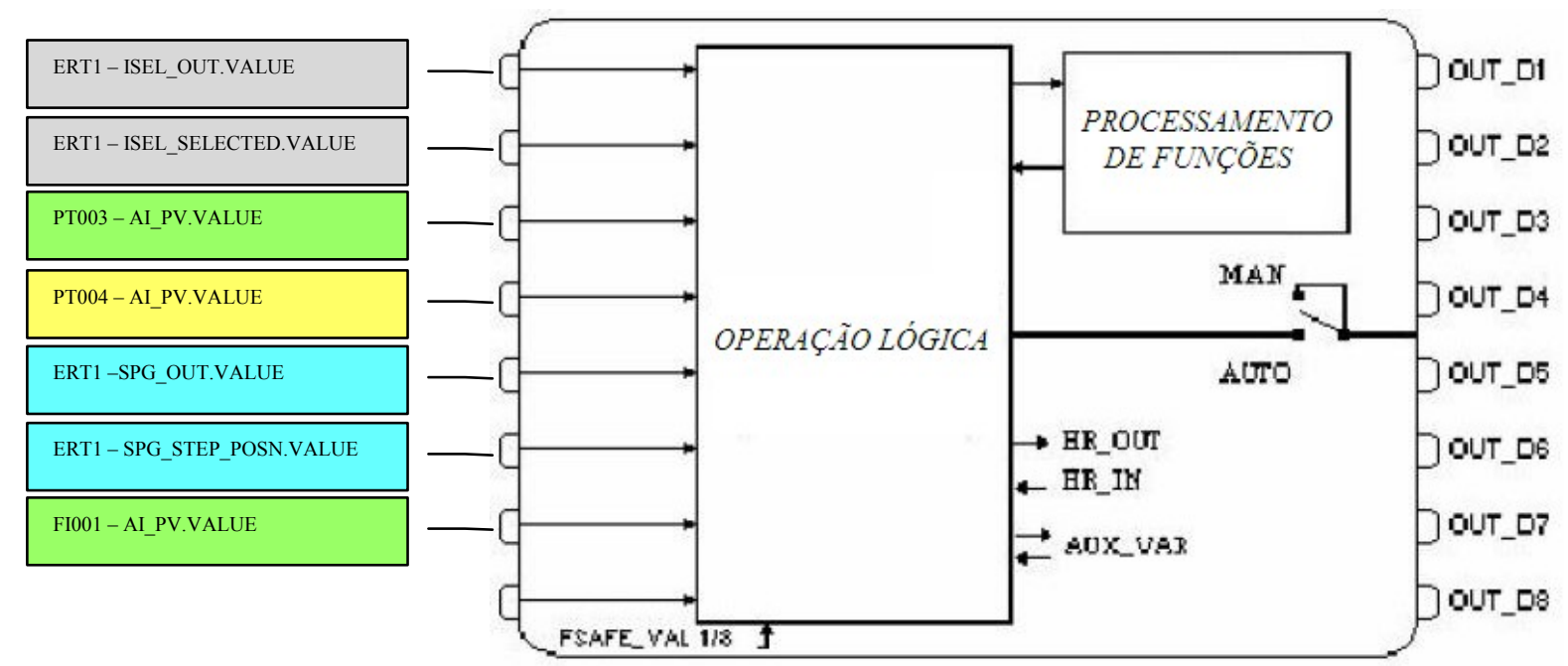

Figura 18 - Bloco FFB referenciado às variáveis de controle da rede Foundation. 
As aplicações de controle da rede Foundation consistem de blocos de função conectados. Esta conexão é desenvolvida em uma área lógica pré-definida no software de desenvolvimento denominada Estratégia. Na Fig. 13 é possível visualizar esta área destacada como "São Vicente - Setor Centro".

\subsection{A estratégia de controle}

A estratégia de controle proposta visa, basicamente, a manutenção da pressão do ponto crítico da zona pitométrica em um valor pré-estabelecido por meio do controle da pressão de entrada desta zona. Para isto, o sinal de pressão proveniente do ponto crítico deve ser monitorado constantemente pelo dispositivo controlador que, por sua vez, aciona a válvula de controle em caso de queda ou aumento da pressão neste ponto.

A estratégia prevê, também, a redundância automática da estação de telemetria do ponto crítico, efetuando a comutação do sinal a ser lido para uma estação redundante em caso de falha da estação principal.

As funções necessárias ao controle são divididas entre os dispositivos da rede Foundation, com a intenção de se obter os diferentes recursos disponibilizados por cada equipamento. $\mathrm{O}$ processamento dos sinais provenientes dos instrumentos de processo e o acionamento da VRP são realizados pelo dispositivo controlador. Este dispositivo processa programas desenvolvidos na linguagem Ladder além atuar como mestre do barramento, efetuando o gerenciamento da rede Foundation. 
A estratégia de controle da rede Foundation, também localizada no dispositivo controlador, é apresentada na Fig. 19 a seguir:

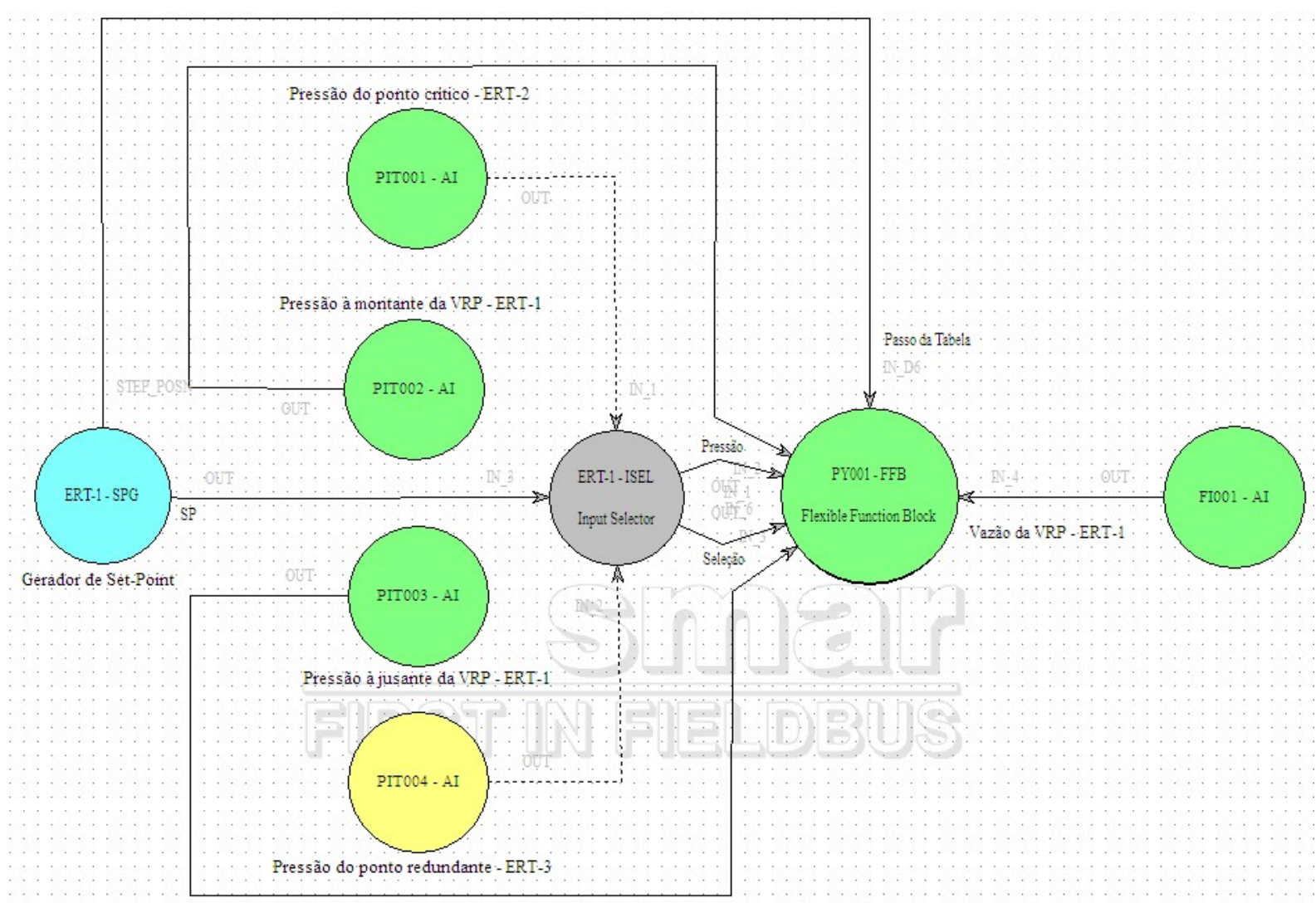

Figura 19 - Tela do software de configuração de sistemas Foundation Syscon contendo a estratégia de controle de um setor pitométrico.

$\mathrm{Na}$ Fig. 19 é possível visualizar que os sinais analógicos (AI) provenientes dos transmissores PIT001 e PIT004 são conduzidos a uma função denominada seletora de sinais (ISEL) (ANEXO 4). Essa função, programada no dispositivo PIC001, monitora continuamente ambos os transmissores, verificando a qualidade dos sinais enviados por meio dos sub-status da rede Foundation. A função ISEL é parametrizada para permitir a passagem do sinal do instrumento PIT001, o transmissor de pressão do ponto crítico da zona pitométrica, para a função de programação flexível (FFB). Em caso de problemas na ERT 2, onde esse transmissor encontra-se instalado, automaticamente o bloco ISEL comuta o sinal enviado para a função FFB, adotando o sinal proveniente do transmissor PIT004, localizado 
em outra ERT e que corresponde à pressão do ponto crítico redundante do setor pitométrico controlado.

O bloco gerador de set-point (SPG) constitui a terceira redundância do sistema de controle. Em caso de perda dos sinais dos transmissores de pressão de ambos os pontos críticos, o sinal deste bloco é selecionado pela função ISEL. O bloco SPG efetua a geração de uma sequência de set-points que determinam a posição da VRP. Esta sequência corresponde a uma tabela hora x pressão, determinada empiricamente por meio de ensaios em diferentes períodos do dia e que correlacionam a pressão necessária à jusante da VRP para manutenção da pressão objetivada no ponto crítico do setor controlado.

A função FFB recebe todos os sinais analógicos da malha de controle Foundation, e tem a atribuição de disponibilizar estes sinais à zona de programação Ladder do dispositivo PIC001. Por meio dessa função, os sinais dos dispositivos Foundation podem ser transferidos ao programa Ladder, constituindo parte do algoritmo de controle da VRP.

Além dos sinais das variáveis controladas disponibilizadas pelas funções AI, também são transferidos ao algoritmo de controle, por meio da função FFB, os status de processamento de algumas destas funções. Na Fig. 19 pode-se verificar que as funções ISEL e SPG possuem ligações de envio desses sinais à função FFB. Estas ligações permitem o envio ao algoritmo das informações sobre qual transmissor tem o seu sinal de controle utilizado em um determinado momento ou e em qual passo de execução do set-point automático encontra-se o bloco SPG. 


\subsection{O algoritmo de controle}

O algoritmo de controle, programado na função FFB, obtém os sinais dos transmissores e do gerador de set-point disponibilizados pela área de programação da estratégia Foundation, mostrada na Fig. 19. A função FFB recebe estes sinais, processa-os de acordo com o algoritmo nela programado e manipula as saídas físicas de controle do cartão de saídas discretas.

A primeira linha do algoritmo de controle, mostrada na Fig. 20, estabelece a banda morta tolerável para atuação da VRP. O sinal do set-point proveniente do CCO (\%M0169) recebe o acréscimo e o decréscimo de um valor e o resultado deste cálculo é alocado nas memórias $\% \mathrm{M} 0023$ e \%M0024 respectivamente. Os dois valores resultantes correspondem ao range da banda morta no qual a variável de processo será considerada dentro do valor de set-point, ordenando a parada da válvula de controle.

Dados empíricos levaram ao estabelecimento do valor de 1 mca para cima e para baixo do set-point como range de banda morta. Embora valores maiores fossem toleráveis, o valor de 2 mca de span tem por objetivo forçar a atuação das válvulas solenóides de admissão de água pressurizada na cabeça de VRP com relativa frequência, possibilitando a limpeza dos resíduos que tendem a se acumular na sede destas válvulas. 

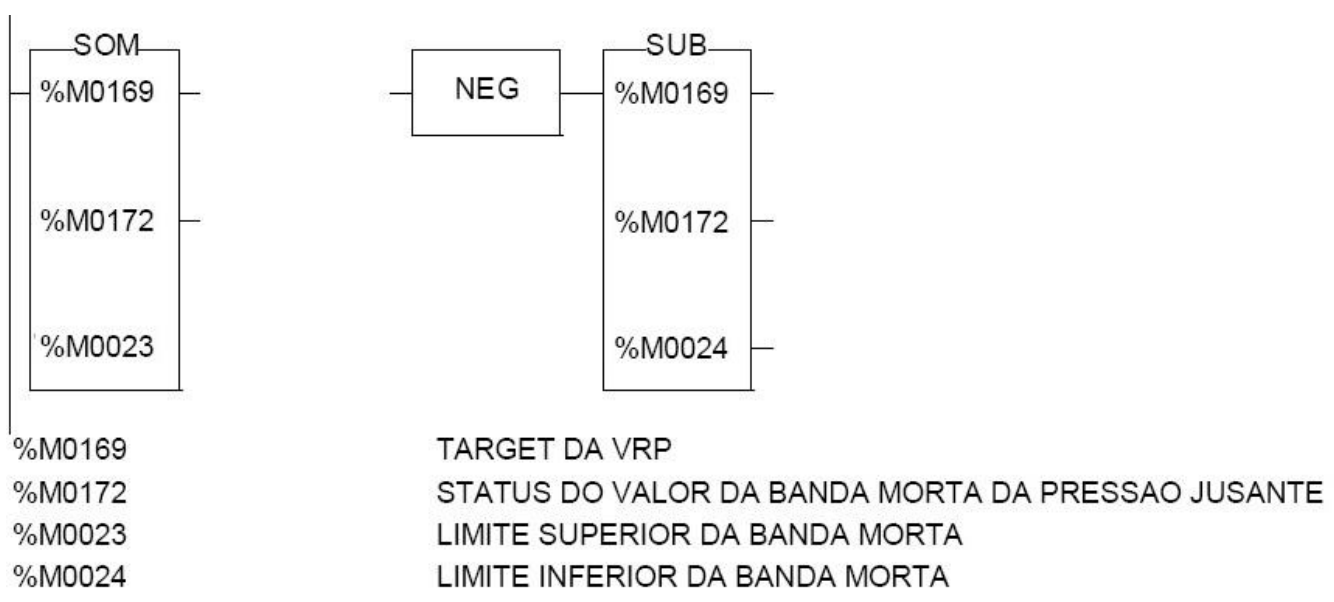

Figura 20 - Fragmento do algoritmo de controle da VRP responsável pelo estabelecimento da banda morta do set-point.

Visando otimizar o funcionamento da VRP, o algoritmo de controle prevê três faixas de operação que determinam como ocorrerá a atuação nas válvulas solenóides que a comandam. A faixa determinada pelo limite de ajuste grosso, estabelecida no fragmento de algoritmo da Fig. 21, determina que a atuação nas válvulas solenóides ocorra continuamente, até que a variável de processo esteja localizada dentro da faixa estabelecida pelo valor da constante \%KM (na Fig. 21 fixada com o valor de $4 \mathrm{mca}$ ). Se a variável de processo estiver fora dessa faixa, ou seja, acima ou abaixo 4 mca do valor do set-point, haverá um rápido deslocamento da posição atual da VRP até a posição necessária para manutenção da pressão do ponto crítico do setor no valor desejado. Este deslocamento rápido, no entanto, ocasionalmente provoca o fenômeno de overshoot ${ }^{3}$ na variável do processo, fazendo com que VRP se desloque além do necessário para manter a pressão no set-point desejado. Para isto, o algoritmo de controle prevê mais dois modos de atuação, os modos de ajuste médio e fino. O objetivo é que um modo de atuação conduza a variável de processo para dentro do range de pressão

\footnotetext{
${ }^{3}$ Ação na qual a variável manipulada de uma malha de controle recebe uma atuação além da necessária para manutenção da variável de processo no valor desejado, provocando um deslocamento desta variável além deste valor.
} 
correspondente ao modo imediatamente superior. Cada modo promove uma atuação menos incisiva na VRP, possibilitando um refinamento na atuação da válvula e consequentemente uma aproximação rápida da variável do processo ao set-point com o mínimo de overshoot.
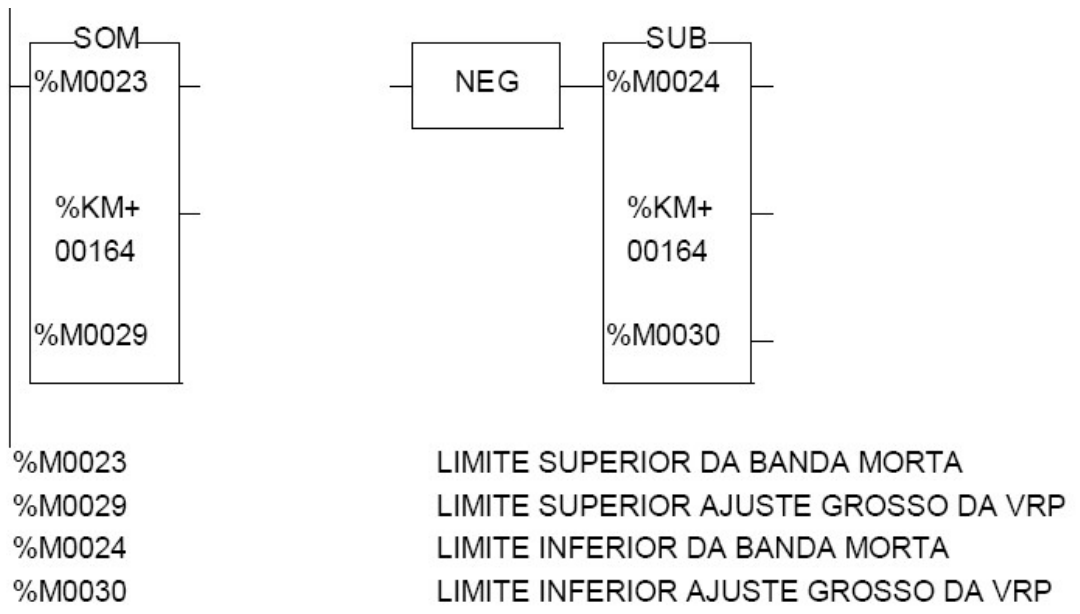

Figura 21 - Fragmento do algoritmo de controle responsável pelo estabelecimento da faixa de ajuste grosso da VRP.

A memória \%M0001, mostrada na Fig. 22, corresponde à variável de processo ou variável controlada. Em condições normais de funcionamento do sistema de controle, esta memória possui o valor da pressão do ponto crítico do setor controlado. Essa memória pode conter, ainda, o valor da pressão do ponto crítico redundante, caso ocorra falha no transmissor do ponto crítico principal ou, como última redundância do controle automático, o valor da pressão à jusante da VRP, que será controlada a partir da função geradora de set-point, presente na estratégia de controle Foundation.

A determinação da variável que será alocada na memória \%M0001 é feita pela função ISEL, também presente na estratégia de controle Foundation ou, no caso de se optar pelo controle de contenção a partir da tabela hora x pressão, pelo sistema supervisório do CCO. 
O fragmento do algoritmo mostrado na Fig. 22 verifica se a variável de processo encontra-se dentro da faixa que determina o ajuste grosso da VRP, habilitando a memória discreta \%A0000.0 neste caso.

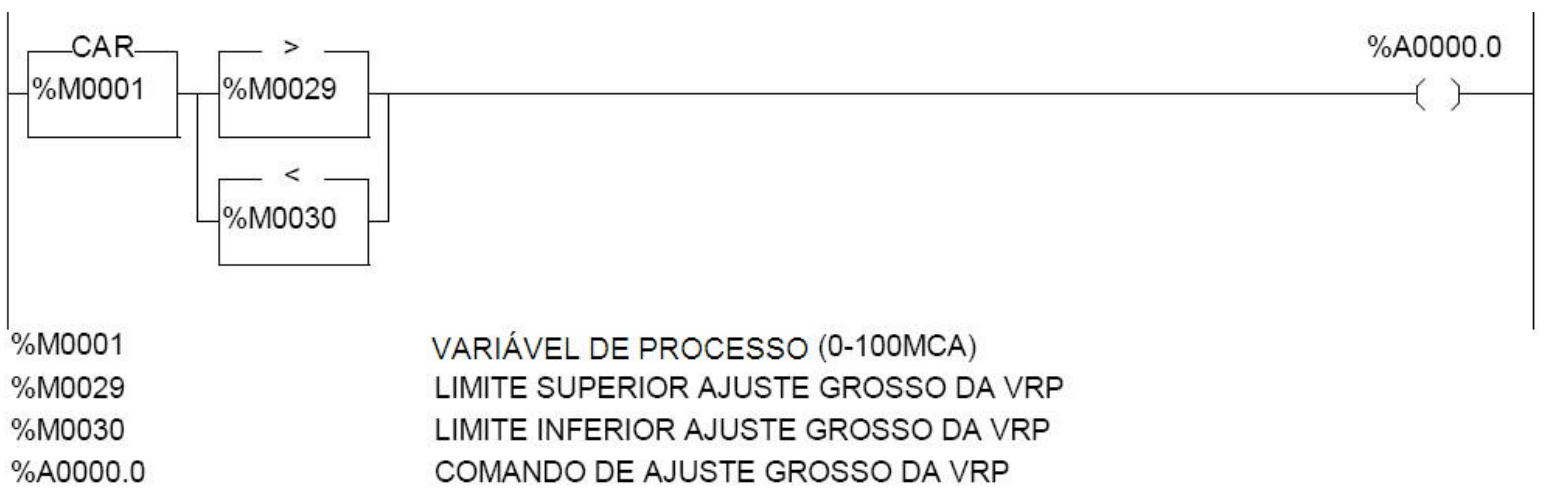

Figura 22 - Fragmento do algoritmo de controle da VRP responsável pela verificação do valor da variável de processo em relação aos limites de banda morta de ajuste grosso.

O fragmento do algoritmo mostrado na Fig. 23 estabelece os limites da banda morta para que a variável de processo seja considerada dentro da faixa de ajuste fino. Os limites são determinados a partir de valores fixos, obtidos empiricamente e inseridos nas memórias constantes \%KM. Dentro do range 0 a 4095, relativo à resolução de 12 bits permitida pela memória do dispositivo de controle, o valor 82 corresponde a 2 mca.
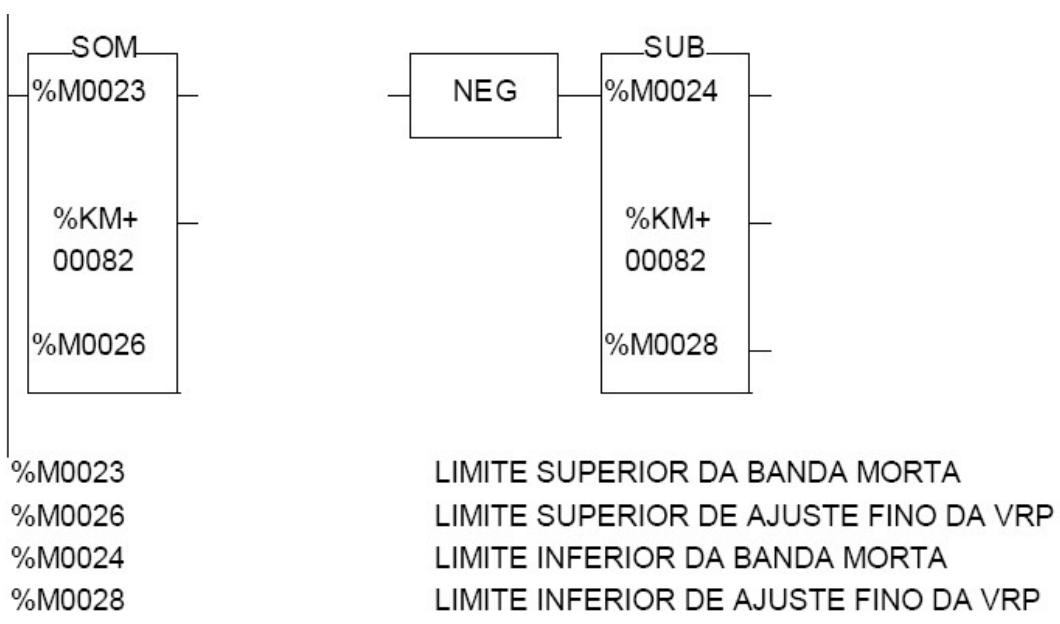

Figura 23 - Fragmento do algoritmo de controle responsável pelo estabelecimento da faixa de ajuste fino da VRP. 
A exemplo do fragmento de algoritmo da Fig. 22, a memória \%M0001 mostrada na Fig. 24 corresponde à variável de processo ou variável controlada que pode, ocasionalmente, possuir o valor da pressão do ponto crítico do setor controlado, do ponto crítico redundante ou da pressão à jusante da VRP. Esse fragmento verifica se a variável de processo encontra-se dentro da faixa que determina o ajuste fino da VRP, habilitando a memória discreta $\%$ A0001.5 neste caso.

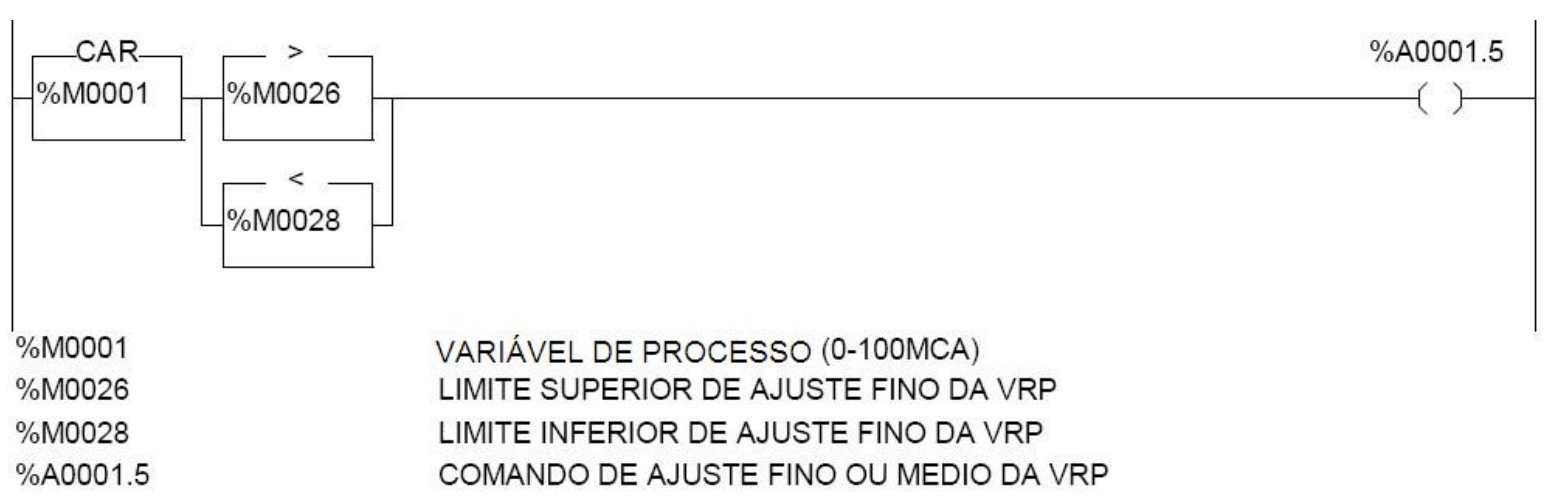

Figura 24 - Fragmento do algoritmo de controle da VRP responsável pela verificação do valor da variável de processo em relação aos limites da faixa de ajuste fino.

O modo de atuação nas válvulas solenóides que comandam a VRP é determinado pela distância que o valor da variável de processo está do set-point. Se essa variável estiver a mais de 4 mca do set-point de pressão desejado, as válvulas solenóides serão atuadas continuamente até que a variável de processo aproxime-se deste valor. Uma vez que essa variável se encontre a uma diferença menor que 4 mca do set-point, o algoritmo promove atuações pulsadas nas válvulas solenóides, permitindo uma aproximação suave da variável controlada. O algoritmo prevê dois tipos de atuações pulsadas, uma com pulsos mais curtos, denominada comando de ajuste fino e outra de pulsos mais longos, denominada de comando de ajuste médio. 
As faixas que determinam os tipos de atuação nas válvulas solenóides são mostradas no Quadro 4, a seguir:

\begin{tabular}{|c|c|c|}
\hline $\begin{array}{c}\text { Distância da variável de } \\
\text { processo em relação ao set- } \\
\text { point. }\end{array}$ & Modo de atuação & $\begin{array}{c}\text { Tipo de atuação nas } \\
\text { válvulas solenóides que } \\
\text { comandam a VRP }\end{array}$ \\
\hline Maior que 4 mca & $\begin{array}{c}\text { Comando de ajuste grosso } \\
\text { da VRP }\end{array}$ & Contínua \\
\hline $\begin{array}{c}\text { Menor que } 3,99 \text { mca e maior } \\
\text { que } 2 \text { mca }\end{array}$ & $\begin{array}{c}\text { Comando de ajuste médio } \\
\text { da VRP }\end{array}$ & $\begin{array}{c}\text { Pulsada - com intervalos de } \\
6 \text { seg. }\end{array}$ \\
\hline Menor que 1,99 mca & $\begin{array}{c}\text { Comando de ajuste fino da } \\
\text { VRP }\end{array}$ & $\begin{array}{c}\text { Pulsada - com intervalos de } \\
2 \text { seg. }\end{array}$ \\
\hline
\end{tabular}

Quadro 4 - Faixas que determinam os tipos de atuação nas válvulas solenóides da VRP.

O fragmento de algoritmo da Fig. 25 executa a movimentação da constante 60, que equivale a 6 segundos de pulso, para a memória \%M0031. Esta memória determinará o tempo de pulso de comando do ajuste médio da VRP, caso a memória discreta \%A0001.5 esteja habilitada pela lógica presente na Fig. 24.
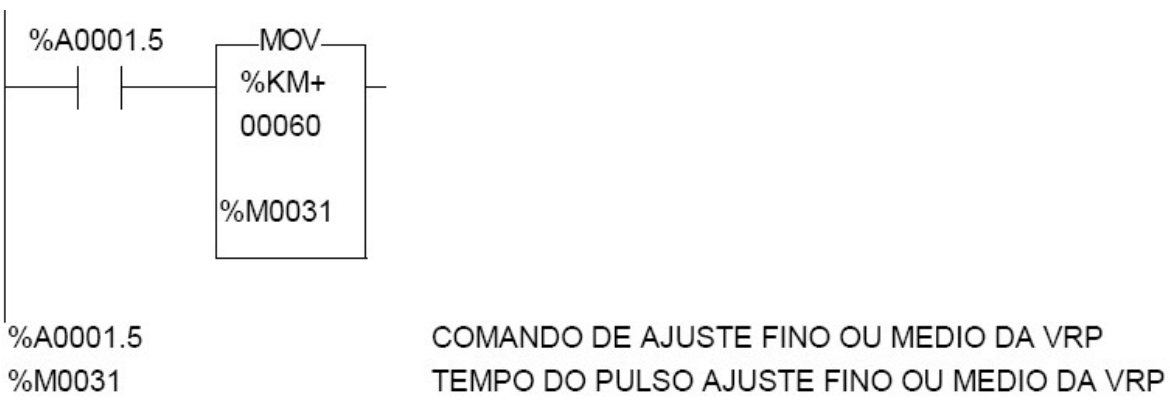

Figura 25 - Fragmento do algoritmo de controle responsável pela movimentação da constante de pulsação para atuação do ajuste médio da VRP.

O fragmento de algoritmo representado na Fig.26 executa a movimentação da constante 20, que equivale a 2 segundos de pulso, para a memória \%M0031. Esta memória determinará 
o tempo de pulso de comando do ajuste fino da VRP, caso a memória discreta \%A0001.5 esteja desabilitada pela lógica presente na Fig. 24.

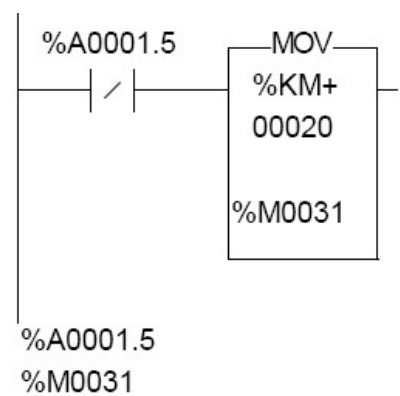

COMANDO DE AJUSTE FINO OU MEDIO DA VRP TEMPO DO PULSO AJUSTE FINO OU MEDIO DA VRP

Figura 26 - Fragmento do algoritmo de controle responsável pela movimentação da constante de pulsação para atuação do ajuste fino da VRP.

O fragmento de algoritmo representado na Fig. 27 habilita a abertura da VRP caso a chave presente no painel de comando da ERT esteja na posição remoto (memória \%E0000.4) e a variável de processo esteja abaixo do valor desejado menos o limite inferior da banda morta determinada remotamente. Esse fragmento determina também o desligamento da memória \%A0002.0 e \%A0002.2 caso a variável de processo (\%M0001) esteja acima do setpoint (\%M0169). Esse desligamento habilita o fechamento automático da VRP.

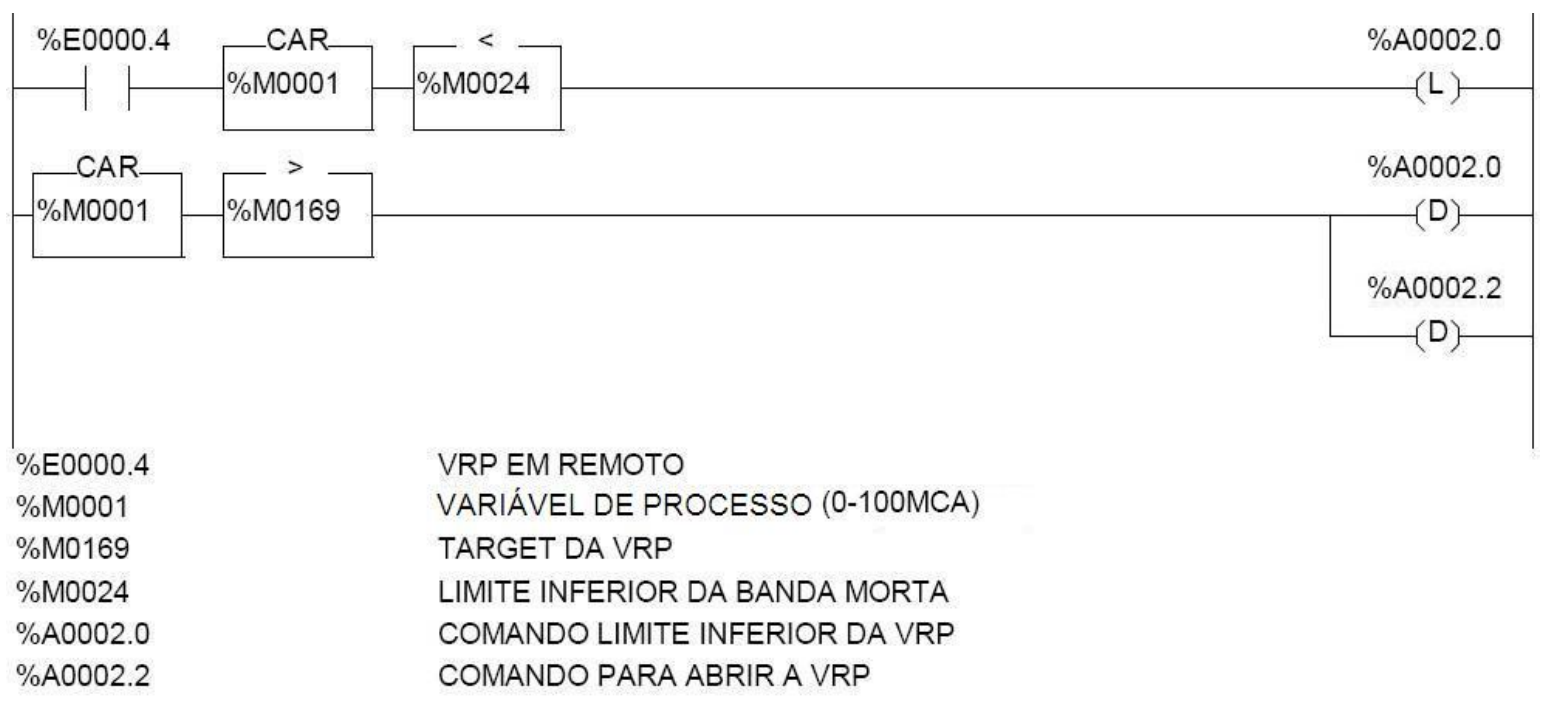

Figura 27 - Fragmento do algoritmo de controle responsável pela habilitação da atuação remota na VRP e do seu fechamento automático. 
O fragmento de algoritmo representado na Fig. 28 habilita o fechamento da VRP caso a chave presente no painel de comando da ERT esteja na posição remoto (memória \%E0000.4) e a variável de processo esteja acima do valor desejado mais o limite superior da banda morta determinada remotamente. Esse fragmento determina também o desligamento das memória \%A0002.1 e \%A0002.3 caso a variável de processo (\%M0001) esteja abaixo do set-point (\%M0169). Esse desligamento habilita a abertura automática da VRP.

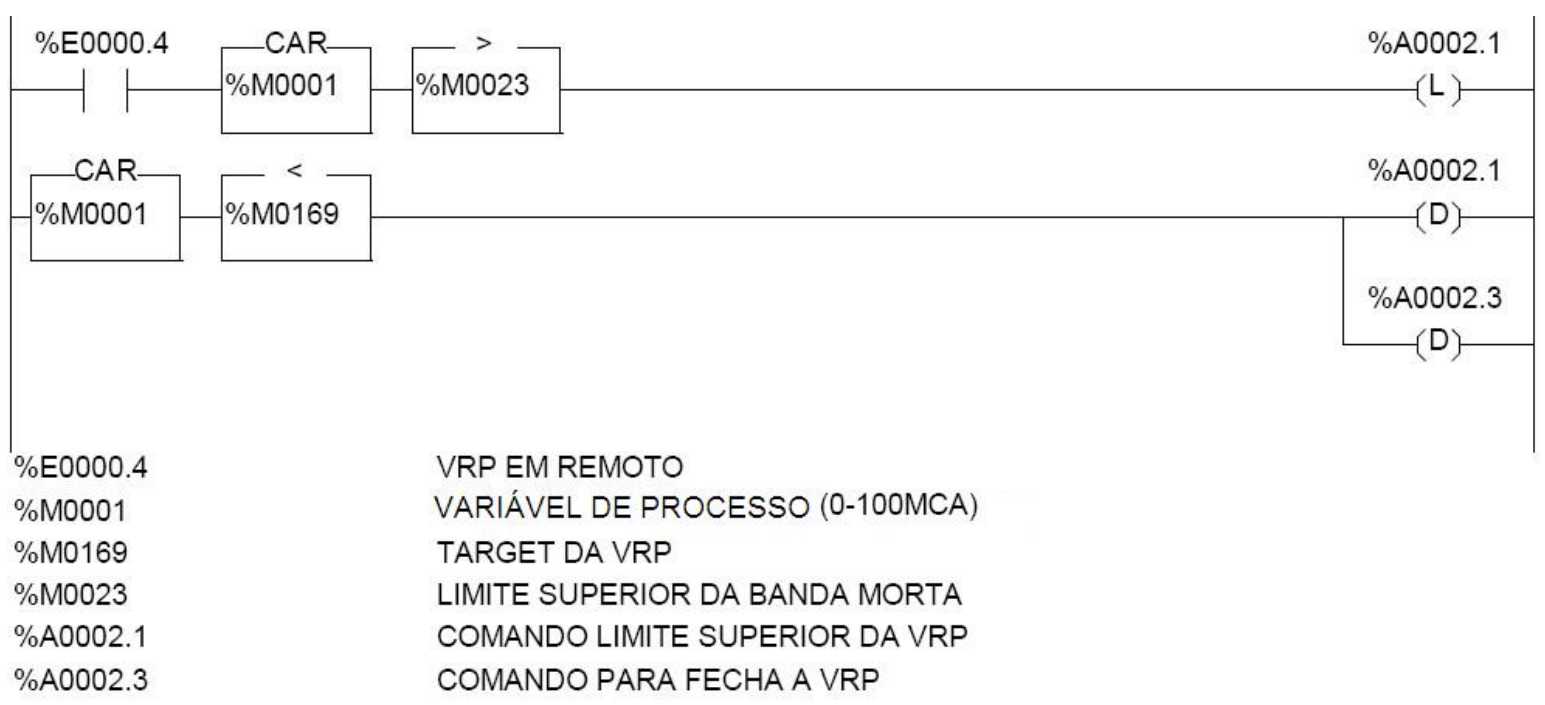

Figura 28 - Fragmento do algoritmo de controle responsável pela habilitação da atuação remota na VRP e da sua abertura automática.

A distância entre VRP e os pontos críticos de medição de pressão, muitas vezes, é de alguns quilômetros, o que ocasiona um tempo morto de 5 a 10 segundos entre a atuação no elemento final de controle e a resposta da variável controlada. Dessa forma, é necessário que o algoritmo de controle contenha rotinas que permitam à malha controlada estabilizar-se entre cada ciclo de atuação. 
O fragmento de algoritmo representado na Fig. 29 estabelece um degrau de atuação equivalente a 2,5 mca, que é somado ao valor atual da variável de processo e transferido à memória \%M0025.

Essa soma é proporcionada pelo desligamento da memória discreta \%A0002.2 e ocorre quando a variável controlada está abaixo do set-point. Uma vez que a variável controlada atinja o set-point, o valor desta variável acrescido à 2,5 mca, é transmitido à memória $\% \mathrm{M} 0160$.
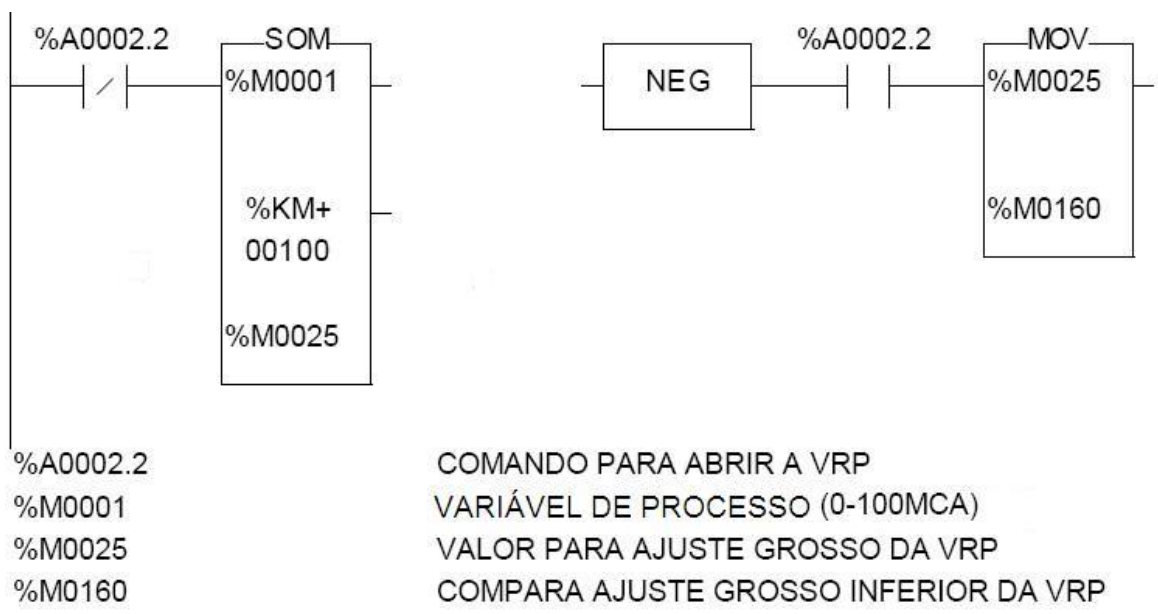

Figura 29 - Fragmento do algoritmo de controle que estabelece um degrau de 2,5 mca para abertura da VRP a cada período de estabilização da malha controlada.

O fragmento de algoritmo representado na Fig. 30 determina a abertura da VRP sempre que a variável de processo está abaixo do valor do set-point. Esta condição é estabelecida pelo operando normal-aberto parametrizado pela memória discreta \%A0002.0. A memória discreta \%A0002.2 é acionada pela primeira linha do fragmento da Fig. 30 e é desabilitada pela linha seguinte. O tempo entre os acionamentos é determinado pelo primeiro temporizador que é parametrizado com uma constante de 10 segundos. 
O segundo temporizador estabelece a largura do pulso na válvula solenóide de abertura da VRP a cada ciclo de atuação. Esse tempo de pulso, por sua vez, é alocado na memória \%M0031 e é determinado pelo modo de atuação em que a VRP encontra-se no momento: comando de ajuste grosso, médio ou fino.

Os ciclos de atuação na válvula solenóide de abertura da VRP são interrompidos cada vez que a variável controlada atinge um valor 2,5 mca acima do valor em que se encontrava anteriormente. Estes degraus de atuação são estabelecidos por meio do comparador de valor maior, parametrizado na Fig. 30 pela memória \%M0160.

A lógica de atuação em degraus é suprimida se a variável de processo estiver muito afastada do set-point, o que determina que a VRP está em modo de ajuste grosso. Esta supressão é proporcionada pelo operando normal-fechado parametrizado pela memória discreta \%A000.0, localizado em paralelo à lógica de comparação presente no fragmento de algoritmo da Fig. 30 . 


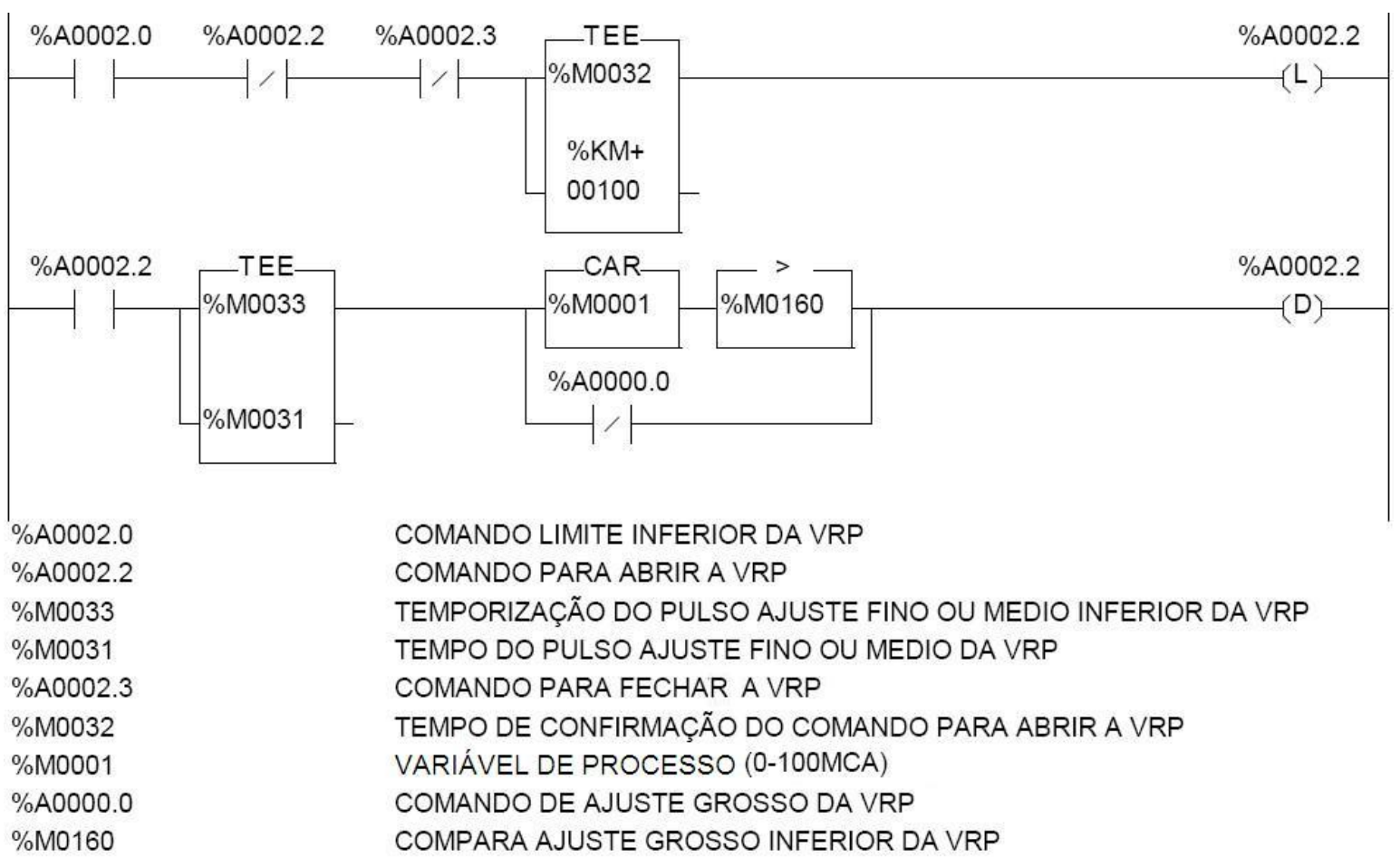

Figura 30 - Fragmento do algoritmo de controle que determina a abertura da VRP em degraus condicionada às condições estabelecidas pelo modo de atuação momentâneo.

A exemplo da Fig. 29, o fragmento de algoritmo da Fig. 31 estabelece um degrau de atuação equivalente a 2,5 mca, mas que neste caso é subtraído do valor atual da variável de processo e transferido à memória \%M0027.

Esta subtração é proporcionada pelo desligamento da memória discreta \%A0002.3 e ocorre quando a variável controlada está acima do set-point. Uma vez que a variável controlada atinja o set-point, o valor desta variável, decrescido da diferença de 2,5 mca, é transmitido à memória \%M0161. 


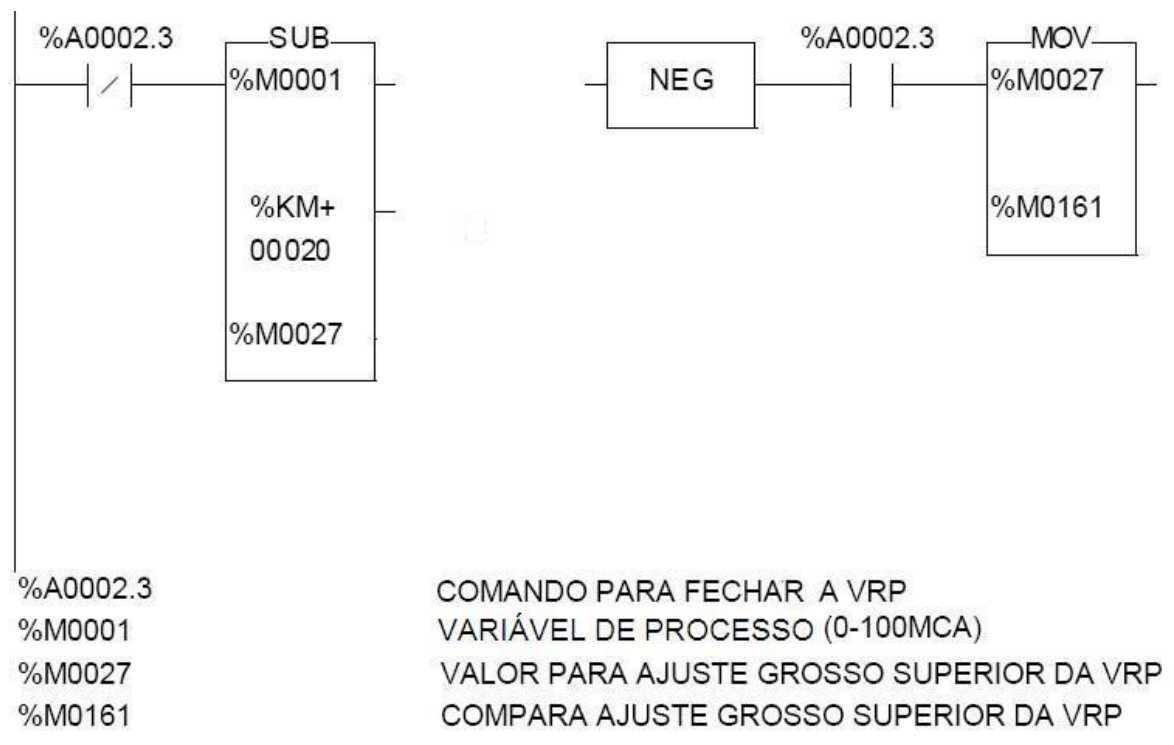

Figura 31 - Fragmento do algoritmo de controle que estabelece um degrau de 2,5 mca para fechamento da VRP a cada período de estabilização da malha controlada.

O fragmento de algoritmo representado na Fig. 32 determina o fechamento da VRP sempre que a variável de processo está acima do valor do set-point. Esta condição é estabelecida pelo operando normal-aberto parametrizado memória discreta \%A0002.1. A memória discreta \%A0002.3 é acionada pela primeira linha do fragmento da Fig. 32 e é desabilitada pela linha seguinte. $\mathrm{O}$ tempo entre os acionamentos é determinado pelo primeiro temporizador que é parametrizado com uma constante de 10 segundos.

O segundo temporizador estabelece a largura do pulso na válvula solenóide de abertura da VRP a cada ciclo de atuação. Esse tempo de pulso, por sua vez, é alocado na memória \%M0031 e é determinado pelo modo de atuação em que a VRP encontra-se no momento: comando de ajuste grosso, médio ou fino.

Os ciclos de atuação na válvula solenóide de abertura da VRP são interrompidos cada vez que a variável controlada atinge um valor 2,5 mca abaixo do valor em que se encontrava 
anteriormente. Estes degraus de atuação são estabelecidos por meio do comparador de valor menor, parametrizado na Fig. 32 pela memória \%M0161.

A lógica de atuação em degraus é suprimida se a variável de processo estiver muito afastada do set-point, o que determina que a VRP está em modo de ajuste grosso. Esta supressão é proporcionada pelo operando normal-fechado parametrizado pela memória discreta \%A000.0, localizado em paralelo à lógica de comparação presente no fragmento de algoritmo da Fig. 32 .

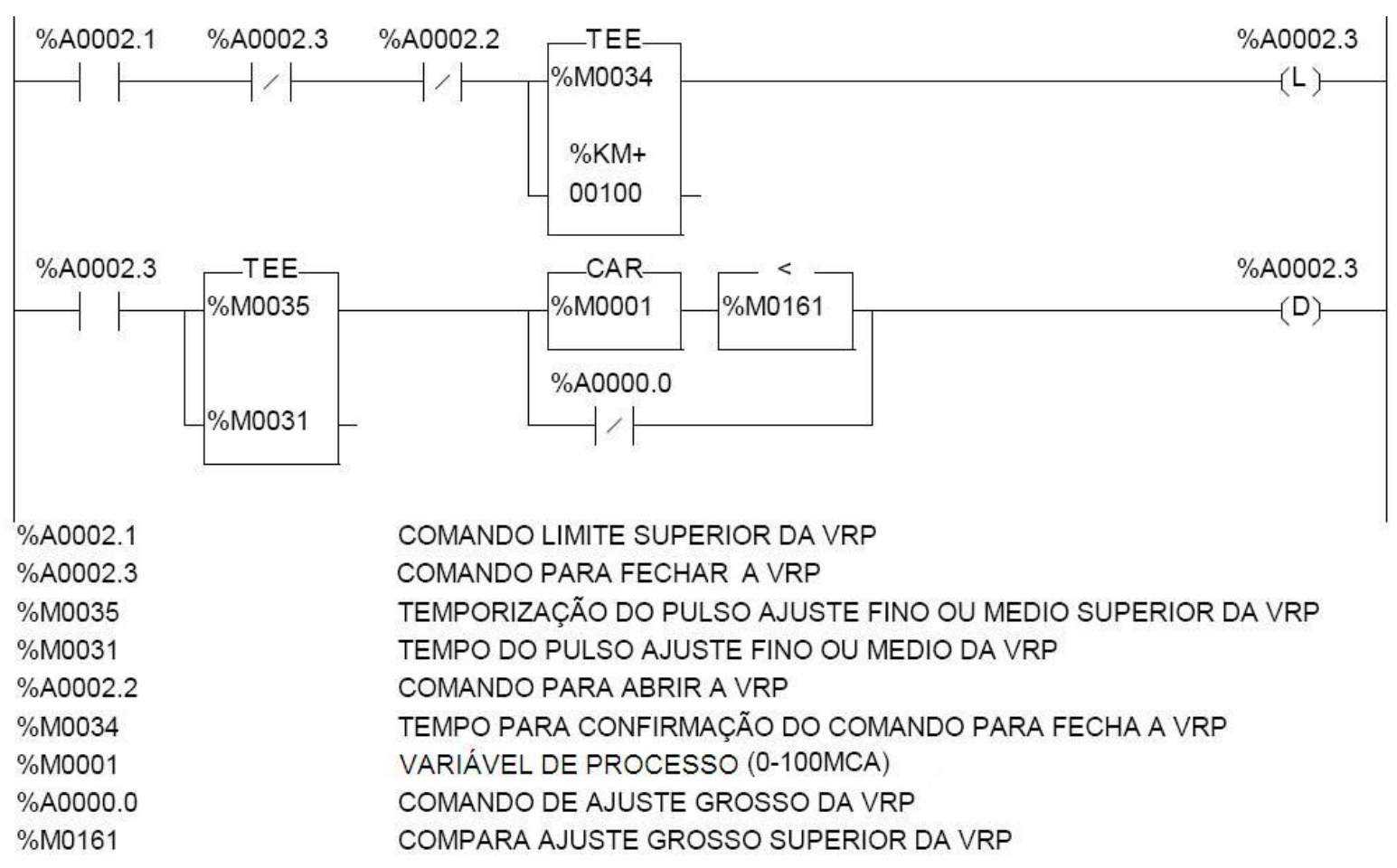

Figura 32 - Fragmento do algoritmo de controle que determina o fechamento da VRP em degraus condicionado às condições estabelecidas pelo modo de atuação momentâneo.

O fragmento de algoritmo representado na Fig. 33 transfere o resultado da lógica de acionamento das válvulas solenóides às saídas físicas do controlador. As condições para atuação nas saídas são as de que a chave do painel da ERT esteja na posição remoto 
(\%E0000.4) e o comando da VRP esteja no modo automático (\%A0001.1). A comutação entre os modos manual e automático é executada a partir de um comando enviado pelo sistema supervisório do CCO.

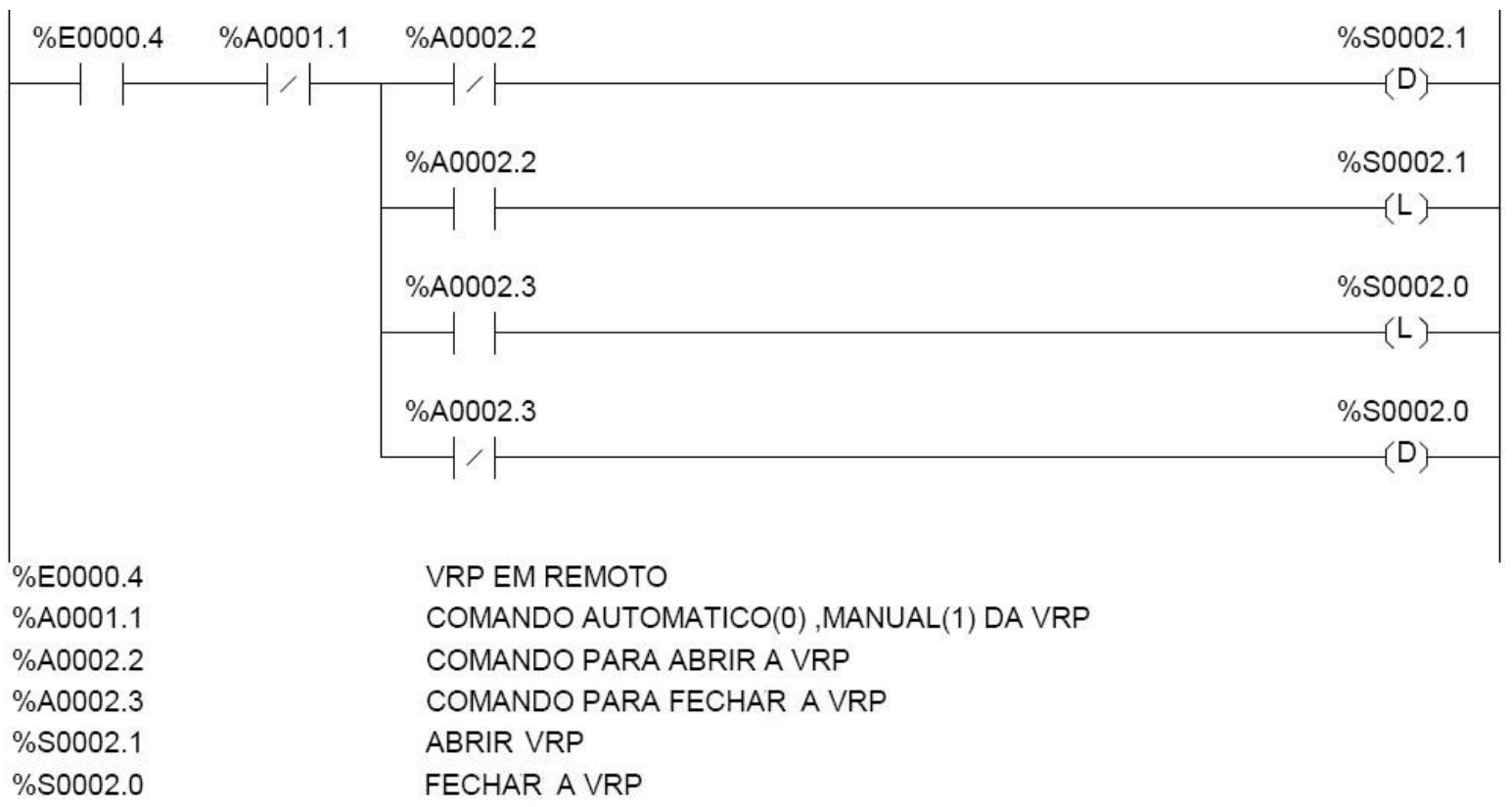

Figura 33 - Fragmento do algoritmo de controle que transfere o resultado da lógica de acionamento automático das válvulas solenóides às saídas físicas do controlador.

O fragmento de algoritmo representado na Fig.34 possibilita o acionamento manual da VRP a partir do CCO. As condições para atuação manual nas saídas são as de que a chave do painel da ERT esteja na posição remoto (\%E0000.4) e o comando da VRP esteja no modo manual (\%A0001.1). A comutação entre os modos manual e automático é executada a partir de um comando enviado pelo sistema supervisório do CCO. 


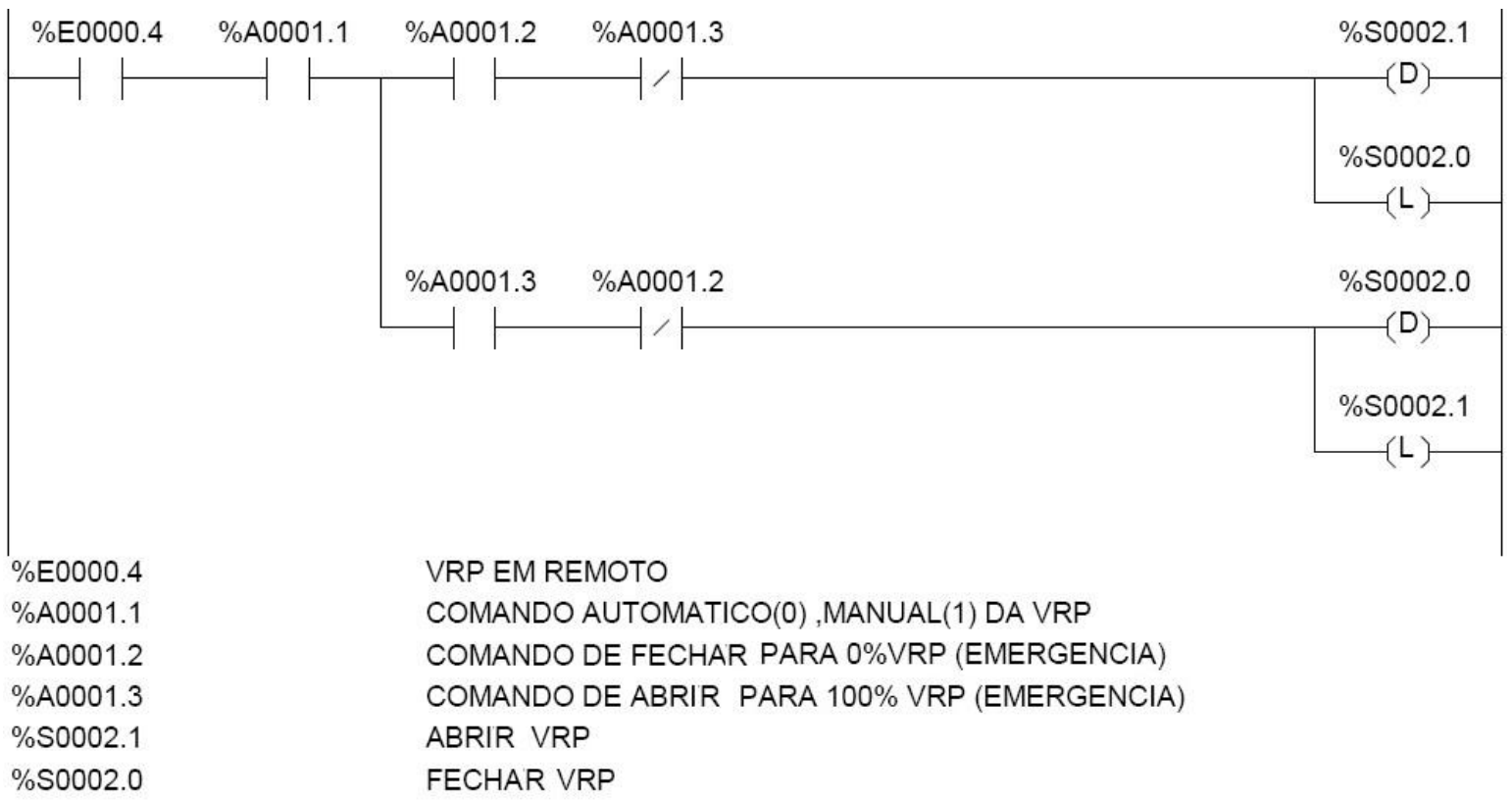

Figura 34 - Fragmento do algoritmo de controle que possibilita o acionamento manual remoto das válvulas solenóides que comandam a VRP.

O fragmento de algoritmo representado na Fig. 35 desativa o comando remoto da VRP. A memória \%E0000.4 corresponde a uma entrada física do controlador que e é acionada a partir de uma chave presente no painel de comando da ERT.

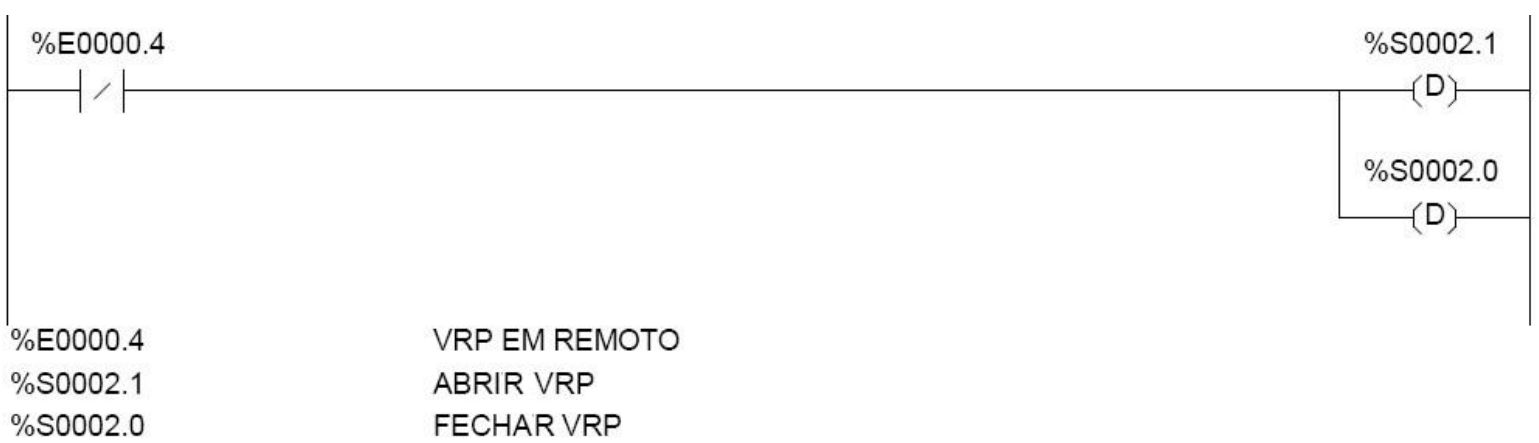

Figura 35 - Fragmento do algoritmo de controle desativa o comando remoto da VRP.

Uma vez na condição local, a VRP só pode ser acionada por meio de comandos hidráulicos que, em paralelo com as válvulas solenóides, possibilitam a admissão de pressão 
no atuador da válvula, oportunizando a atuação manual-local no elemento final de controle. A Fig. 36 a seguir mostra estes comandos:

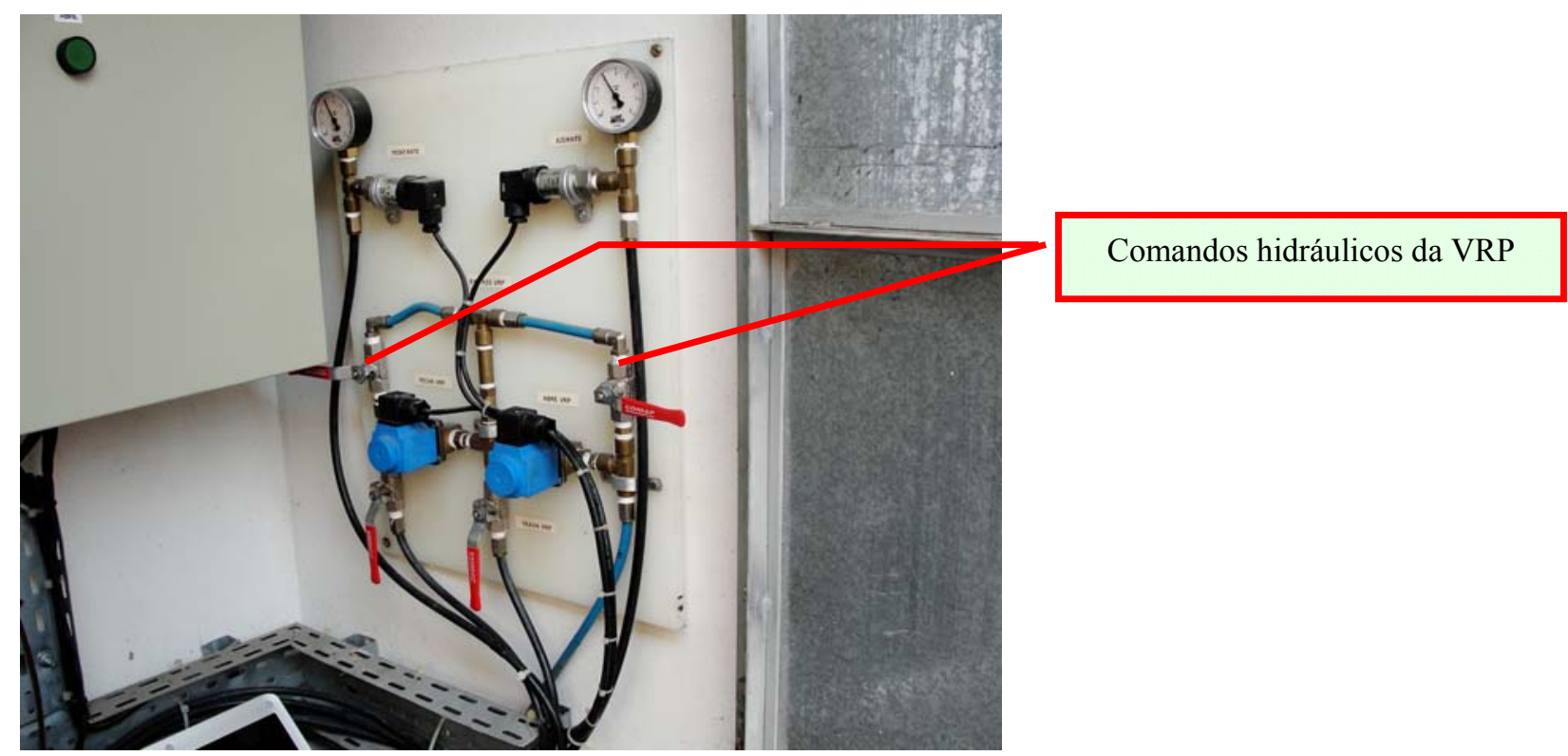

Figura 36 - Fotografia demonstrando os comandos hidráulicos de acionamento manual-local da VRP, em paralelo às válvulas solenóides de acionamento - ERT Centro de São Vicente - SABESP - Superintendência do Litoral, 2011.

\subsection{Arquitetura do sistema aquisição e controle}

A grande revolução nos SCADAs se deu com a introdução de dois padrões: o de incorporação e ligação de objetos (OPC) para comunicação com os controladores e demais dispositivos de controle, e os padrões da web para disseminar informações a baixo custo para todas as áreas da companhia.

Desde 1998 os sistemas supervisórios oferecem estações clientes leves que podem exibir quaisquer dados da planta em um computador pessoal convencional dotado de um browser. 
Numa primeira fase as informações eram disponibilizadas para leitura, mas o usuário não podia interagir com o sistema. Uma vez vencidas as barreiras iniciais de segurança, hoje já é possível a supervisão de uma planta industrial a quilômetros de distância de sua localidade geográfica.

Hoje em dia, como já exposto, os meios e os dispositivos de comunicação disponíveis para o estabelecimento de uma arquitetura de automação e controle são de uma enorme diversidade. Esta gama de possibilidades, no entanto, deve ser encarada com cautela no planejamento da arquitetura de um sistema de automação aplicado a redes de abastecimento hídrico.

A arquitetura apresentada na Fig. 37, utilizada na Superintendência do Litoral da SABESP para supervisão das zonas pitométricas do sistema de setorização, ilustra diferentes tipos de estações pertencentes a um sistema de supervisão.

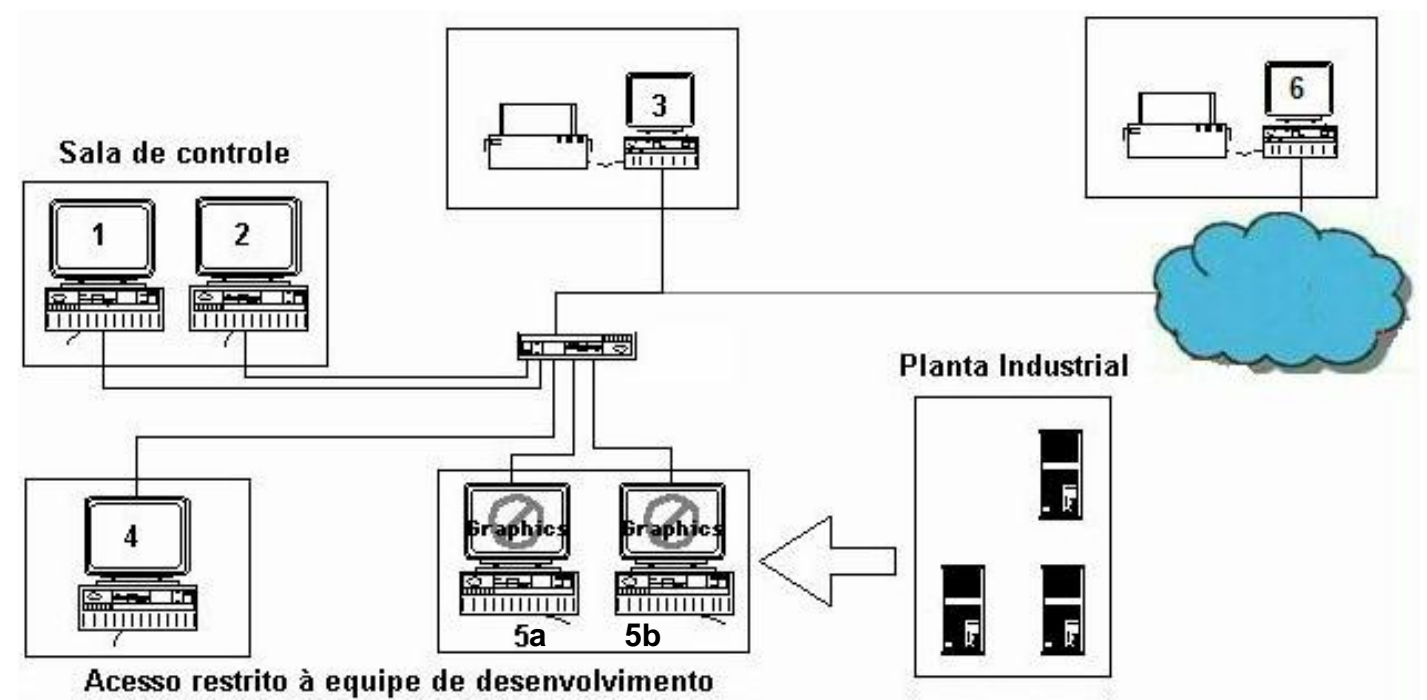

Figura 37 - Diagrama ilustrando diferentes tipos de estações pertencentes ao sistema de supervisão de arquitetura segmentada adotado na Superintendência do Litoral da SABESP. 
Dentro de uma proposta de segmentação da uma arquitetura SCADA, com vistas à sua aplicação na supervisão de sistema de setorização, cada estação deve possuir privilégios específicos, de forma a organizar as atribuições pertinentes a cada tipo de usuário do sistema.

As estações 1 e 2, representadas na Fig. 37 são reservadas à operação do sistema, destinadas aos controladores de processo que possuem privilégios de monitoramento e atuação nos componentes do sistema de abastecimento hídrico. O acesso a essas estações acontece por meio de senha pessoal ou de biometria, estabelecendo um sistema de segurança e responsabilidade. Em alguns CCOs destinados à supervisão de grandes sistemas de abastecimento hídrico, o número de estações e de operadores pode chegar a quatro ou cinco, incluindo o engenheiro de processos. É comum, também, a projeção em painéis de grandes dimensões das telas de sinótico referentes à visão global de todo o sistema ou de uma área específica.

A estação 6, representada na Fig. 37, é reservada ao monitoramento remoto do sistema. Interligada a uma intranet, possibilita acesso às telas do sistema de abastecimento hídrico de uma região específica. Embora as tecnologias atuais possibilitem, como já descrito, a atuação em dispositivos remotos do sistema de abastecimento hídrico por meio desta estação, recomenda-se fortemente que tal privilégio seja restrito apenas aos controladores de processo presentes no CCO. Entretanto, com o aumento do tamanho e da complexidade do sistema de abastecimento hídrico, admite-se a distribuição das atividades de supervisão atribuídas ao CCO principal a CCOs secundários, que na Superintendência do Litoral da SABESP são denominados CCOs regionais. Tal distribuição, entretanto, deve vir acompanhada das seguintes condições: 
a) A supervisão dos CCOs secundários deve ser restrita ao subsistema de sua responsabilidade.

b) A supervisão destes subsistemas deve ser subsidiada por um sistema integrado de informações operacionais de forma que os CCOs secundários disponham também de informações aos sistemas a eles associados.

c) Os CCOs secundários devem operar em caráter de autonomia monitorada, orientados pelo CCO principal, gestor do macro-sistema.

A estação 3, representada na Fig. 37, reservada ao engenheiro de processos ou ao gerente de sistemas, pode ou não possibilitar a atuação nos componentes do sistema de abastecimento hídrico. No caso da habilitação deste privilégio, recomenda-se que esta estação encontre-se no mesmo ambiente físico das estações de operação, constituindo mais uma deste tipo, porém com a capacidade de emissão e impressão de relatórios.

A estação 4, representada na Fig. 37, é a estação de engenharia. Por meio desta estação é possível obter acesso a todos os módulos do sistema de supervisão. Esta estação é destinada aos desenvolvedores do sistema e, devido às amplas possibilidades a ela permitidas, em geral é de acesso restrito, ficando localizada em uma sala próxima ao CCO, porém separada dele.

As estações 5a e 5b, representadas na Fig. 37, que são o núcleo do sistema de supervisão, são as denominadas estações SCADA. Por meio destas estações é que é feito o acesso aos dispositivos de controle localizados nas estações remotas de controle das zonas pitométricas. A aquisição e o envio de dados entre essas estações e o CCO são feitos por meio do padrão 
OPC, que faz interface entre as informações provenientes e as destinadas aos dispositivos de campo e o sistema de supervisão.

Todas as intervenções, sejam elas de operação ou de engenharia (desenvolvimento), têm reflexo direto nestas estações. Nelas estão localizados a base de dados do sistema de supervisão, os históricos de comportamento das variáveis e o núcleo de gerenciamento de todo o sistema. Apenas uma estação opera de cada vez, fazendo a varredura e atualizando o valor de todos os dispositivos de campo na sua base de dados. Enquanto isto, a outra estação aguarda em stand-by por alguma falha da estação principal e, caso isto ocorra, toma imediatamente o lugar desta por meio de um sistema de chaveamento automático, que transfere todo o aparato de comunicação para suas entradas de dados, constituindo assim, um sistema redundante.

\subsection{Sistema de supervisão das estações de controle das zonas pitométricas}

Os Sistemas de Informação ${ }^{4}$ são definidos como “[...] os sistemas que permitem a coleta, o armazenamento, o processamento, a recuperação e a disseminação de informações" (BARRELLA; BRUNSTEIN, 2000, p.3).

O núcleo do sistema de informação e supervisão das zonas pitométricas é constituído por um sistema supervisório que, como já descrito, é composto por um sistema computacional munido de programa aplicativo para supervisão de processos.

\footnotetext{
${ }^{4}$ Conceitua-se Sistema de Informação (SI), como todo sistema que utiliza ou não recursos de informática para tratamento, geração e/ou manipulação de informações. Porém, neste trabalho, ao se discutir SI, refere-se àqueles que utilizam Tecnologia da Informação.
} 
Este sistema, instalado no CCO, concentra as informações das estações remotas de controle das VRPs disponibilizando remotamente:

(a) o acesso à tela de comando de cada estação;

(b) a monitoração do estado operacional dos equipamentos da estação;

(c) a visualização dos alarmes ocorridos;

(d) os valores das variáveis medidas e calculadas pelos dispositivos autônomos;

(e) os parâmetros de funcionamento estabelecidos;

(f) o registro histórico de todas as variáveis, monitoradas e controladas.

A Fig. 38 mostra uma tela de supervisão de uma estação remota de controle de uma VRP.

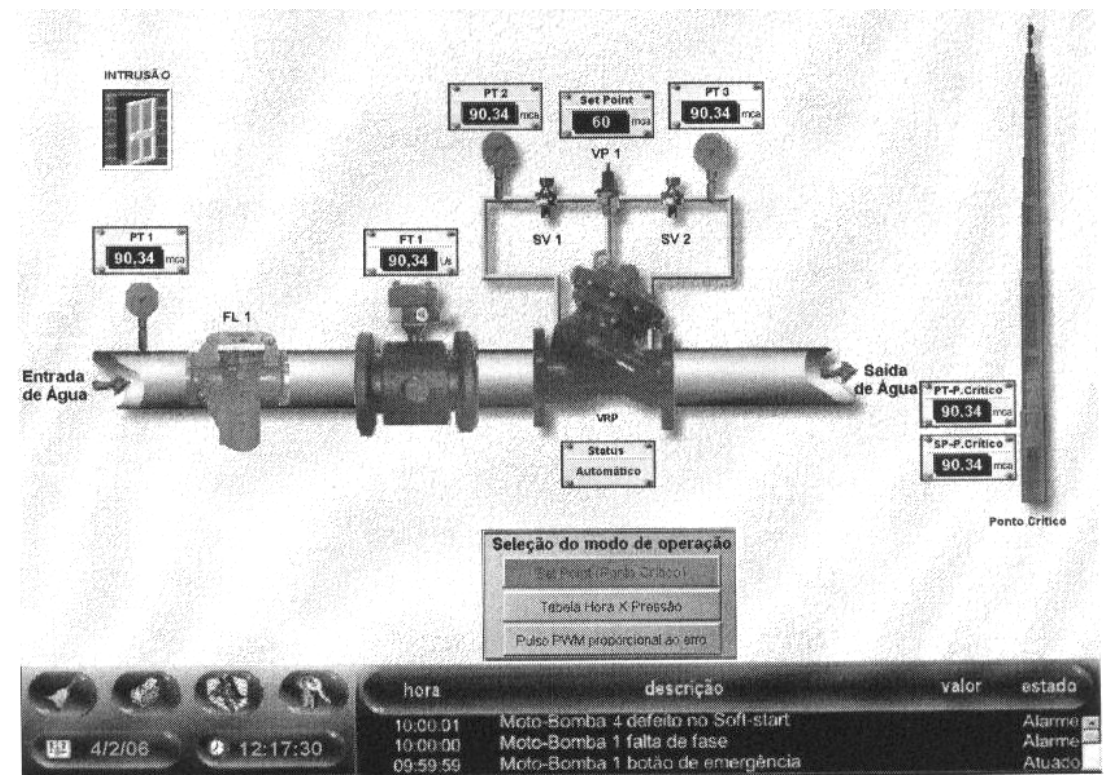

Figura 38 - Tela do sistema de supervisão de uma estação remota de controle de uma VRP - Fonte: Sistema de supervisão da Companhia de Saneamento Básico do Estado de São Paulo - Superintendência do Litoral, 2009. 
O controle das zonas pitométricas pelo sistema de supervisão ocorre por meio da visualização das variáveis de controle, tipicamente a pressão e a vazão de cada setor, e pela parametrização das estações remotas de controle das VRPs localizadas na entrada de cada zona.

A modificação destes parâmetros pode ocorrer em função da mudança das características do sistema de abastecimento hídrico, como por exemplo, aumento da rugosidade da tubulação ou manutenção temporária em um dos setores, ou ainda, de forma mais comum, pela modificação sazonal do perfil de consumo da população.

O sistema supervisório permite, ainda, o acesso a parâmetros mais técnicos, como constantes do algoritmo de controle ou parâmetros de programação do controlador. Estes parâmetros, no entanto, por definirem a filosofia de controle do sistema e demandarem conhecimento técnico mais aprofundado dos equipamentos, são acessados mediante a digitação de senhas específicas, concedidas, em geral, aos engenheiros de automação. A Fig. 39 a seguir mostra uma das telas de configuração de parâmetros de controle de um das zonas pitométricas, acessada mediante digitação de senha concedida aos engenheiros responsáveis pela parametrização do sistema. 


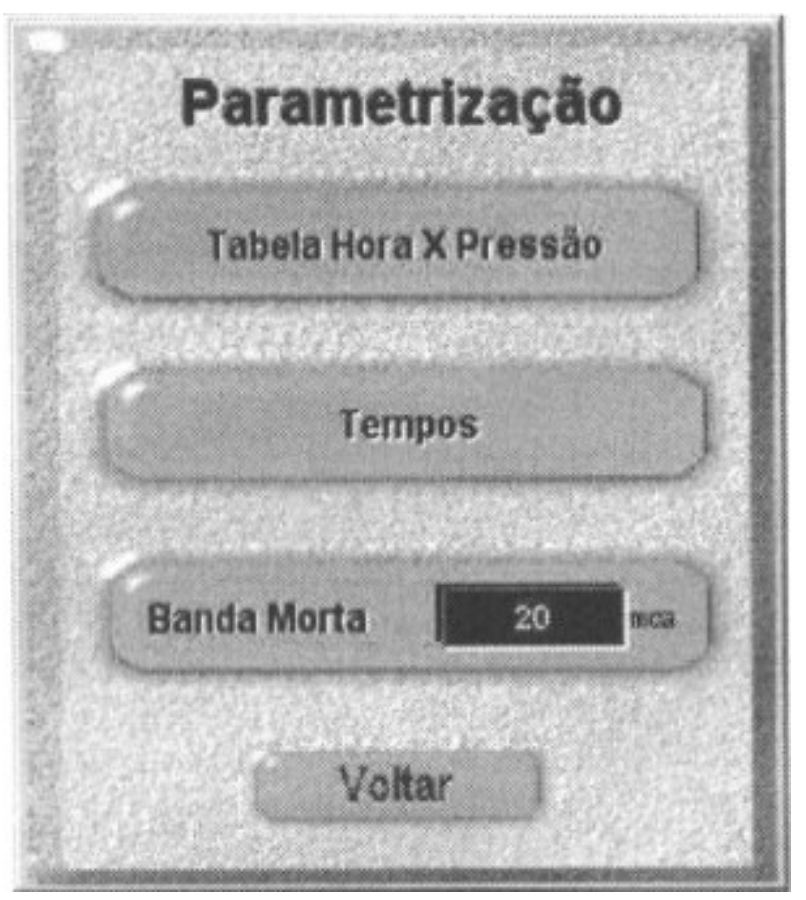

Figura 39 - Tela do sistema de supervisão de uma estação remota correspondente à interface de configuração dos parâmetros de controle de um das zonas pitométricas - Fonte: Sistema de supervisão da Companhia de Saneamento Básico do Estado de São Paulo - Superintendência do Litoral, 2009.

\subsection{Sistema Integrado de Compartilhamento e Gestão de Informações de}

\section{Abastecimento Hídrico}

Nos anos 90, foram percebidos grandes avanços nas telecomunicações e informática. Nesse período, houve o surgimento da Rede Mundial de Computadores ou Internet e com isso, tornou-se possível às empresas, independentemente do local de suas instalações físicas, trocarem informações de uma forma bastante ágil.

Em CERRI (2004, p.27) é afirmado que a "problemática da ausência de integração das informações internas e dos sistemas de software departamentais foi praticamente extinta com o surgimento das redes de comunicação de dados e dos Sistemas de Gestão de Informações". 
Em MEDEIROS E FERREIRA (2003, p.141) é exposto que "o grande ganho dos Sistemas Integrados de Gestão de Informações está na integração entre seus módulos. Diferentemente dos sistemas convencionais, em que os técnicos de desenvolvimento devem preocupar-se com a integração, estes sistemas encarregam-se disso naturalmente".

Caracteriza-se, assim, um Sistema Integrado de Gestão de Informações como um conjunto de sistemas de informação, que se utiliza de uma base de dados centralizada e que atende, em grande parte, às necessidades de democratização das informações operacionais de uma companhia, disponibilizando estas informações aos vários setores que a compõem.

Tendo-se por base a grande diversidade das companhias potenciais usuárias destes sistemas, é de se esperar que estes ofereçam grande flexibilidade para atendimento às necessidades diversificadas. Sabe-se, no entanto, que por maior que seja a flexibilidade apresentada por tais sistemas, a escolha pela adoção de um Sistema Integrado de Gestão de Informações comercializado por empresas fornecedoras desta solução, implica esforços de adaptação da companhia que fez a sua aquisição.

Em CERRI (2004, p.27) é explicado que “[...] não existe a melhor forma ou uma única maneira de projetar um Sistema de Informação (SI). Aspectos como aplicabilidade, flexibilidade, tamanho, complexidade, e tecnologia não são comuns a todas as empresas. Ademais, as empresas que vão desenvolver um SI diferem em termos de capacidade, experiência, gestão e infraestrutura tecnológica. Dessa forma, torna-se imperativo que o desenvolvimento seja precedido de uma compreensão do negócio para o qual ele será utilizado $[\ldots] "$. 
Com base nesta necessidade de conhecimento aprofundado sobre os subsistemas internos à companhia e dos processos a serem integrados, é que muitas empresas que detêm a expertise no desenvolvimento de sistemas de integração de informações, optam por desenvolver os seus próprios, ao invés de optarem por soluções de mercado que acabariam por acarretar problemas como: consequente dependência do fornecedor do sistema de integração, falta do conhecimento sobre o sistema integrado de gestão e necessidade de eventuais alterações em processos internos para adaptação ao sistema adquirido.

Tais problemas podem alimentar a resistência à mudança na postura operacional dos setores que serão envolvidos nesse sistema. De acordo com SACCOL (2003, p.329), "a utilização de um sistema integrado de gestão por si só não torna uma empresa verdadeiramente integrada. Da mesma forma, para que ela se torne orientada a processos, será necessária uma mudança de ordem cultural e, principalmente, comportamental. Algumas empresas não possuem um histórico, cultura e clima que permitam a adoção dessa atitude, enquanto que em outras empresas um sistema integrado de gestão simplesmente contribuirá para operacionalizar uma postura já adotada”.

Ponderando-se os aspectos sobre a compra de uma solução de mercado e o desenvolvimento de uma própria, a Superintendência do Litoral da SABESP optou por esta última.

O desenvolvimento de um Sistema Integrado de Compartilhamento e Gestão de Informações de Abastecimento Hídrico, que teve seu início na Superintendência do Litoral da SABESP em março de 2005, contribuiu para superar a morosidade do sistema causada pelo fato de que, até então, as informações de processo coletadas pelo CCO eram compartilhadas 
por meio de planilhas "físicas", preenchidas a partir das informações obtidas do sistema de supervisão, da coleta de dados via rádiocomunicação e por meio do contato via telefone com os operadores das estações remotas que não se encontravam integradas ao sistema de automação.

Uma vez que as informações coletadas pelo processo utilizado estão armazenadas em uma base de dados do sistema de supervisão, o desenvolvimento de um sistema de compartilhamento deve envolver, basicamente, a exportação contínua das informações para um banco de dados compartilhado pelos diversos setores que as utilizam.

A pré-existência de uma intranet corporativa também veio ao encontro da difusão das informações operacionais às diversas gerências que compõem a Superintendência do Litoral da SABESP.

O sistema implantado incorpora aspectos demandados por diversos setores especializados da Superintendência. Entre eles estão:

a) Segmentação das atribuições do CCO principal: a extensão do sistema de abastecimento gerenciado pela Superintendência do Litoral da SABESP explica a necessidade de divisão das atitudes operacionais entre as gerências regionais que a compõem. A inexistência de um sistema integrado de informações operacionais, no entanto, impossibilita esta divisão, pois, uma vez que o sistema de bacias hídricas é integrado (as diversas cidades que integram o sistema compartilham os mesmos mananciais), para que as atitudes operacionais sejam distribuídas, é necessário que os 
CCOs regionais disponham também de informações sobre os sistemas a eles associados (ANEXO 5).

b) Integração de produção e consumo em um único sistema: a inexistência de um vínculo contínuo de informações entre o sistema comercial de micromedição e tarifação e o sistema de macromedição (produção) determinam que a solicitação de dados ao CCO principal e ao departamento de hidrometria seja pontual e que o fornecimento se faça em planilhas "físicas". A implantação de um sistema de gerenciamento e compartilhamento da informação permite que os dados solicitados possam ser disponibilizados de forma contínua e instantânea. Desta forma, os reflexos que as atitudes operacionais causam em outras instâncias da companhia podem ser analisados de uma forma muito mais efetiva.

c) Integração das atividades de manutenção em um único sistema: considerando-se a estreita ligação da manutenção à operação do sistema de abastecimento hídrico, a demora em identificar a razão de eventuais quedas no desempenho de determinados setores do sistema de abastecimento hídrico, bem como a impossibilidade de priorizar a manutenção de um sistema em relação a outros, exige que, para atuar de forma mais ágil e efetiva, o setor de manutenção possa tanto obter informações de necessidades de intervenção integrados aos dados operacionais do sistema, quanto identificar os impactos causados pela perda de subsistemas.

d) Desenvolvimento de um sistema de gerenciamento de perdas hídricas: a falta de informações organizadas e sistemáticas sobre as perdas de recursos hídricos no sistema impede a realização de um trabalho articulado por parte dos controladores de saneamento dos diversos CCOs e a priorização do equilíbrio do sistema. A estruturação de um sistema com a função de orientar as atitudes operacionais a partir de informações por ele 
disponibilizadas permite que os resultados obtidos possam ser transformados em subsídios operacionais como faixas ótimas de operação de reservatórios, vazões e pontos de pressão nas principais adutoras, superando com isso, o problema de desarticulação dos diversos setores envolvidos (ANEXO 6).

e) Implementação de um sistema de comparação entre os dados obtidos pelo processo de análises químicas e da instrumentação analítica de processo: a impossibilidade de exercer a análise contínua de variáveis químicas que determinam a qualidade da água em um número maior de pontos do processo é suprida por coletas periódicas de água em diversos pontos do sistema de saneamento. A falta de integração entre as informações obtidas a partir da análise contínua das variáveis químicas, feita pela instrumentação de processo, e as informações provenientes da análise laboratorial, acaba por comprometer a percepção da possível necessidade de aferição de algum analisador de processo ou da contaminação da água em pontos intermediários do sistema.

Subsidiar o setor de manutenção dos sistemas de instrumentação de processo mediante a implementação de um sistema de comparação com os dados obtidos pelo processo laboratorial de análises químicas representa a possibilidade de superação desse problema, bastando que, para isto, os dados oriundos da instrumentação de campo sejam disponibilizados no sistema de gestão ao lado dos dados resultantes do departamento de análises químicas (ANEXO 7).

A clareza na exposição das necessidades de cada setor usuário do Sistema Integrado de Compartilhamento e Gestão de Informações de Abastecimento Hídrico e o envolvimento direto destes setores no desenvolvimento deste sistema possibilitou a construção de uma 
arquitetura integrada de fácil adaptação com relação à sua operação, fato que colabora para a mudança cultural de uma visão departamental para a uma visão de processos.

O resultado do desenvolvimento desta arquitetura consiste em um sistema modular, em que cada setor da companhia é responsável pela entrada de dados referentes à sua área de competência. Estes dados ficam disponíveis a outros setores que, por sua vez, também disponibilizam os seus dados.

A partir do caso da Superintendência do Litoral da SABESP observa-se que o acesso aos diversos módulos do Sistema Integrado de Compartilhamento e Gestão de Informações de Abastecimento Hídrico é feito por meio de uma intranet corporativa. O acesso a esta intranet, restrito a apenas localidades internas à companhia, em conjunto com medidas de proteção como firewalls e sistemas de backup implementados nos servidores de dados, garantem a segurança das informações.

Cada setor usuário das informações possui acesso apenas aos módulos de sua competência, cuja entrada de dados é de sua responsabilidade. Quando os dados são de interesse coletivo, o acesso também é permitido mesmo aos módulos cuja responsabilidade é de outros setores, desde que com o uso de senhas, que habilitam apenas a visão das informações, e em situações específicas, também a sua edição. 


\section{CONCLUSÃO}

A expansão dos sistemas de abastecimento hídrico é um processo contínuo e necessário à propagação do saneamento básico às comunidades que se encontram em franco crescimento na maioria das regiões brasileiras. O planejamento deste processo tem fundamental importância na posterior manutenção destes sistemas e na identificação das inevitáveis necessidades de intervenção que, quase sempre, são de caráter emergencial, pois comprometem um serviço relacionado à saúde pública da população.

Este planejamento tem ainda mais relevância levando-se em consideração o momento de crescimento acelerado em que se encontram as cidades da Baixada Santista, alavancado pelo súbito desenvolvimento econômico da região nos últimos anos. Segundo Anícia Pio, gerente de meio ambiente do Centro das Indústrias do Estado de São Paulo - CIESP em entrevista concedida ao Jornal A Tribuna (2010,pg. A2), “[...] o fornecimento de água potável para toda a Baixada Santista corre risco [...] o volume dos recursos hídricos existentes na região diminuiu bastante de uns anos para cá e os três rios que abastecem a região estão em níveis preocupantes".

O gerenciamento da pressão e um bom plano de pesquisa de vazamentos, de acordo com pesquisas realizadas junto a engenheiros da SABESP, constituem procedimentos de suma importância dentro de um plano para redução de perdas hídricas em um sistema de abastecimento urbano (FERNANDES, 2006, p. 49).

Neste contexto, a setorização apresenta-se como uma opção que vai ao encontro destes objetivos, ao passo que trás benefícios como o controle mais eficiente das redes de 
abastecimento, melhor gerenciamento de perdas e maior eficácia das intervenções de manutenção.

A importância da divulgação de opções como esta se dá em função da constante e crescente evolução tecnológica, que permitirá aos sistemas de automação de abastecimento alcançar os patamares de confiabilidade e robustez necessários à prestação destes serviços.

\subsection{Resultados}

A dicotomia imposta pela necessidade de aumento da demanda hídrica urbana e o iminente déficit entre os recursos disponíveis e os demandados, impõe a necessidade de atualização tecnológica e otimização dos sistemas de abastecimento, oportunizando a sua expansão com base na eficiência da detecção e controle de vazamentos, eficácia operacional e processos de manutenção rápidos e efetivos.

Neste contexto, urge a necessidade de implementação de sistemas que permitam a redução do índice de perdas hídricas que, embora se encontre atualmente no alarmante patamar de $32 \%$ na região, antes da implantação da técnica de setorização na cidade de São Vicente, atingia valores acima de $40 \%$ de toda água tratada produzida na superintendência do litoral.

Uma expansão eficaz, no entanto, torna-se impraticável sem a utilização de recursos que proporcionem autonomia aos sistemas de controle das redes de abastecimento. O protocolo de comunicação de dispositivos industriais Foundation Fieldbus, além de possibilitar a implementação de algoritmos que proporcionam esta autonomia, possibilita monitoração 
efetiva dos ativos da malha de controle, oportunizando a realização de diagnósticos aprofundados dos instrumentos e dispositivos que compõem esta malha.

Os resultados de parte do sistema proposto nesta pesquisa que já se encontra implementado pela Superintendência do Litoral da SABESP e que envolve o controle das nove zonas pitométricas da cidade de São Vicente por meio de instrumentação analógica e controladores lógico programáveis, são evidentes. A eficácia do algoritmo pode ser constatada no gráfico mostrado na Fig. 40 a seguir, que ilustra a manutenção da pressão do setor "Centro" da cidade de São Vicente (linha azul do gráfico) no valor definido pela tabela hora x pressão (linha rosa).

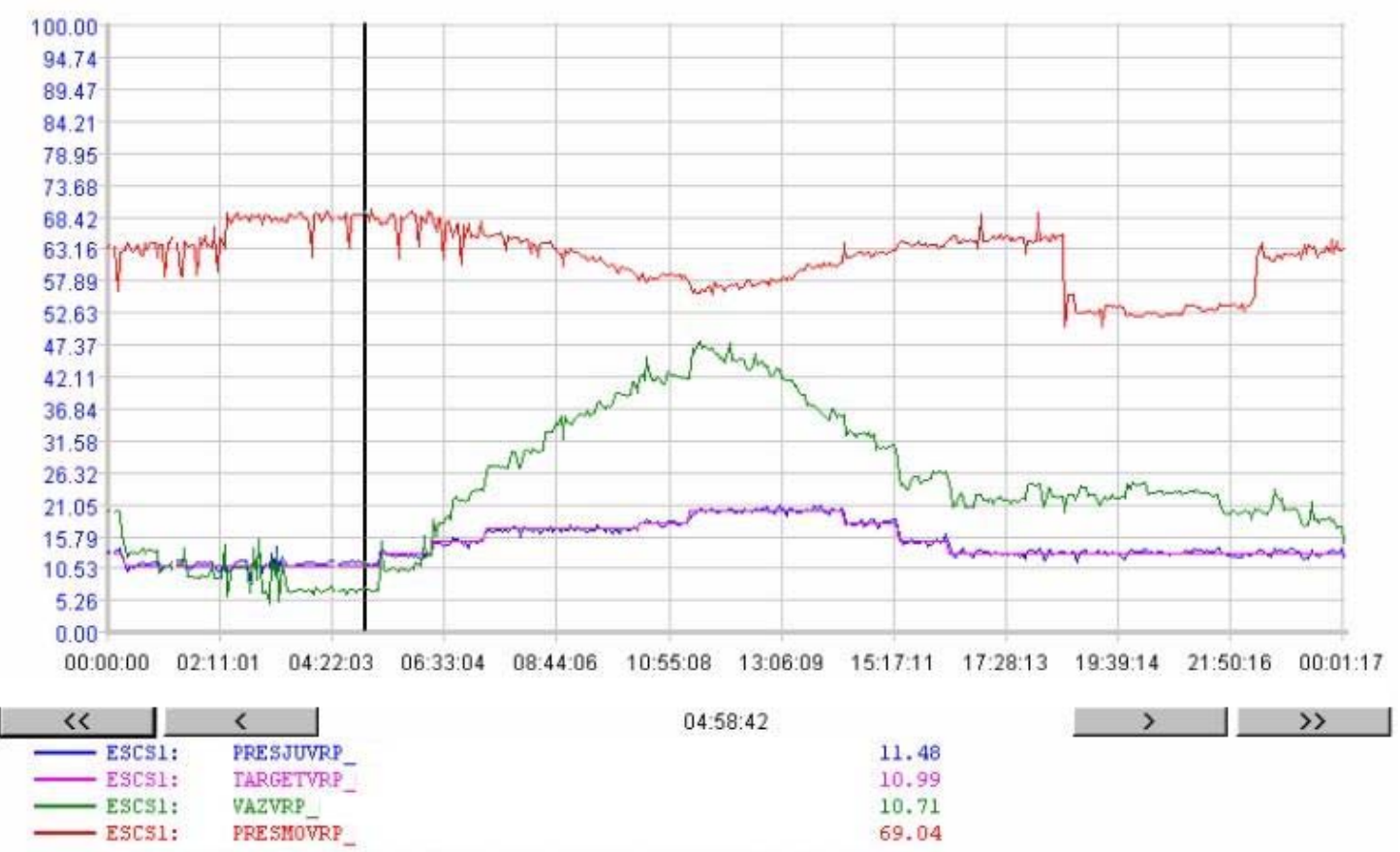

Figura 40 - Gráfico do sistema de supervisão ilustrando as curvas de resposta das variáveis referentes à zona pitométrica "Centro" da cidade de São Vicente - Fonte: Companhia de Saneamento Básico do Estado de São Paulo - Superintendência do Litoral, 2009. 
A Fig. 41 a seguir, ilustra a manutenção da pressão do setor "Praias" da cidade de São Vicente (linha azul escura do gráfico) no valor definido pelo ponto crítico da zona pitométrica (azul clara).

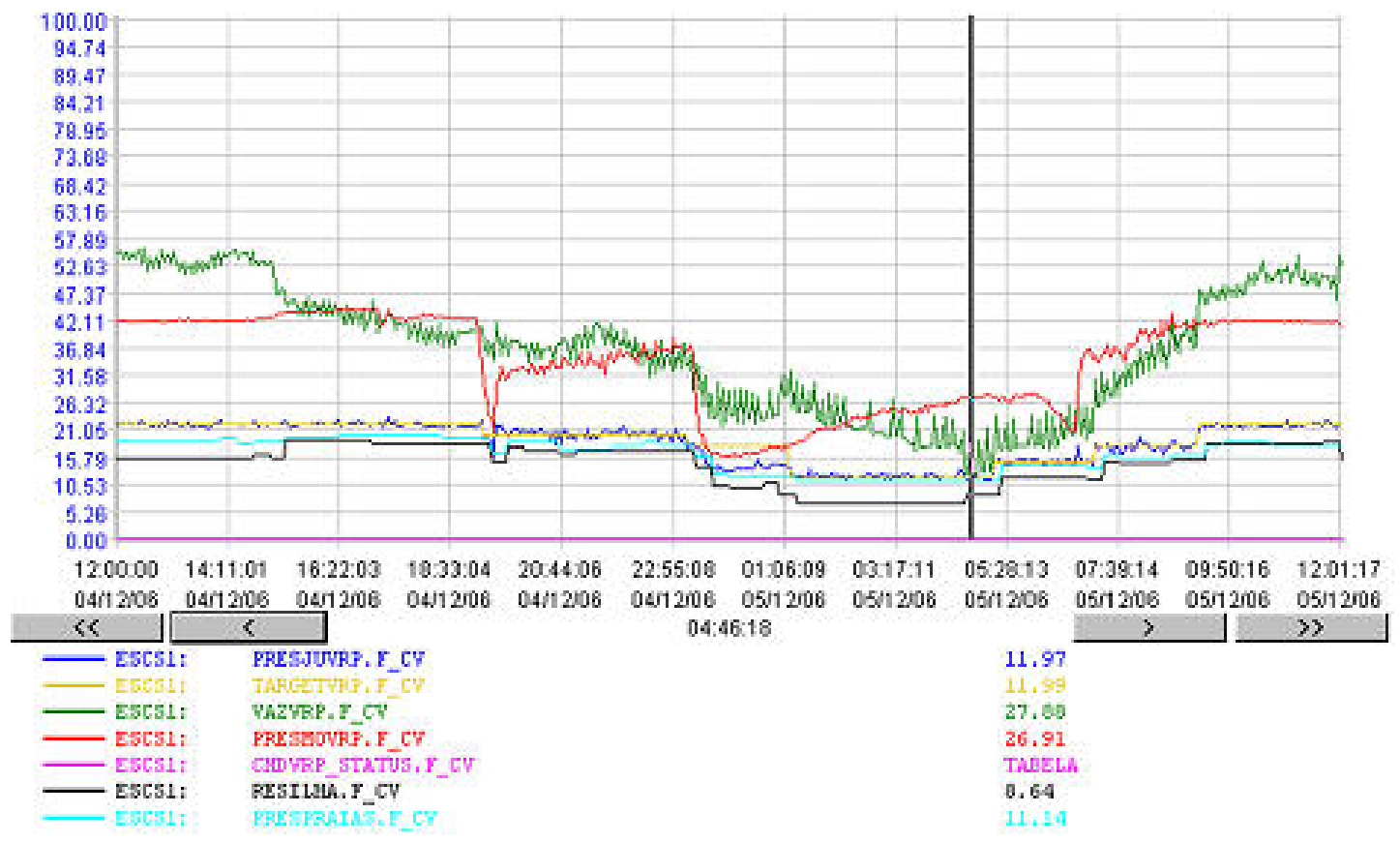

Figura 41 - Gráfico do sistema de supervisão ilustrando as curvas de resposta das variáveis referentes à zona pitométrica "Praias" da cidade de São Vicente - Fonte: Companhia de Saneamento Básico do Estado de São Paulo - Superintendência do Litoral, 2009.

Estima-se, portanto, que com a difusão da implementação de soluções de automação cada vez mais avançadas, em conjunto com a setorização e a consequente melhoria de gestão dos sistemas de abastecimento hídrico de outras cidades da região da Baixada Santista, o índice de perdas hídricas da região chegue, até o ano de 2014, a valores próximos de $24 \%$ (informação verbal) ${ }^{5}$, o que irá inseri-la em patamares mais próximos ao de países que investem a décadas no controle das perdas hídricas como Alemanha (com perdas de 7\%), Japão (10\%), Inglaterra

\footnotetext{
${ }^{5}$ Concedida por Reynaldo Young Ribeiro, Superintendente do Litoral da Unidade de Negócio da Baixada Santista em apresentação no auditório desta superintendência (2009).
} 
(19\%), França (26\%) e Itália (29\%). Estes valores, como exposto em KINGDOM, LIEMBERGER, e MARIN (2006), convergem para o índice de perdas considerado como ideal pelo Banco Mundial, que recomenda patamares abaixo de $25 \%$, considerando o ponto de vista econômico que relaciona o investimento necessário para alcance e manutenção destes índices e o custo marginal de obtenção, tratamento e distribuição da água.

\subsection{Proposições para futuros trabalhos}

A importância da divulgação das soluções e conhecimentos tecnológicos expostos neste trabalho se dá, também, em função da constante e crescente evolução e da aplicabilidade natural destas técnicas na diversidade de configurações, topologias e arquiteturas existentes nas redes de abastecimento de água de outras regiões do Brasil e de outros países.

Neste contexto, deve-se buscar mecanismos que possibilitem o desenvolvimento de pesquisas para este setor, de forma que as soluções desenvolvidas e as técnicas implementadas possam ser difundidas e disponibilizadas, constituindo um set de tecnologias que, se utilizadas corretamente, implicam a melhor gestão de distribuição e controle de perdas dos recursos hídricos.

A evolução das tecnologias é cada vez mais rápida, e o surgimento de novas técnicas e equipamentos proporciona cada vez mais opções para a integração de sistemas de grande porte e para os de proporção reduzida, como os presentes em pequenas cidades. Tecnologias que já são realidade nos sistemas de telecomunicações como o WiMAX e redes de telefonia celular $3 \mathrm{G}$ ainda têm sua aplicabilidade pouco explorada no setor de automação de sistemas 
distribuídos e podem constituir o mote de novas pesquisas quanto à sua utilização na automação de sistemas de abastecimento hídrico.

Além das próprias tecnologias, o desenvolvimento de metodologias aprofundadas que contemplem o planejamento da sua integração com os sistemas pré-existentes, pautadas na priorização das partes mais críticas destes sistemas, constitui campo fértil para a realização de novos trabalhos de pesquisa.

Espera-se que este trabalho forneça indicadores da necessidade de aprofundamento de pesquisas no setor de saneamento e que venha contribuir para a difusão de conhecimentos tecnológicos disponíveis nesta área. 


\section{REFERÊNCIAS BIBLIOGRÁFICAS}

ABCON - Site da Associação Brasileira das Concessionárias Privadas de Serviços Públicos de Água e Esgoto. Disponível em <http://www.abcon.com.br >. Acessado em 02 Ago. 2010.

ANTUNES, S. Como renovar os contratos de concessão de água e esgoto - Revista Consultor Jurídico. São Paulo, 2006. Disponível em <http://www.conjur.com.br/2006-jan12/renovar_contratos_concessao_agua_esgoto> Acesso em: 05 mai. 2011.

ASSOCIAÇÃO BRASILEIRA DE NORMAS TÉCNICAS. Projeto de reservatório de distribuição de água para abastecimento público - NBR 12217. Rio de Janeiro, 1994.

Projeto de rede de distribuição de água para abastecimento público - NBR 12218. Rio de Janeiro, 1994.

A TRIBUNA. País já tem 185,7 milhões de habitantes. Santos: Sistema A Tribuna de Comunicação, Caderno C, 05 nov. 2010.

Já há déficit na oferta de água. Santos: Sistema A Tribuna de Comunicação, Caderno A, 29 jun. 2010.

ANATEL Manual de Projetos Técnicos (SITAR). Disponível em $<$ http://www.anatel.gov.br/Portal/exibirPortalRedireciona.do?caminhoRel=Empresas\&codigo Documento $=60402>$. Acesso em: 14 ago. 2010 . 
ANDRADE, A. A. Emprego de Sistemas Especialistas em Sistemas Supervisórios de Automação Industrial. São Paulo: Dissertação (Mestrado) - EPUSP, 2001.

BAPTISTA, J. M. Como Melhorar a Qualidade em Sistemas de Abastecimento de Água. In: $4^{\circ}$ CONGRESSO DA ÁGUA, 1998, Lisboa (Portugal), Anais eletrônicos... 1998. Disponível em <www.aprh.pt/congressoagua98/files/com/c71.pdf>. Acesso em: 01 nov. 2010.

BARRELLA, W. D. BRUNSTEIN, I. Necessidades e tendências dos sistemas ERP, 2000. In: SIMPÓSIO DE ENGENHARIA DA PRODUÇÃO UNESP, 2000, Bauru. Anais $\begin{array}{llll}\text { eletrônicos... } & \text { Bauru, } & 2000 . & \text { Disponível }\end{array}$ $<$ http://www.simpep.feb.unesp.br/anais7/ana7c.html >. Acesso em: 14 nov. 2010, p.1-3.

BARRETO, G. C. GOMES, D. M. CARDOSO, L. A. GUTIERREZ, L.; PEREIRA, J. A. R. Impacto da setorização no abastecimento de água em áreas urbanas. João Pessoa, PB. Anais... 2006.

BERGE, J. Fieldbuses for Process Control: Engineering, Operation, Maintenance. Carolina do Norte, EUA: The Instrumentation, Systems, and Automation Society, 1998.

BERG, O. BERG, T. HJELMSTAD, J.F. HAAVIK ,S. SKAUG, R. Spread Spectrum in Mobile Communication. Nova Jersey, EUA, IET, 1998.

BRASIL. Secretaria Nacional de Saneamento Ambiental. Sistema Nacional de Informação sobre Saneamento. Brasília, 2004. 
BROTHERS, K. J. A practical approach to water loss reduction. EUA, IWA Water Loss Task Force, Water21 report, 2003.

CARdoso, C. A. GPRS, EDGE, 1XRTT e Porque Não Wi-Fi. Disponível em $<$ www.wince.com.br/cgi-bin/comparacoes/03.idc?IDComparacoes=30> Acesso em: 02 ago. 2010.

CAStro, W. CASSIOLATO, C. AgUiAR, J. R. B. GIMENES, D. R. PAGANO, M. A. O. RIBEIRO, R. T. Gerenciamento de ativos. Controle e Instrumentação, São Paulo, Ano 09, n. 100, 2005.

CERRI, M, L. Enterprise Resource Planning: Um estudo sobre estratégias de implantação. São Paulo: Dissertação (Mestrado) - EP-USP, 2004, p.20-33.

CARMO, C. M. TÁVORA JÚNIOR, J. L. Avaliação da eficiência técnica das empresas de saneamento brasileiras utilizando a metodologia DEA. In: XXXI ENCONTRO NACIONAL DE ECONOMIA, 2003, Porto Seguro, Anais... 2003, p.3-5. Disponível em: < http://www.anpec.org.br/encontro2003/artigos/D32.pdf>. Acesso em: 16 nov. 2010.

COELHO, M. S. Apostila de Instrumentação Digital. São Paulo: SENAI, 2006.

COELHO, M. S. LOBUE F. S. Apostila de Sistemas Digitais de Controle. São Paulo: SENAI, 2006, p.10-50. 
CORRIPIO, A. B. Tuning of Industrial Control Systems. Carolina do Norte, EUA, The Instrumentation, Systems, and Automation Society, 2000.

DI BERNADO, L. Métodos e Técnicas de Tratamento de Água. São Paulo: RIMA, 2005.

EBATA, Y. Development of the Intranet based SCADA (supervisory control and data acquisition system) for power system. In: POWER ENGINEERING SOCIETY WINTER MEETING, 2000, Cingapura, Anais... 2000, p.20-80. Disponível em: $<$ http://ieeexplore.ieee.org/Xplore/login.jsp?url=/iel5/6841/18401/00847593.pdf?arnumber=8 47593>. Acesso em: 08 fev. 2008.

FERNANDES, J. P. Sob pressão - Controle e Instrumentação. São Paulo, ed. 117, 2006, p.50-62.

FILHO, M. Automação no saneamento básico: diferentes necessidades para um mesmo objetivo. Controle \& Instrumentação, São Paulo ed. 61, 2001, p.50-62.

FONSECA, R. F. Modelo para Automação de Sistemas de Abastecimento Hídrico. Dissertação de Mestrado. São Paulo, EP-USP, 2009.

FREIRE, C. C. PEREIRA, J. S. RIBEIRO, M. M. R. KIRCHHEIN, R. LANNA, A. E. L. Aspectos legais da gestão dos recursos hídricos subterrâneos no Brasil. In: CONGRESSO NACIONAL DEL AGUA/ II SIMPOSIO DE RECURSOS HIDRICOS DEL CONO SUR, 1998, Santa Fé. Anais... Santa Fé, Argentina, 1998. v. 4. p. 403-412. 
HAMilton, S. MCKenZIE R. SEAGO, C. A Review of Performance Indicators for Real Losses from Water Supply Systems. Inglaterra, House of Commons Report, 2006.

KINGDOM, B. LIEMBERGER, R. MARIN P. The challenge of reducing non-revenue water in developing countries. EUA, The World Bank Group, Paper nº 8, 2006.

MEDEIROS, A. C. M. FERREIRA, S. B. L. Administração de projetos complexos: ERP na Petrobras, São Paulo, 2003. In: SOUZA, C.A.; SACCOL, A.Z. (Org.). Sistemas ERP no Brasil: teoria e casos. São Paulo, 2003.

NATIONAL LEAKAGE INITIATIVE - National water council standing committee report. Inglaterra, Water Research Center, 1980.

HOUAISS - Dicionário online. Disponível em: <http://houaiss.uol.com.br/>. Acesso em: 06 dez. 2010.

LAMBERT A. O. What Do We Know About Pressure:Leakage Relationships in Distribution Systems? República Checa, Proceedings of the IWA Conference in Brno, 2000. MINISTÉRIO DA SAÚDE - Portaria n 518, de 25 de março de 2004.

MOLlENKAMP, R. A. Controle Automático de Processos. São Paulo, Ebras, 1995. 
MOSSIN, E. A. CAROPRESO, R. T. SILVA A. J. R. Customização com blocos flexíveis. Mecatrônica Atual, São Paulo, v.6, n.36, 2007 p. 60-63.

MURRILL, P. W. Fundamentals of Process Control Theory. Carolina do Norte, EUA, The Instrumentation, Systems, and Automation Society, 1998.

PEREIRA, S. L. Aspectos Sobre Processos Automatizados de Pesagem Rodoferroviária: Uma Proposta de Modernização de Postos em Operação. Tese de Doutorado, EP-USP, 1995.

PEREIRA, S. L. SOUZA, M. Instrumentação inteligente empregada na gestão de sistemas de tratamento de água e análise de benefícios e vantagens. Controle e Instrumentação, São Paulo, Ano 10, n.117, 2006, p.58-66.

PETTERSON, R. Visuals for Information: Research and Practice. California, EUA, Educational Technology Publications, 1989.

PNCDA - Documento técnico de apoio do programa nacional de combate ao desperdício de água: Secretaria Especial de Desenvolvimento Urbano, Brasília, 1999.

SABESP - Companhia de Saneamento Básico do Estado de São Paulo: Memorial descritivo do projeto típico de automação de válvulas redutoras de pressão, SABESP - Superintendência do Litoral, Santos. 2006, pág 07. 
SABESP - Site da Companhia de Saneamento Básico do Estado de São Paulo. Disponível em $<$ http://www.sabesp.com.br/>. Acesso em: 14 nov. 2010.

SACCOL, A. Z. Um olhar crítico sobre modismos em tecnologia da informação: analisando o discurso dos vendedores de pacotes ERP, 2003. In: SOUZA, C.A. SACCOL, A.Z. (Org.). Sistemas ERP no Brasil: teoria e casos. São Paulo: Atlas Paulo, 2003, p.324-347.

SILVEIRA, P. R. \& SANTOS, W.E. Automação e Controle Discreto. São Paulo: Érica, 1998, p.20-24.

SNIS - Sistema Nacional de Informações Sobre Saneamento. Ministério das Cidades, Secretaria Nacional de Saneamento Ambiental. Instituto de Pesquisa Econômica Aplicada IPEA: Diagnóstico dos serviços de água e esgotos, 2002. Brasília, DF. Disponível em $<$ http://www.snis.gov.br/diag_2002_ae.htm>. Acesso em: 01 nov. 2008.

SMAR - Como implementar projetos com Foundation Fieldbus. SMAR Equipamentos Industriais, Sertãzinho, 1998.

SOUZA, M. Proposta de um sistema de gestão empregando instrumentação inteligente e redes de campo na automação do processo de tratamento de água. São Paulo: Dissertação (Mestrado) - EPUSP, 2006.

SVERZUT, J. U. Redes GSM, GPRS, EDGE e UMTS - Evolução a Caminho da Terceira Geração (3G). São Paulo: Érica, 2005. 
THOMTON, J. Managing leakage by managing pressure: a practical approach, EUA, IWA Water Loss Task Force, Water21 report, 2003.

TROJAN, F. MARÇAL, R. RESENDE, L.M. STLADER, C.C. Automação em sistemas urbanos de abastecimento de água: Uma ferramenta para redução de perdas de produção.In: I ENCONTRO ESTADUAL DE ENGENHARIA DA PRODUÇÃO E I SIMPÓSIO DE GESTÃO INDUSTRIAL, 2000, Ponta Grossa. Anais... Ponta Grossa, PR, 2000.

TAMAKI, H. O. SILVA, G. S. GONÇALVES, O. M. A medição setorizada como instrumento de gestão da demanda de água em sistemas prediais: estudo de caso na Universidade de São Paulo. USP. São Paulo, EP-USP 2005, p.65-70.

TSUTIYA, M. T. Abastecimento de Água. Departamento de Engenharia Hidráulica e Sanitária da Escola Politécnica da Universidade de São Paulo. São Paulo, - EP-USP, 2004. 
ANEXOS E APÊNDICES 
ANEXO 1 - Gráfico demonstrando a relação entre o coeficiente de descarga de um orifício de $1 \mathrm{~mm}$ de diâmetro e o número de Reynolds

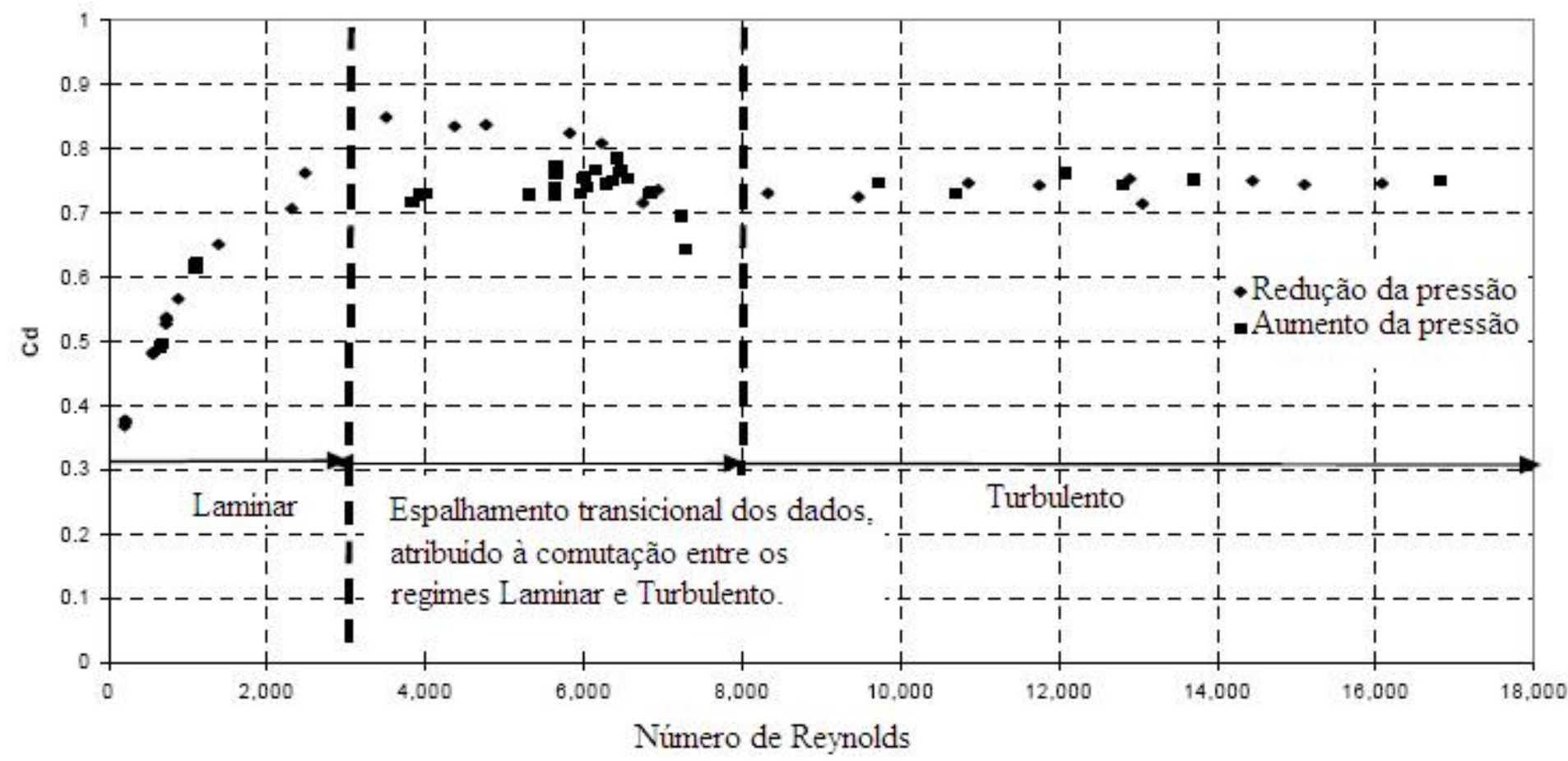

Fonte: LAMBERT A. O. What Do We Know About Pressure:Leakage Relationships in Distribution Systems? República Checa, Proceedings of the IWA Conference in Brno, 2000. 
ANEXO 2 - Detalhamento do bloco AI utilizado na estratégia de controle Foundation.

\section{Al - Entrada Analógica}

\section{Vlsăo Geral}

A bloco de Entrada Analogica obtem $0 s$ dados de entrada do Bloco Transdutor, seleclonado pelo nümero do canal e dlsponibiliza-o para outros blocos funcionals atraves das suas saldas.

\section{Esquematico}

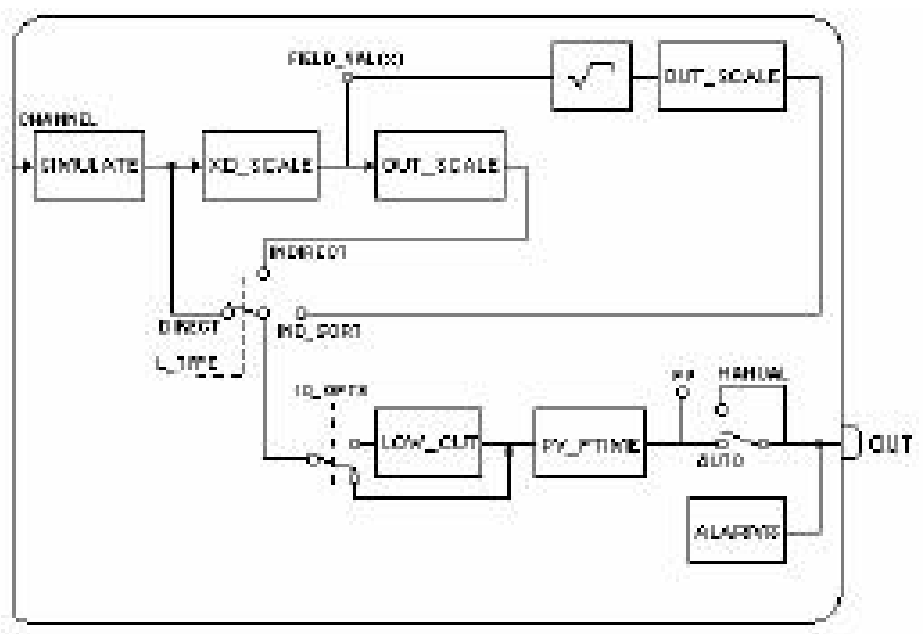

\section{Descriçăo}

O bloco Al e conectado ao bloco transdutor atraves do parametro CHANNEL que deve equiparar-se ao seguinte parametro no bloco transdutor.

- Parametro SENSOR_TRANSDUCER_NUMEER para o TT302

- Parametro TERMINAL__NUMBER parä o IF302

O parametro CHANNEL deve ser setado para 1 (um) se o bloco Al estiver executando no LD302. Náo e necessarila nenhuma configuraçăo no bioco transdutor para conecta-lo ao bloco Al.

A escala do Transdutor (XD_SCALE) e aplicada ao valor do canal para produzir o FIELD_VAL em porcentagem. O Codigo de Unidades de Engenharia e a falxa do parametro XD_SCALE dévem ser apropriados para o sensor do bioco transdutor conectado ao bloco Al, de outra forma, uma Indicaçăo de alame de bloco de configuraçăo de erro sera gerada.

O parametro L_TYPE determina como os valores que passam pelo bloco transdutor serd́o usados dentro do bloco. As opçbes sáo:

- Direct - o vaior do transdutor e passado diretamente para a PV. Por essa razáo, e desnecessarto o uso do OUT_SCALE;

- Indirect - o valor PV e o valor FIELD VAL baseado no OUT SCALE;

- Indirect win Square Root - o väor PV e ralz quadrada do FIELD_VAL baseado no OUT_SCALE.

PV e OUT sempre tem escalas Identicas baseadas no OUT_SCALE

o parametro LOW CUT e uma caracteristica opclonal que pode ser usada para eliminar ruldos proximos a zero de um sensor de fluxo. O parametro LOW_CUT tem uma opçăo correspondente "Low cutort no parametro IO_OPTS. Se o bit "LOW_CUTOFF" for verdadeiro, qualquer saida abalxo do valor de corte (LOW_CUT) sera mudada para zero.

\section{BLOCK_ERR}

O BLOCK_ERR do bloco AJ refetira as seguintes causas:

- Biock Configuration Error - 0 erro de conflguraçấo ocorre quando uma ou mals das segulntes sltuaçбes ocorre:

- Quando os parametros CHANNEL ou L_TYPE tem valores invaldos:

- Quando o XD_SCALE năo tem uma uñidade de engenharia ou falxa adequadas ao sensor do biloco transdutor, 
- Quando o parametro CHANNEL e a configuraçăo HC (DFI302) náo såo compativels.

- Simulate Active - Quando o Simulaçăo esta atva;

- Input Fallure -falha no modulo E/S (DFI302):

- Out of Service - Quando o bloco esta no modo OIS;

- Quando ha falina do sensor de um transmissor.

Modos Suportados

OIS, MAN E AUTO.

status

O bloco Al năo suporta modo cascata. Entấ, o status de salda năo tem um sub-status cascata.

Cuando o valor OUT excede a falxa OUT_SCALE e năo ha uma condiçăo rulm no bioco, ent5o o status OUT sera "uncertain, EU Range Violation".

As seguintes opçbes do STATUS_OPTS aplicam-se, onde Limited refere-se aos ilmites do sensor. (veja as opçdes dos Blocos Funcionnals para malores detalhes sobre cada opça)

- Propagate Fault Forward

- Uncertain if Limited

- bad if Limited

- Uncertain if Man mode 
ANEXO 3 - Detalhamento do bloco SPG utilizado na estratégia de controle Foundation.

\section{SPG - Gerador de Rampas de Setpoint}

\section{Descriçăo}

O bloco gerador de Setpoint e normaimente usado para gerar setpoint para o bloco PID nas aplicaçbles como controle de temperatura, reatores de batelada, etc. Nessas aplicaçఏes, o Setpoint deve seguir um certo modelo en funçăo do tempo.

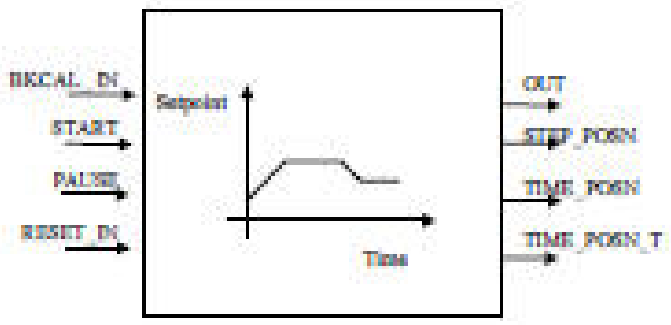

\section{Esquematico}

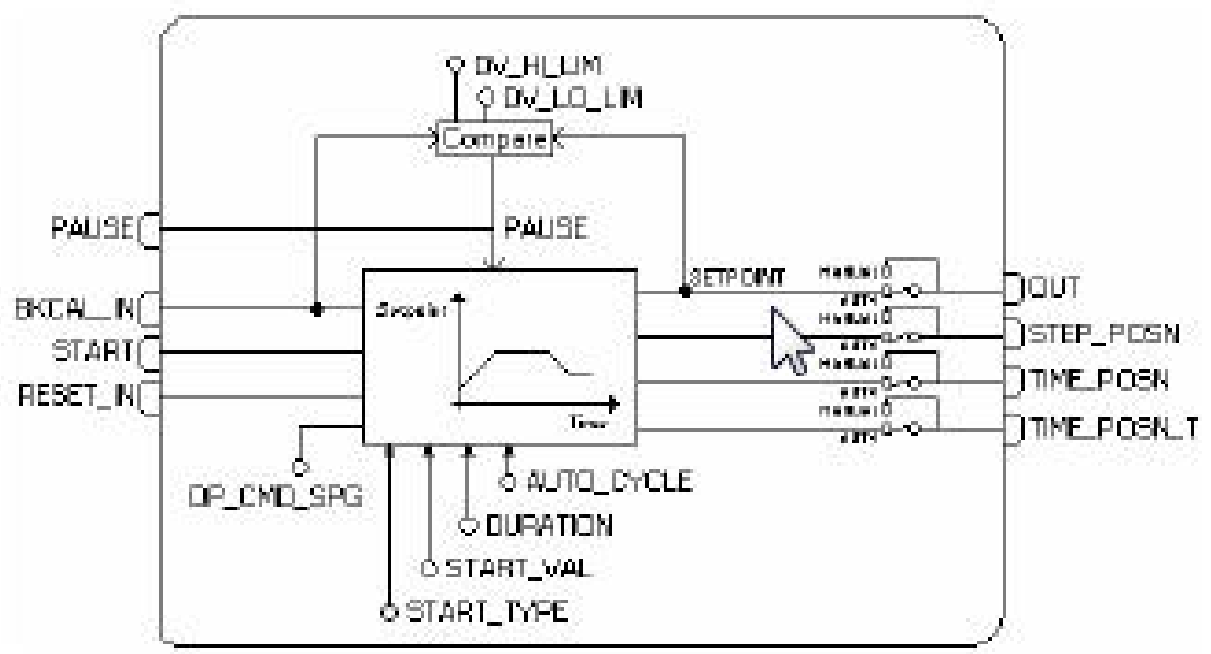

O algoritmo do bloco deve estar de acordo com o seguinte:

1) A curva e determinada por dez segmentos ou passos. Cada segmento e definido por um vaior InIclal [START_VAL] e um tempo de duraçăo [DURATION]. O valor InIcial do proximo segmento determina se o segmento anterlor aumenta, diminul ou mantem-se constante. A curva e dada por dols arranjos paralelos e um parametro para a unidade de tempo:

START_VAL (Valor Iniclal) - Fomado por um arranjo de ate 11 pontos analogicos que definem o valor Iniclal de cada passo, em Unidades de Engenharla.

DURATION (Tempo de Duraçăo) - Formado por um arranjo de ate 10 pontos analogicos que definem a duraçajo, em segundos, de cada passo. Um valor Nulo define o ultimo passo.

TIME_UNITS - Um parametro Intemo Unsigned-8 e usado para especilicar as unidades de tempo usadās no dlsplay.

2) Os dols arranjos definem o valor de Setpoint (ebxo y) em funçáo do tempo (elxo t). Entre dols pontos dados, o Setpoint e calculado por interpolaçao. Como cada segmento e definido por [START_VAL], [DURATION], e [START VAL] -1, un modelo com " $n$ " segmentos necessitara $n+1$ valores hiniclals e n tempos de duraçáo. Como exemplo, 05 dols arranjos definem qa curva mostrada na fig. 1 :

\begin{tabular}{|c|c|c|c|c|c|c|}
\hline & $\mathbf{1}$ & $\mathbf{2}$ & $\mathbf{3}$ & $\mathbf{4}$ & $\mathbf{5}$ & $\mathbf{6}$ \\
\hline OTART_VAL & 25 & 50 & 50 & 100 & 100 & 25 \\
\hline DURATION & 60 & 50 & 120 & 60 & 60 & 0 \\
\hline
\end{tabular}




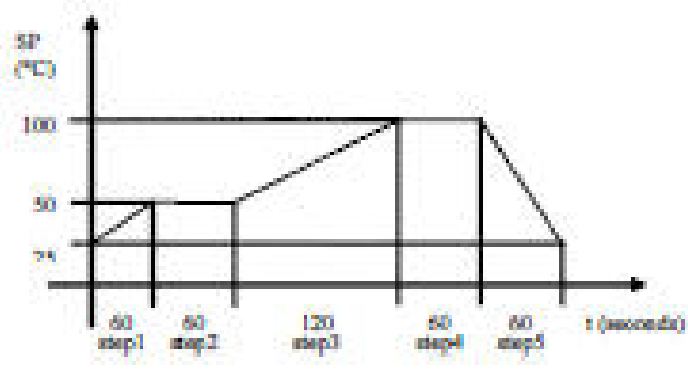

Flo.1-Curva de Betpoint

3) O temporizador e iniciado por uma transiçăo de falso para verdadeiro na entrada START.

4) O temporizador pode ser interrompido a qualquer tempo por uma mudança no sinal discreto PAUSE de falso para verdadeiro. Recomeçara rodando quando PAUSE for setado para falso. 0 PAUSE ng̊ forçara o modo manual.

5) O temporizador e tambem interrompido por um PAUSE provocado por um desvio entre BKCAL_IN e o Setpoint gerado. Se o desvlo exceder DV_HI_LIM ou DV_LO_LIM, um alarme e Indlcadō no DV_HI_ALM ou DV_LO_ALM, respectivamente. Ámbos alarmeśs param o temporizador e retomam a operaçăo normal quando o desvio esta dentro dos limites pre escrttos.

6) O Setpoint esta na coordenada ' $y$ ". enquanto o tempo esta na coordenada " $t$. O valor Sepoint e disponivel para a salda OUT. E tambem disponivel no PRE OUT ate mesmo quando o bloco esta no modo Man. Com o proposito de visualizaçăo, a Unidadé de Engenharla de OUT e dada por OUT_SCALE.

7) Tres saldas Informam o ponto atual da curva:

STEP_POSN - informa o segmento atual ou passo.

TIME_POSN - informa o tempo decorrido desde o iniclo do passo atual.

TIME_POSN_T - Intorma o tempo decorrido desde o inicio da curva.

8) Com o bloco em manual, o operador pode escrever nas saldas STEP_POSN, TIME_POSN e TIME_POSN_T para selecionar um ponto particular na curva. Quando o bioco e chaveadó de voita para äuto, a curva iniclara daquele ponto. O timer e reiniclado pela attvaç5o da entrada START.

9) Com o bloco em manual, o operador pode tambem modificar OUT. Como o valor ajustado pode corresponder a mals que um ponto no modelo ou nenhum, se o operador a (ustar um valor alem dos limites de modelo, o valor OUT val do ustmo valor ajustado para o ponto antes do modo chaveado, seguindo uma rampa detnida pelo BAL_TIME.

10) Outra operaçăo que pode ser felta com o bloco em manual, e avançar ou retomar o tempo atraves dos seguintes comandos do operador (OP_CMD_SPG):

ADVANCE - ajusta o tempo para o iniclo do proximo passo.

REPEAT - ajusta o tempo para o iniclo do passo atual.

11) As saldas podem ser modificadas somente com o bioco no modo manual.

12) $O$ operador pode dar um comando RESET usando OP_CMD_SPG com o bloco em qualquer modo. O temporizador e ajustado para zero, Le., para o iničlo do modelo. Neste caso, o operador deve reiniclar, chaveando a entrada START de falso para verdadelro. Por essa raz\$̊, o bloco pode ser iniclado ate mesmo que O OP_CMD_SPG permaneça com valor RESET.

13) A entrada RESET_IN permite um sinal discreto vindo de outro bloco para ajustar o temponizador para zero.

Enquanto este pardmetro de entrada tem valor TRUE, o bloco permanecera no reset, portanto, estara disponivel para InIclar somente depois que este parametro for para FALSE.

14) Cuando o temporizador atinge o ultimo ponto do modelo, automaticamente retomara para zero (RESET) e reiniclara (START) automaticamente, se o parametro AUTO_CYCLE e ajustado para verdadeiro. 
15) O status de operaçăo e dado pelo parametro SPG_STATE

READY - Quando o modelo esta no iniclo, esperando por um sinal de iniclalizaçăo (START).

ACTIVE - Quando o temporizador esta "on".

PAUSE - Quando o sinal PAUSE parou o temporizador.

AT_END - Quando o tempo atinge o utilimo ponto do modelo.

16) O paramento PAUSE_CAUSE llsta a causa do estado PAUSE:

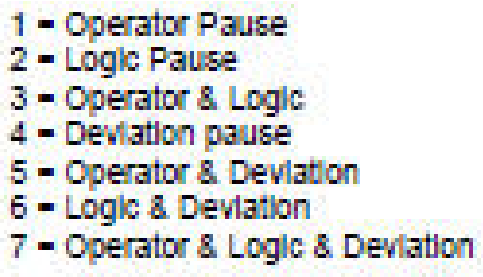

Logic Pause acontece quando os Imites de desvio săo excedidos ou os blocos PID năo estăo no modo Cascata (Cas).

17) Algumas vezes ha um grande desvio entre a varlavel controlada (dlsponivel no BKCAL_IN) e o valor Iniclal da curva. Nesta situaçăo, o temporizador näo pode ser iniclado ou o controle iniciara com uma grande erro. Para evitar esses problemas, o parametro START_TYPE oferece as seguintes opçbes:

a - USE_CURVE- A curva Inicla como especincado pelo START_VAL E DURATION.

b- USE-DUR-A curva Inicla no valor BKCAL_IN e usa a duraç̧⿸丆口 especincada.

c - USE_RATE- A curva inicla no valor BKC $\bar{A} L$ _IN e usa a taxa especificada pelos dols primeiros valores START_VAL E O primelro valor DURATION.

18) A entrada BKCAL_IN pode ser conectada para a salda de um bloco de Entrada Analogica ou para o BKCAL_OUT dē um bloco de controle PID. Se um PID esta conectado, o CONTROL_OPTS do PID deve sër confingurado para usar PV para BKCAL_OUT. Se o PID năo esta no modo Cas, quando o status da operaçăo esta READY (veja 15), a iniclalzaça ocorrera como descrito no tiem 17. Se o status da operaçăo e ACTIVE, o bloco ira para o modo iMan e procede como descrito no Item 9 para tazer o valor de OUT se igualar ao de BKCAL_IN.

Procedimento de Atlvaçato do Algoritmo do Bloco SPG

1) Resetar o bioco. O reset do bloco pode ser felto de duas maneiras: atraves de um puiso na entrada RESET_IN (mudança de valor de 0 para 1 e novamente para 0 ) ou OP_CMD_SPG-RESET_IN. Neste caso o algonttmo esta parado e pronto para iniclalizar a curvà, enţ̄o o parametrō SPG_STATE-READY.

2) Iniciar o algorttmo. A Iniclalizaçăo do algoritmo e realzada atraves de um puso na entrada START. Neste momento o algoritmo começa a executar a curva, entâo SPG_STATE-ACTIVE.

3) O algortmo pode ser interrompldo momentaneamente a qualquer momento de execuçăo da curva (Pausa), atraves da entrada PAUSE-1. Neste caso o SPG_STATE-PAUSE e 0 parametro PAUSE_CAUSE indica a condlçăo que ele fol parado.

4) Quando for detectado o fim do algortmo, o SPG_STATE-AT_END.

5) Para relniclar o algorltmo e necessario voltar ao passo 1.

\section{BLOCK_ERR}

O BLOCK_ERR do bloco SPG refletra as seguintes causas:

- Elock Configuration Emor - o enro de configuraçâo ocorre quando o parametro START_TYPE tem um valor invalldo;

- Out of Service - ocorre quando o bloco esta no modo ors.

\section{Modos Suportados}

OIS, IMAN, MAN E AUTO.

\section{Status}

Se o status de BKCAL_IN e bad e a opçăo Use uncertain do STATUS_OPTS e alustada para verdadelro, 0 desvio dos alarmes năo sáo conslderados.

Se o status de qualquer entrada tornar-se bad ou uncertain e a opçăo respecttva Use bad ou Use uncertain do STATUS_OPTS năo esttver setada, o modo actual do bloco sera forçado para manual. 
ANEXO 4 - Detalhamento do bloco ISEL utilizado na estratégia de controle Foundation.

\section{ISEL - Seletor de Entrada}

\section{Descriçăa}

O bloco Seletor de Sinal fornece a seleça de ate quatro entradas e gera uma salda baseada na açäo configurada. Este bloco recebe nomalmente suas entradas de um All ou outro bloco, e náo diretamente de um transdutor. Em adiç5o ao sinal de seleç5o, o bloco pode tambem fazer selecalo de maximo, minimo, melo, medla e primelro valor bom (first good). Com a combinaçăo de opçdes dos parametros de configuraç5o, o bloco pode funclonar como uma chave rotatoria de posiçato, ou uma seleçáo de priondade valida baseada no uso do parametro Tirst good e o parametro DISABLE_n.

Como uma chave, o bloco pode receber informaçăo chaveada de ambas entradas conectadas ou uma entrada de operador. O bloco pode tambem suportar o concelto de uma seleçăo media. A logica e fornecida por melo de sinals incertos e ruins, em conjunto com açbes configuradas. A apilcaç5o pretendida deste bloco e fomecer seleç5o de sinal de controle no caminho direto somente. Como năo fol desenvolvido para receber sinals da salda de um controlador, náo suporta nenhum caiculo de retorno.

O algoritmo tem as seguintes açbes escolnidas pelo parametro SELECT_TYPE:

- Max - seleciona o maximo de todas entradas good conectadas

- Min - seleciona o minimo de todas as entradas good conectadas

- Mid - seleciona o valor medio de todas as entradas good conectadas, se entradas menores que MIN_GOOD forem conectadas, entăo um erro e gerado. Um codlgo de erro tambem e gerado se valores menores que MIN_GOOD tem status good. Embora a configuraç5o normal para esta caracteristica sela com tres sinals, o bioco gerara uma medla de dols se quatro sinals estăo connigurados ou a medla de dols se tres sinals estắ conffgurados e o status bad e passado em uma das entradas.

- First Good - determina a primelra entrada good encontrada baseada na avalaçăo ascendente das entradas, de IN_1 para IN_4.

- Avg - calcula a media de todas as entradas good conectadas, se menos que duas entradas eståo conectadas, entấo aluste a saida igual a entrada e sera gerado um codlgo de erro. Um codigo de erro e tamben gerado se menos que MIN_GOOD entradas tiverem um status good.

O processamento do bloco e como se segue:

- Se DISABLE_n e verdadeiro, entăo a entrada respectiva IN_n năo sera usada.

- As entradas que possuem status bad sáo ignoradas. Processa a opç5o incerta.

- MIN_GOOD especifica o nümero minlmo de entradas good para o status de OUT ser good. Se nalo ha entradas boas, ou o numero de entradas boas e menor que MIN_GOOD, entâo o status de OUT sera Bad e o valor de SELECTED sera zero.

- Para a opçăo "Medla" ("Avg"), o status de OUT e ajustado para o plor de entradas consideradas, entăo a media das entradas usadas e calculada, se nerhuma e usada, entăo o status da salda e bad.

- Quando SELECT_TYPE e "MIar, "First Good", "Max,, ou "Min", o status de OUT sera o status da entrada selecionada. A opç50 "Flrst Good" inicla na primeira entrada, ent5o, depols, a segunda, ate encontrar una entrada cujo DISABLE_n năo esta setado e seu status e Good, e ent5o transfere este vaior para a salda do bloco.

- Opcionaimente, a entrada OP_SELECT seleciona uma deteminada entrada para a saida. Esta opçăo tem prioridade sobre o calculo de SELECT_TYPE. Se OP_SELECT e malor que zero, a salda OUT segura a entrada selecionada por OP_SELECT, anulando a seleçấo de SELECT_TYPE.

- SELECTED e a segunda salda que indicara qual entrada fol selecionada pelo algoritmo para todas as opçbes de SELECT_TYPE, exceto "Avg", quando reflete o numero de entradas usadas na medla. A saida selecionada SELECTED sempre tem um status good, a menos que o bloco esteja fora de serviço.

BLOCK_ERR

O ELOCK_ERR do bioco ISEL refietira as seguintes causas:

- Block Configuration Error $\rightarrow$ erro de confinguraçăo ocorre quando o parametro SELECT_TYPE tem um valor Invalido;

- Out of Service-ocorre quando o bloco esta no modo o/s.

Modos Suportadios

OIS, MAN E AUTO. 
Status

O status de OUT sera uma copla da entrada selecionada, mas se a salda e uma medla de entradas, o status sera Good Non-cascade - Non-specinc.

\section{Esquematico}

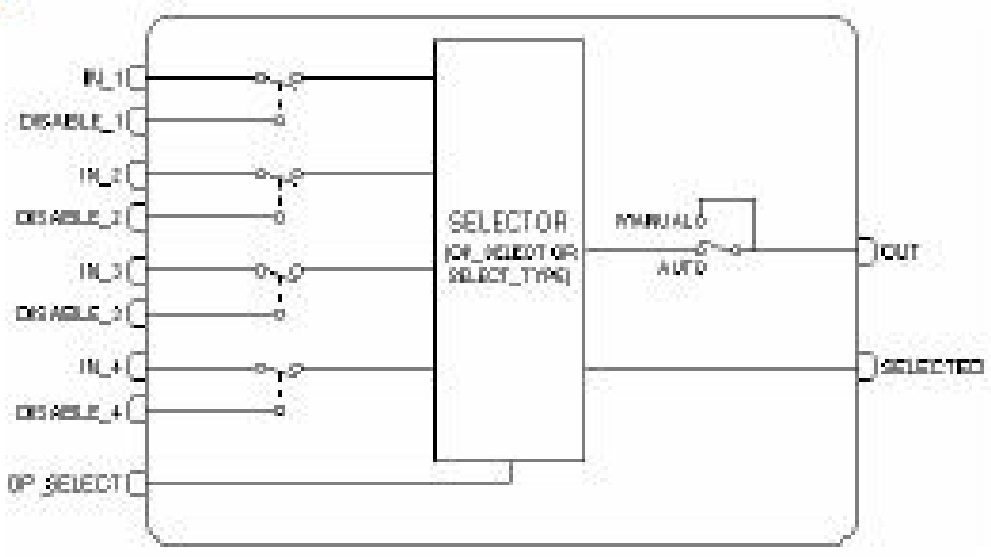


ANEXO 5 - Planilha de compartilhamento de informações do módulo de controle operacional ilustrando a disposição das informações operacionais obtidas a partir do sistema de supervisão.

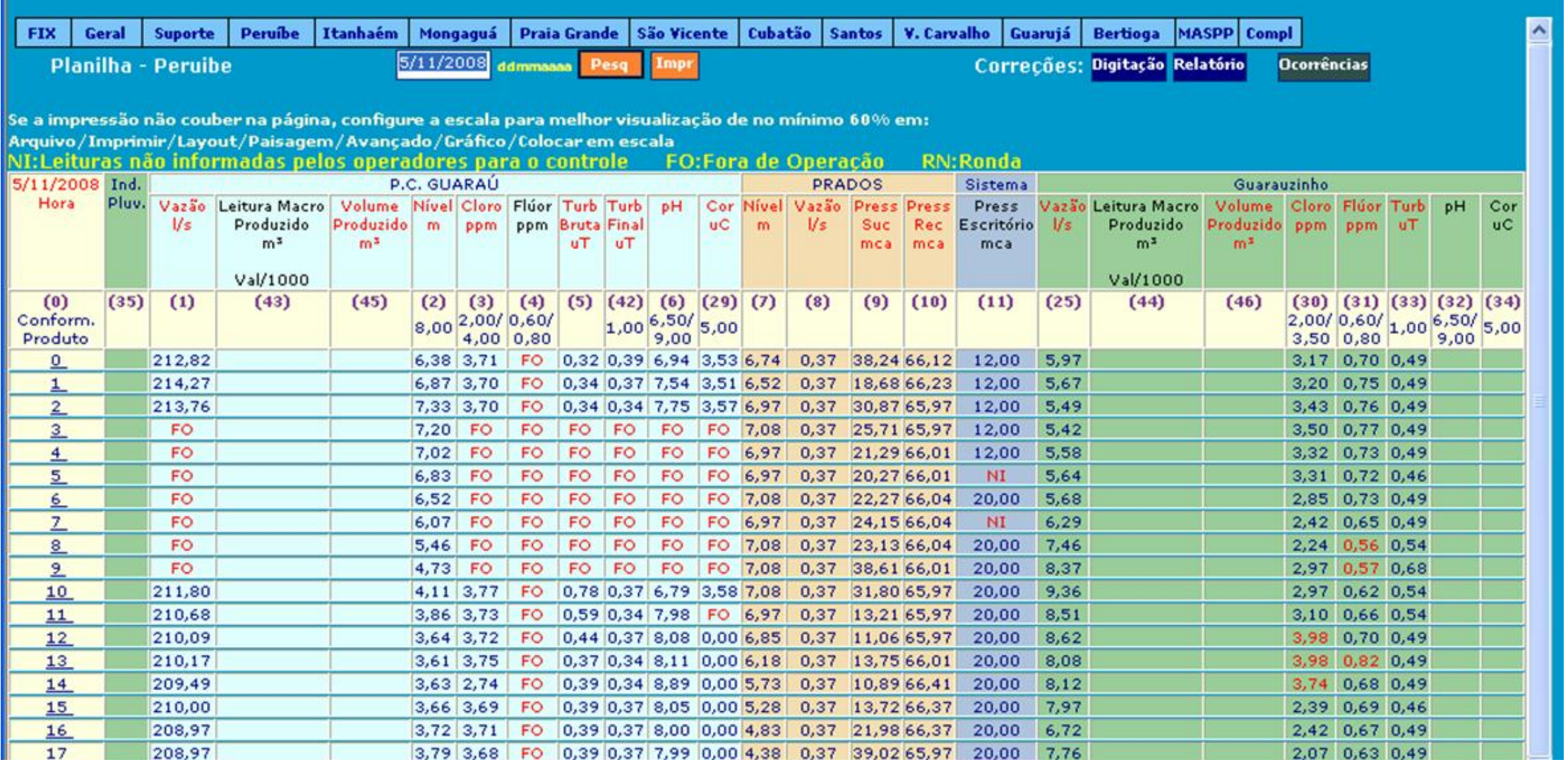

Fonte: Sistema Integrado de Compartilhamento e Gestão de Informações de Abastecimento Hídrico da SABESP - Superintendência do Litoral, 2008. 
ANEXO 6 - Planilha do módulo de análise e solução de problemas de perdas ilustrando a disposição das informações sobre os limites de operação dos principais pontos do sistema.

\section{Definiçã́o de Limites de Controle}

\begin{tabular}{|c|c|c|c|c|c|c|c|c|c|c|c|c|}
\hline \multicolumn{13}{|c|}{$\begin{array}{c}\text { Implantaçäo: 2/1/2008 Período: } 1 / 1 / 2007 \text { à 31/1/2007 } \\
\text { Ponto: Nivel R1 (TXT1) }\end{array}$} \\
\hline Gráfico & $\begin{array}{l}\text { Limite } \\
\text { Superior } \\
\text { Controle }\end{array}$ & Limite B+ & Limite A+ & Limite Médio & Limite A- & Limite B- & $\begin{array}{l}\text { Limite } \\
\text { Inferior } \\
\text { Controle }\end{array}$ & $\begin{array}{l}\text { Meta } \\
\text { Técnica }\end{array}$ & $\begin{array}{l}\text { Auto } \\
\text { comelaçäo }\end{array}$ & Observação & Editar & Exc \\
\hline DESYIO & 0,79 & 0,00 & 0,00 & 0,55 & 0,00 & 0,00 & 0,30 & 0,00 & 0,000000 & * & $\checkmark$ & ぬ \\
\hline X-BARRA-S & 3,56 & 3,44 & 3,33 & 3,22 & 3,10 & 2,99 & 2,88 & 0,00 & 0,000000 & * & $r$ & \\
\hline \multicolumn{13}{|c|}{$\begin{array}{c}\text { Implantaçăo: 4/12/2007 Período: } 1 / 12 / 2006 \text { à 31/12/2006 } \\
\text { Ponto: Nivel R1 (TXT1) }\end{array}$} \\
\hline Gráfico & $\begin{array}{l}\text { Limite } \\
\text { Superior } \\
\text { Controle }\end{array}$ & Limite B+ & Limite A+ & Limite Médio & Limite A- & Limite B- & $\begin{array}{l}\text { Limite } \\
\text { Inferior } \\
\text { Controle }\end{array}$ & $\begin{array}{l}\text { Meta } \\
\text { Técnica }\end{array}$ & $\begin{array}{l}\text { Auto } \\
\text { comelaçäo }\end{array}$ & Observação & Editar & Exc \\
\hline DESYIO & 0,79 & 0,00 & 0,00 & 0.55 & 0,00 & 0,00 & 0,30 & 0,00 & 0,000000 & * & $\checkmark$ & ぬ \\
\hline X-BARRA-S & 3,86 & 3,74 & 3,63 & 3,52 & 3,41 & 3,29 & 3,18 & 0,00 & 0,000000 & * & $v$ & \\
\hline \multicolumn{13}{|c|}{$\begin{array}{c}\text { Implantação: 6/11/2007 Período: } 1 / 1 / 2007 \text { à } 6 / 1 / 2007 \\
\text { Ponto: Nivel R1 (TXT1) }\end{array}$} \\
\hline Gráfico & $\begin{array}{l}\text { Limite } \\
\text { Superior } \\
\text { Controle }\end{array}$ & Limite B+ & Limite A+ & Limite Médio & Limite A- & Limite B- & $\begin{array}{l}\text { Uimite } \\
\text { Inferior } \\
\text { Controle }\end{array}$ & $\begin{array}{l}\text { Meta } \\
\text { Técnica }\end{array}$ & $\begin{array}{l}\text { Auto } \\
\text { comelaçäo }\end{array}$ & Observação & Editar & Exc \\
\hline DESYIO & 0,87 & 0,00 & 0,00 & 0,60 & 0,00 & 0,00 & 0,33 & 0,00 & 0,000000 & * & $r$ & Һ \\
\hline X-BARRA-S & 3,41 & 3,28 & 3,16 & 3,03 & 2,91 & 2,79 & 2,66 & 0,00 & 0,000000 & * & 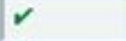 & \\
\hline
\end{tabular}

Fonte: Sistema Integrado de Compartilhamento e Gestão de Informações de Abastecimento Hídrico da SABESP - Superintendência do Litoral, 2008. 
ANEXO 7 - Planilha do módulo de dados de análises químicas, ilustrando a disposição das informações obtidas a partir dos dados dos analisadores de processo, em comparação com os dados obtidos por meio de análises laboratoriais.

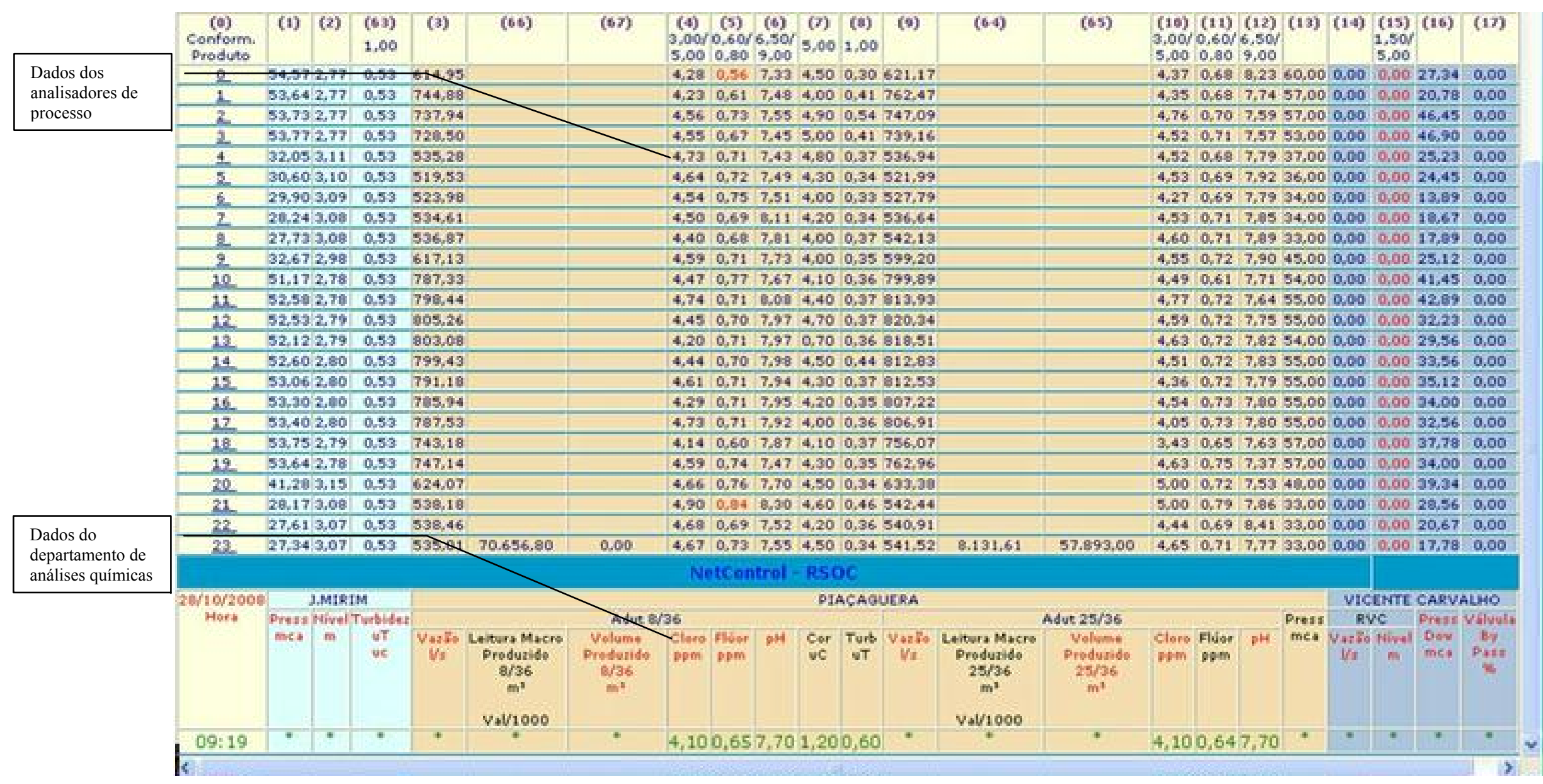

Fonte: Sistema Integrado de Compartilhamento e Gestão de Informações de Abastecimento Hídrico da SABESP - Superintendência do Litoral, 2008. 
APÊNDICE 1 - Quadro comparativo entre os protocolos Profibus PA e Foundation Fieldbus.

\begin{tabular}{|c|c|c|}
\hline & Profibus PA & Foundation Fieldbus \\
\hline Taxa de transferência & $31,25 \mathrm{kbps}$ & $31,25 \mathrm{kbps}$ \\
\hline $\begin{array}{l}\text { Número máximo de estações } \\
\text { por segmento }\end{array}$ & 32 estações & 32 estações \\
\hline $\begin{array}{l}\text { Capacidade de } \\
\text { endereçamento na rede }\end{array}$ & 126 endereços & 240 endereços \\
\hline $\begin{array}{l}\text { Gerenciamento da } \\
\text { comunicação }\end{array}$ & Multimestre & $\begin{array}{l}\text { Link Active Schedule } \\
\text { redundante }\end{array}$ \\
\hline Apresenta interoperabilidade & Sim & Sim \\
\hline $\begin{array}{l}\text { Apresenta possibilidade de } \\
\text { programação remota }\end{array}$ & Sim & Sim \\
\hline $\begin{array}{l}\text { Distribuição das funções de } \\
\text { controle }\end{array}$ & $\begin{array}{l}\text { Dependente de um } \\
\text { controlador central (CLP) } \\
\text { para execução dos algoritmos } \\
\text { de controle }\end{array}$ & $\begin{array}{l}\text { O algoritmo de controle de } \\
\text { uma determinada malha pode } \\
\text { estar localizado, de forma } \\
\text { redundante, em vários } \\
\text { dispositivos da malha de } \\
\text { controle }\end{array}$ \\
\hline
\end{tabular}


APÊNDICE 2 - Diagrama ilustrando a relação entre as camadas de um protocolo padronizadas pelo modelo ISO/OSI e as utilizadas pelo protocolo Foundation Fieldbus. Elaborado com base no diagrama exposto por BERGE (1998).

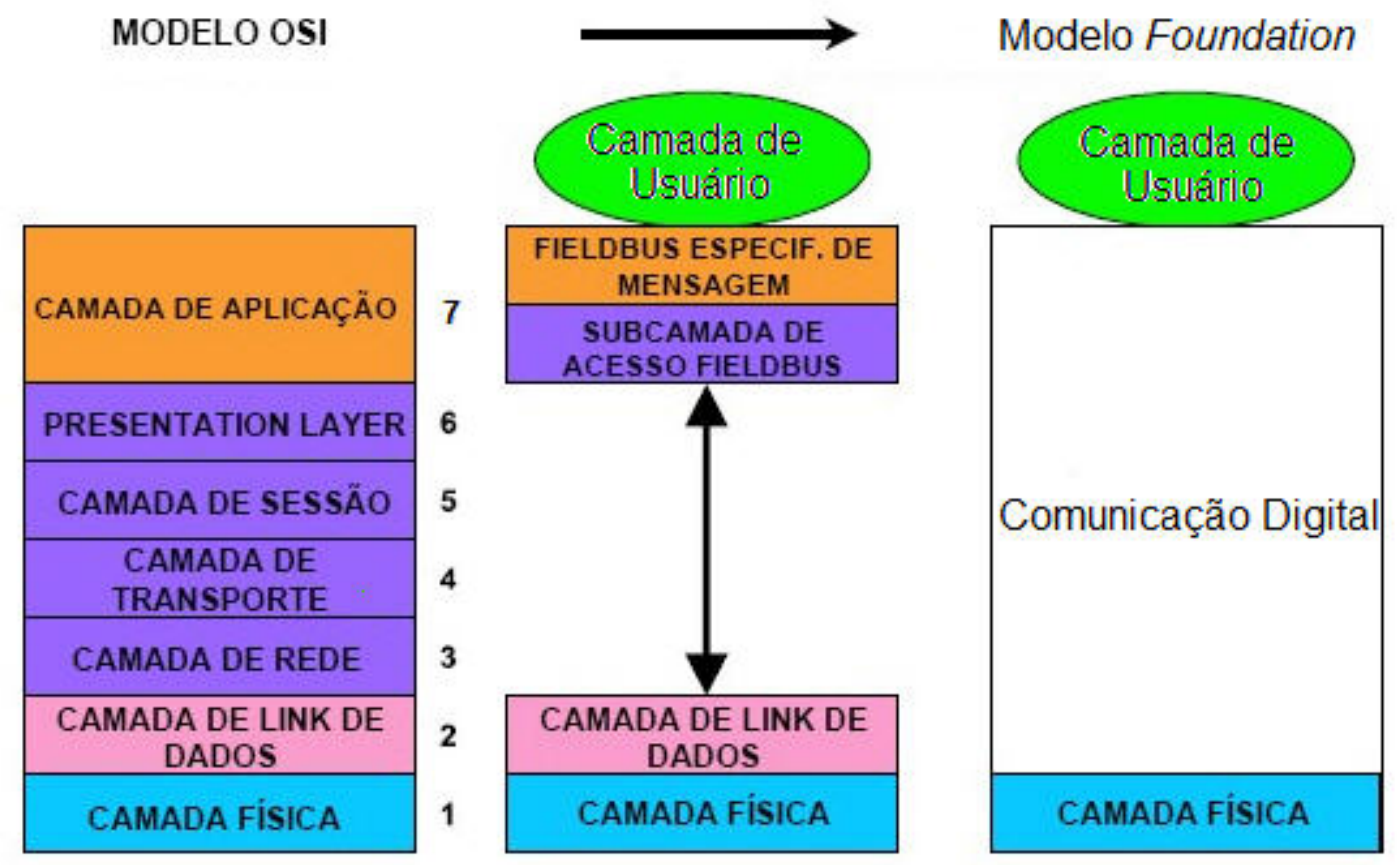


APÊNDICE 3 - Esquema ilustrando a implementação dos padrões físicos contemplados no modelo Foundation em diferentes topologias de rede.

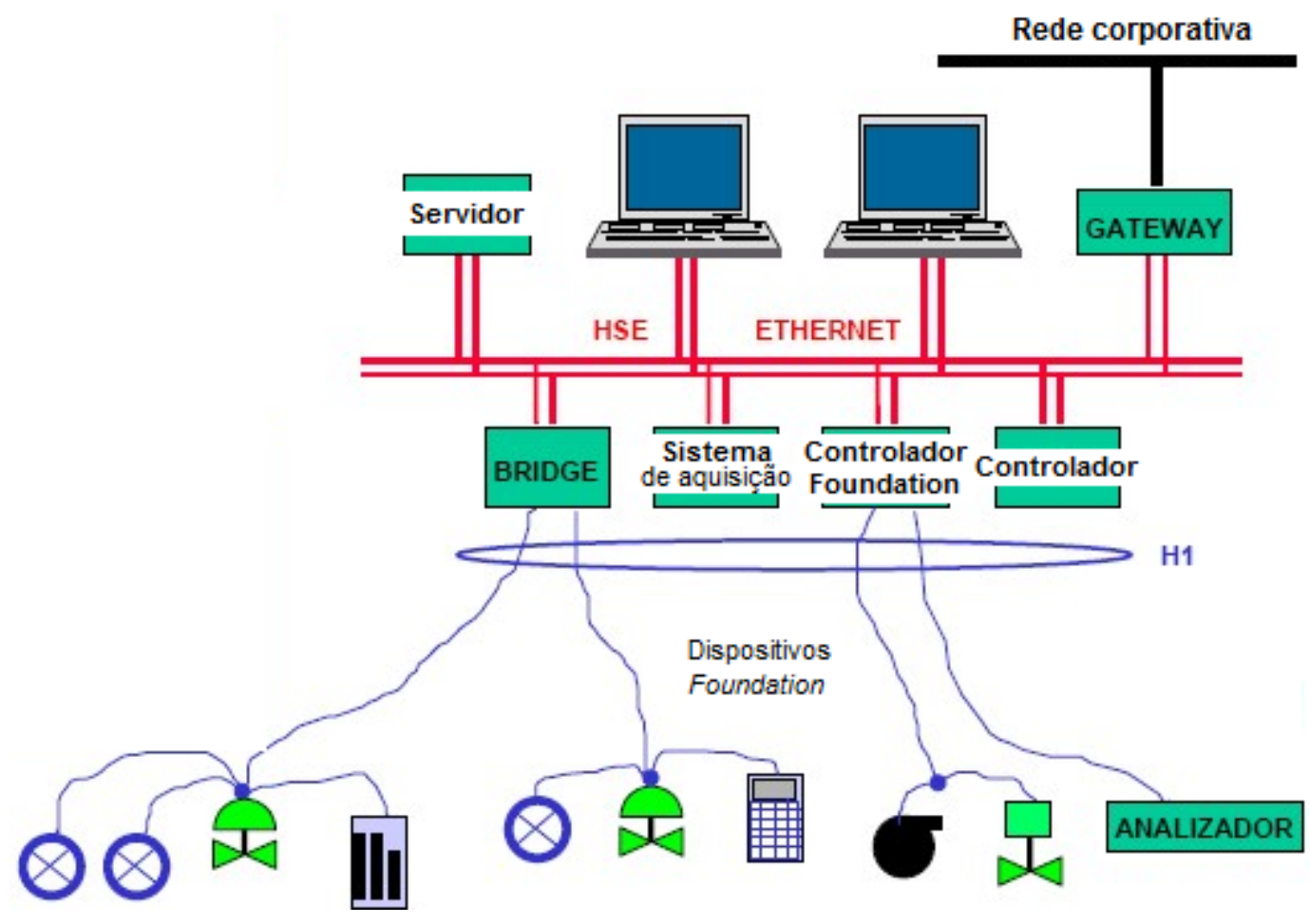


APÊNDICE 4 - Regras de interconexão entre instrumentos Foundation Fieldbus.

a) Um instrumento Foundation deve ser capaz de se comunicar entre os seguintes números de equipamentos:

- Entre dois e trinta e dois instrumentos numa ligação sem segurança intrínseca e alimentação separada do barramento de comunicação;

- Entre dois a seis instrumentos alimentados pelo mesmo barramento de comunicação numa ligação com segurança intrínseca;

- Entre um e doze instrumentos alimentados pela mesma fiação de comunicação numa ligação sem segurança intrínseca. Esta regra, no entanto, não impede a ligação de mais instrumentos do que o especificado.

b) Um barramento que contenha o número máximo de instrumentos estipulados na regra disposta no item (a), e operando na velocidade de $31,25 \mathrm{kbit} / \mathrm{s}$, não deve ter, entre a soma dos trechos de cabeamento que componham a topologia implementada, o comprimento maior que $1.900 \mathrm{~m}$.

c) O número máximo de repetidores para a regeneração do sinal entre dois instrumentos não pode exceder a quatro sob risco de degradação do sinal de informação. 
d) Falhas em qualquer elemento de comunicação ou derivação, com exceção de curtocircuito ou baixa impedância, não deverá prejudicar a comunicação por mais de $1 \mathrm{~ms}$.

e) Deve ser respeitada a polaridade em sistemas que utilizem pares trançados, seus condutores devem ser identificados e esta polarização deve ser mantida em todos os pontos de conexão.

f) Em sistemas com meio físico redundante:

- Cada canal deve atender às regras de configuração de redes;

- Não deve existir um segmento não redundante entre dois segmentos redundantes;

- Os repetidores também deverão ser redundantes;

- Os números dos canais Fieldbus deverão ser mantidos na configuração lógica, dos dispositivos de controle do protocolo Foundation.

g) A malha que reveste os cabos do barramento não deverá ser utilizada como condutor de energia. 
APÊNDICE 5 - Requisitos físicos e elétricos mínimos para cabos utilizados na interligação de instrumentos em uma rede Foundation Fieldbus.

- Z0 em fr $(31,25 \mathrm{kHz})=100 \Omega \pm 20 \%$;

- Atenuação máxima em 1,25 fr (39kHz) = 3.0 dB/km;

- Máxima capacitância não balanceada da blindagem $=2 \mathrm{nF} / \mathrm{km}$;

- Resistência DC máxima (por condutor) = $22 \Omega / \mathrm{km}$;

- Atraso máximo de propagação entre 0,25 fr e 1,25 fr = $1.7 \mu \mathrm{s} / \mathrm{km}$;

- Área seccional do condutor (bitola) $=$ nominal $0,8 \mathrm{~mm}^{2}$;

- Cobertura mínima da blindagem deverá ser maior ou igual a 90\% de toda a extensão do cabo. 
APÊNDICE 6 - Esquema ilustrando as regras relacionadas ao comprimento dos cabos, impostas para cada topologia aplicável a projetos baseados em instrumentos Foundation Fieldbus.

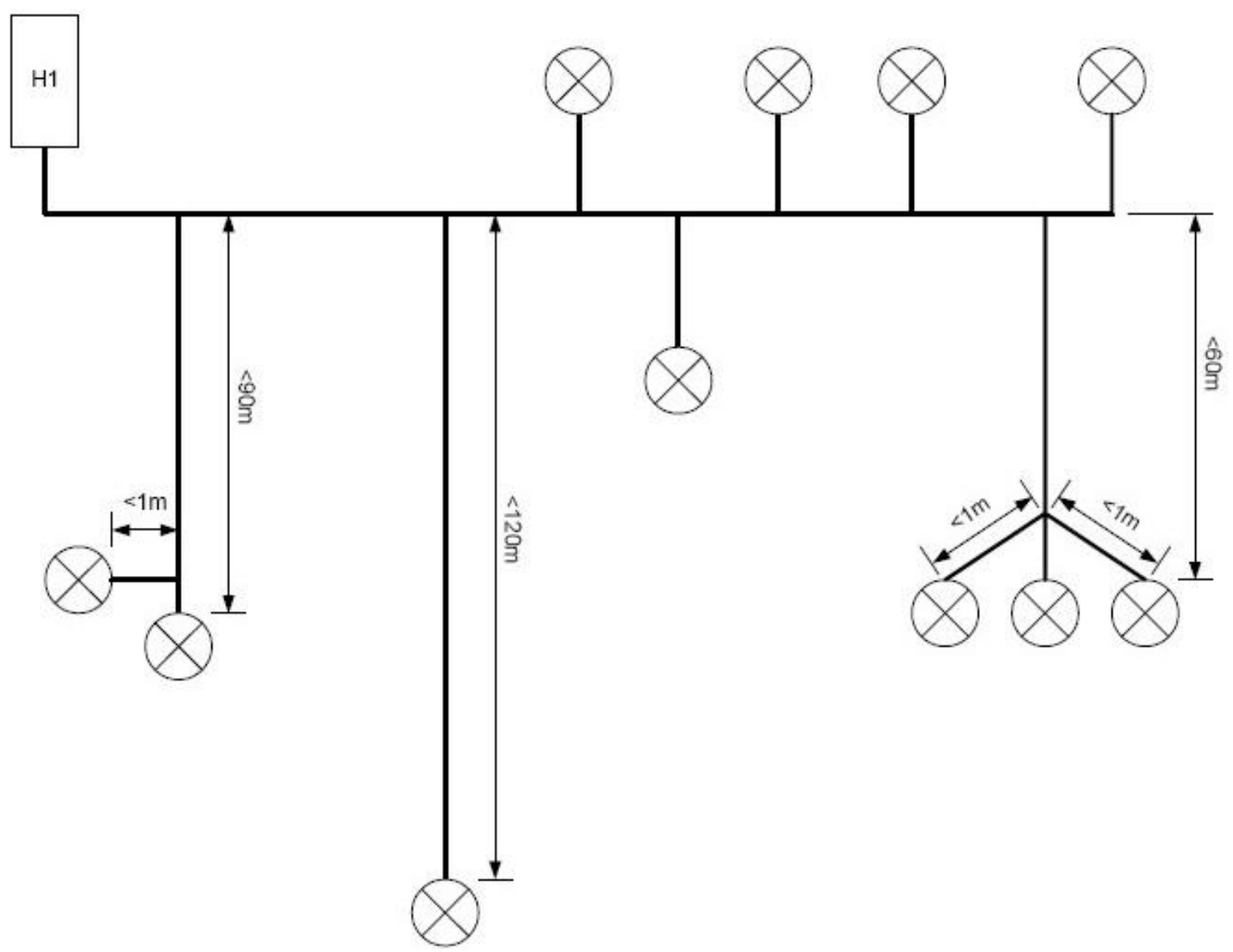


APÊNDICE 7 - Especificações do protocolo Foundation relacionadas à camada link de dados.

- Formas de acesso à rede por meio de passagem de token. O token é um termo relacionado à vez de um determinado equipamento utilizar o barramento para exercer a comunicação. Quando termina de enviar as mensagens, o equipamento retorna o token para o Link Active Scheduler (LAS), que se trata de uma função exercida por um equipamento responsável pelo gerenciamento da comunicação da rede Foundation. O LAS mantém a concessão de transmissão por meio do barramento, transmitindo-a a um dispositivo da rede quando solicitado.

- Modelo produtor-consumidor, no qual um equipamento pode produzir ou consumir variáveis e informações que são transmitidas através da rede usando o modelo de acesso supra descrito. O produtor disponibiliza as variáveis e informações em buffers e qualquer estação pode acessar a estes dados durante o período em que detiver a concessão de comunicação na rede. Por exemplo: um controlador consome a variável de processo produzida por um sensor, e produz a saída consumida por um atuador. Segundo COELHO e LOBUE (2006) este modelo consiste em um dos mais eficientes para transferência de dados entre vários dispositivos.

- Gerenciamento da troca de dados, garantindo a execução de aplicações de tempo crítico. Esta característica é concretizada por regras estabelecidas no LAS, que coordena o tempo necessário para cada transação na rede, garantindo o período de troca de dados e as interrupções necessárias às operações críticas. 
- Sincronização de tempo por meio de mecanismos que produzem referências temporais na rede e que garantem a sincronização das atividades de processo.

- Endereçamento que pode ser conferido a um grupo de estações, a uma única estação ou até a uma variável. Esta flexibilidade de endereçamento permite otimização do acesso às mensagens.

- Estabelecimento de um macro cycle. Um importante aspecto quando se trabalha com sistemas Fieldbus, consiste no tempo gasto para que todos os dispositivos do barramento possam disponibilizar seus parâmetros de controle e monitoração. Este tempo, que é configurável e tipicamente encontra-se entre 80 e 300 milissegundos, deve ser minimizado tanto quanto possível, pois pode comprometer o período de atualização dos links entre os blocos funcionais que operam na malha de controle em relação à velocidade do processo. A atualização destes links é feita a cada macro cycle e o tempo relacionado a este processo pode variar dependendo dos tipos de instrumentos presentes no barramento e dos seus parâmetros para a publicação. Num projeto onde os tempos críticos relacionados à atualização dos valores dos dispositivos são muito pequenos, da ordem de milissegundos, deve-se verificar o tempo do macro cycle cerificando-se de que este não é o excedido, o que comprometeria a dinâmica de controle do processo. O tempo de ciclo em um barramento Foundation é dividido em tráfego operacional (cíclico), onde são publicadas as informações de controle e tráfego acíclico, onde são publicadas informações adicionais, como por exemplo, dados de monitoração ou atuações provenientes do sistema de supervisão. O tempo de tráfego cíclico pode ser determinado pela seguinte equação: 


$$
\text { Tcíc. }(\mathrm{s})=\sum \mathrm{T} \text { ex.bl }+\sum \mathrm{Nlex} . \mathrm{x} 30 \times 10^{-3}
$$

Onde:

Tcíc.: Tempo de tráfego cíclico;

Tex.bl. : Tempo de execução dos blocos funcionais de cada dispositivo;

Nlex: Número de links externos (entre os dispositivos).

O tempo total do macro cycle é definido por:

$$
\text { Tmc(s) = Tcíc. }+2,3 \times \text { Tcíc. }
$$

Onde:

Tmc: Tempo total do macro cycle.

- Estabelecimento de uma comunicação sequencial por meio do controle de prioridades de transmissão estabelecidas pelo LAS. A propriedade de estabelecimento das prioridades de comunicação só pode ser exercida por dispositivos que possuem a capacidade de tornar-se LAS. No protocolo Foundation Fieldbus estes dispositivos são conhecidos como Link Masters. Uma rede Foundation pode ter vários dispositivos com esta propriedade, operando de forma redundante e assumindo o controle do barramento caso o Link Master principal apresente problemas.

- Comunicação cíclica por meio do estabelecimento de uma lista dos tempos necessários à transmissão dos dados de cada dispositivo da rede. $\mathrm{Na}$ ocasião da transmissão de uma mensagem por um dispositivo, o LAS a monta e agrega a esta mensagem uma ordem de comunicação chamada compel data. Esta ordem, endereçada ao dispositivo produtor, contém solicitações de dados a este dispositivo. 
- Comunicação acíclica proporcionada a dispositivos que tenham mensagens prioritárias por meio de concessões de permissão pelo LAS. Estas concessões, destinadas a interrupções de algoritmos ou sinais de alarme, podem ser enviadas a um ou múltiplos destinos.

A operação do LAS envolve também uma série de outras rotinas, além das já expostas, quais sejam:

- Manutenção do itinerário de execuções por meio de uma lista das atividades programadas a acontecerem em um macro cycle.

- Manutenção da lista viva ou live list, que consiste na lista de todos dispositivos do barramento que respondem a uma solicitação de passagem de token. Neste processo o LAS também envia, periodicamente, mensagens denominadas probe node (PN) aos dispositivos não listados na live list. Caso um destes dispositivos tenha sido recém conectado ao barramento, o mesmo responderá com uma mensagem denominada probe response (PR), por meio do qual o LAS adicionará este novo dispositivo à live list, fazendo-o automaticamente compor a rede.

- Sincronização horária de dados por meio da qual o LAS, periodicamente, envia uma mensagem a todos os dispositivos da rede denominada time distribution (TD) para que estes possuam exatamente a mesma base de tempo. Esta sincronização é fundamental para a comunicação cíclica. 
- Monitoramento de outros link masters para estabelecimento da redundância do LAS. Caso o link master que coordena o barramento seja desconectado deste, outros dispositivos com a mesma capacidade podem assumir esta função se previamente configurados. 